\title{
A Habitat-based Wind-Wildlife Collision Model with Application to the Upper Great Plains Region-Final Report
}

\author{
DE-09EE0000529 \\ Project Period (12:09-05:12) \\ Principal Investigator/Author: \\ Gregory Forcey, $\mathrm{PhD}$ \\ 352-372-4747 \\ gforcey@normandeau.com \\ 102 NE $10^{\text {th }}$ Ave, $1^{\text {st }}$ Floor \\ Gainesville, FL 32601 \\ In collaboration with: \\ GIS Associates \\ Matt Krogh \\ Tyson Waldo
}

August 28, 2012

Normandeau Associates, Inc.

$102 \mathrm{NE} 10^{\text {th }}$ Avenue

Gainesville, FL 32601

(352) $372-4747$

www.normandeau.com

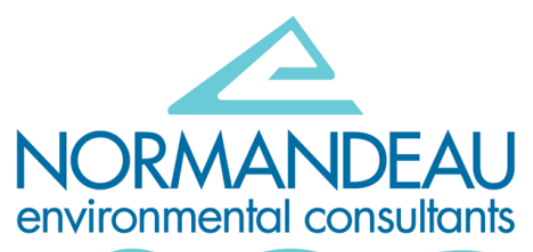


Acknowledgment:

"This report is based upon work supported by the US Department of Energy under Award No DE-09EE0000529.

Disclaimer:

Any findings, opinions, and conclusions or recommendations expressed in this report are those of the author(s) and do not necessarily reflect the views of the

US Department of Energy"

Proprietary Data Notice:

If there is any patentable material or protected data in this report, the recipient, consistent with the data protection provisions of DE-09EE0000529 must mark the appropriate block in Section K of the DOE F 241.3, clearly specify it here, and identify them on appropriate pages of the report. Other than patentable material or protected data, reports must not contain any proprietary data (limited rights data), classified information, information subject to export control classification, or other information not subject to release. Protected data is specific technical data, first produced in the performance of the award, which is protected from public release for a period of time by the terms of the award agreement. Reports delivered without such notice may be deemed to have been furnished with unlimited rights, and the Government assumes no liability for the disclosure, reproduction or use of such reports. 


\section{Executive Summary}

Wind energy is a rapidly growing and relatively clean source of renewable energy, which can ultimately meet growing demands for electricity in the US (Manville 2005). Despite the large potential for wind energy production in the US (AWEA 2009) and the minimal carbon emissions that occur from producing this power, the proliferation of wind energy has some drawbacks, including land disturbance caused by the installation of a wind facility, potential decline in aesthetics of a landscape, difficulty in attaining public acceptance, and threats to aerial and terrestrial wildlife (Kunz et al. 2007a; Kuvlesky et al. 2007). Wind project facilities pose two possible hazards to wildlife: the potential for mortality (i.e., collisions with wind turbines and associated power lines) and the potential for habitat effects (Kuvlesky et al. 2007). While both collisions and habitat effects can impact wildlife, this study examined collision hazards only; other studies currently being funded by the US Department of Energy (DOE) are examining habitat displacement effects.

Most previous studies on collision impacts at wind facilities have taken place at the site-specific level and have only examined small-scale influences on mortality. In this study, we examine landscape-level influences using a hierarchical spatial model combined with existing datasets and life history knowledge for six bird and three bat species: Horned Lark, Red-eyed Vireo, Mallard, American Avocet, Golden Eagle, Whooping Crane, red bat, silver-haired bat, and hoary bat. These species were modeled in the central United States within Bird Conservation Regions 11, 17, 18, and 19 (NABCI 2012). For the bird species, we modeled bird abundance from existing datasets as a function of habitat variables known to be preferred by each species to develop a relative abundance prediction for each species. For bats, there are no existing abundance datasets so we identified preferred habitat in the landscape for each species and assumed that greater amounts of preferred habitat would equate to greater abundance of bats. The abundance predictions for bird and bats were modeled with additional exposure factors known to influence collisions such as visibility, wind, temperature, precipitation, topography, and behavior to form a final mapped output of predicted collision risk within the study region. Separate collision models were derived for each season given differences in habitat and behavior across seasons; season-specific models were combined to form a cumulative model representing collision risk throughout the year. To evaluate our collision predictions, we reviewed published mortality studies from wind farms in our study region and collected data on reported mortality of our focal species to compare to our modeled predictions. Because of the uncertainty with the degree to which abundance and exposure factors influence collision risk, we performed a sensitivity analysis evaluating model performance of 6 different scenarios where habitat and exposure factors were weighted differently. We compared the model performance in each scenario by evaluating observed data vs. our model predictions using spearman's rank correlations (Zar 1999).

Horned Lark collision risk was predicted to be highest in the northwestern and west-central portions of the study region with lower risk predicted elsewhere. Red-eyed Vireo collision risk was predicted to be the highest in the eastern portions of the study region and in the forested areas of the western portion; the lowest risk was predicted in the treeless portions of the northwest portion of the study area. Mallard collision risk was predicted to be highest in the eastern central portion of the prairie potholes and in Iowa which has a high density of pothole wetlands; lower risk was predicted in the more arid portions of the study area. Predicted collision risk for American Avocet was similar to Mallard and was highest in the prairie pothole region 
and lower elsewhere. Golden Eagle collision risk was predicted to be highest in the mountainous areas of the western portion of the study area and lowest in the eastern portion of the prairie potholes. Whooping Crane predicted collision risk was highest within the migration corridor that the birds follow through in the central portion of the study region; predicted collision risk was much lower elsewhere. Red bat collision risk was highly driven by large tracts of forest and river corridors which made up most of the areas of higher collision risk. Silver-haired bat and hoary bat predicted collision risk were nearly identical and driven largely by forest and river corridors as well as locations with warmer temperatures, and lower average wind speeds.

Although available data were limited, we were able to evaluate the Horned Lark, red bat, silverhaired bat, and hoary bat models to see how our collision predictions formed against and independent dataset. Horned Lark collisions were mostly influenced by abundance and predictions showed a moderate correlation between observed and predicted mortality $(\mathrm{r}=0.55)$. Red bat, silver-haired bat, and hoary bat predictions were much higher and shown a strong correlations with observed mortality with correlations of $0.85,0.90$, and 0.91 respectively. Red bat collisions were influenced primarily by habitat, while hoary bat and silver-haired bat collisions were influenced mainly by exposure variables. Stronger correlations between observed and predicted collision for bats than for Horned Larks can likely be attributed to stronger habitat associations and greater influences of weather on behavior for bats (Kunz and Fenton 2003; Arroyo-Cabrales 2008a; 2008b, Gonzales et al. 2008).

Our model outputs provide a convenient and easy landscape-level tool to quickly screen for siting issues at a high level. The model resolution is suitable for state or multi-county siting but users are cautioned against using these models for micrositing. The U.S. Fish and Wildlife Service recently released voluntary land-based wind energy guidelines for assessing impacts of a wind facility to wildlife using a tiered approach. The tiered approach uses an iterative approach for assessing impacts to wildlife in levels of increasing detail from landscape-level screening to site-specific field studies (USFWS 2012). Our models presented in this paper would be applicable to be used as tools to conduct screening at the tier 1 level and would not be appropriate to complete smaller scale tier 2 and tier 3 level studies. For smaller scale screening ancillary field studies should be conducted at the site-specific level to validate collision predictions during the permitting process.

Although the collision predictions cannot be compared among species, the mapped outputs are useful for showing the relative predicted collision risk for a given species and can be used to inform the siting process at a high level about how the collision predictions compare to other areas. Our model can be adapted to other species and geographic areas assuming adequate input data are available. As improvements are made in the input datasets over time and as more data become available, these models may be useful at a smaller scale. Additional data from postconstruction mortality monitoring would allow us to validate our models with a larger data set, which would provide additional confidence in the collision predictions. 


\section{Contents}

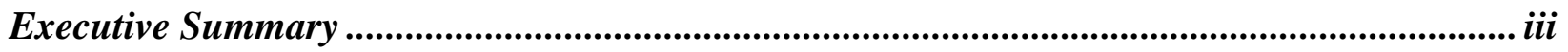

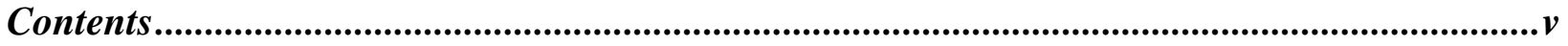

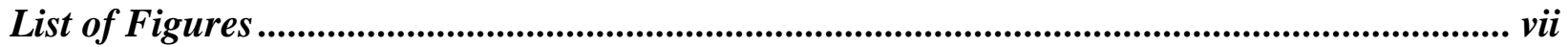

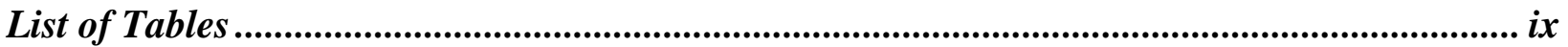

Acronyms and Abbreviations ....................................................................................................... $x$

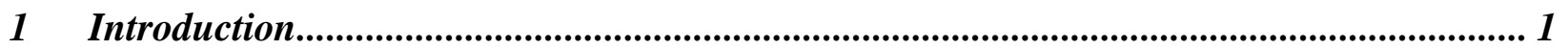

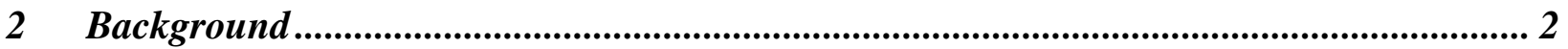

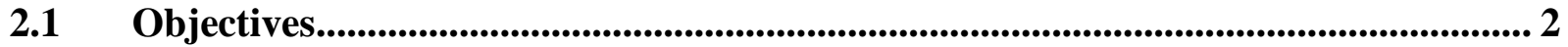

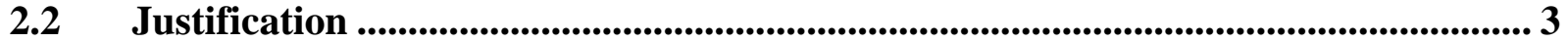

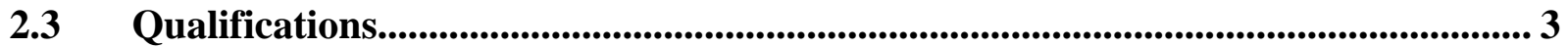

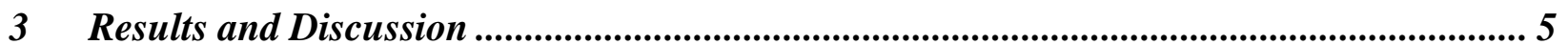

3.1 Literature Review ....................................................................................................5 5

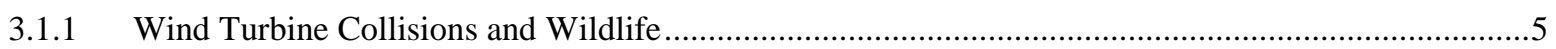

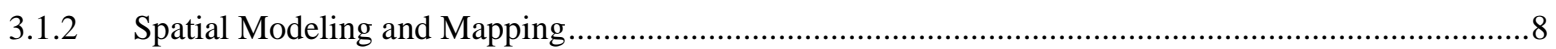

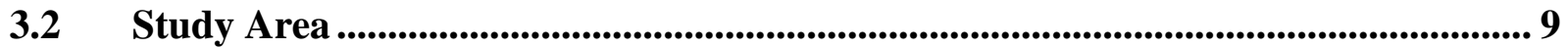

3.3 Methods......................................................................................................................... 10

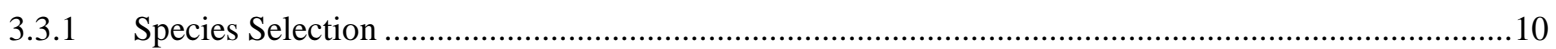

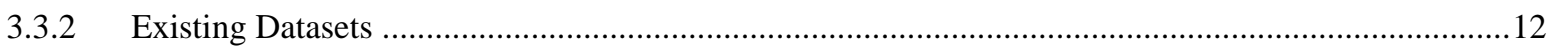

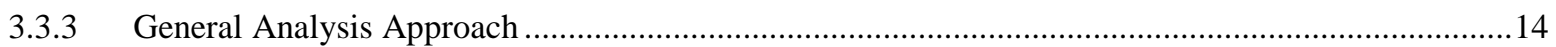

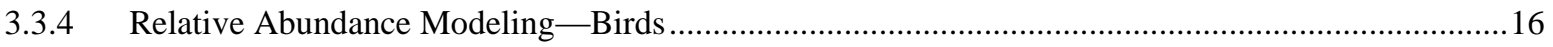

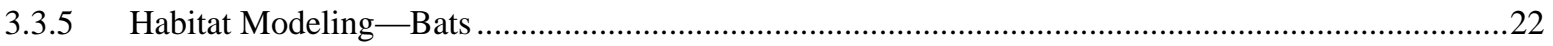

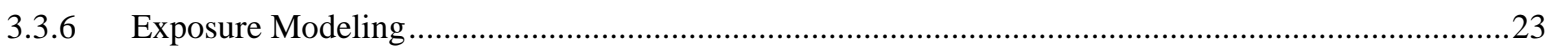

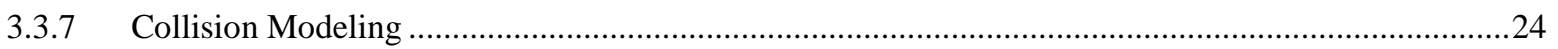

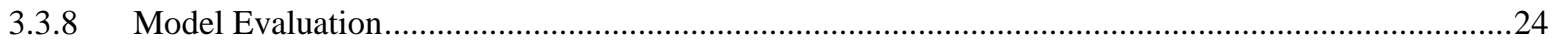

$3.4 \quad$ Results ...................................................................................................................... 27

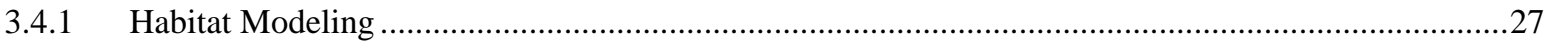

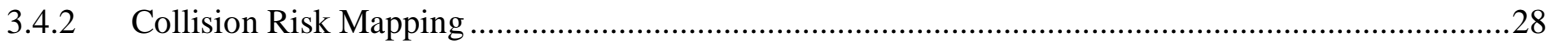

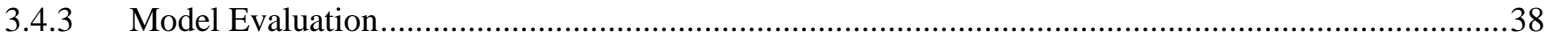

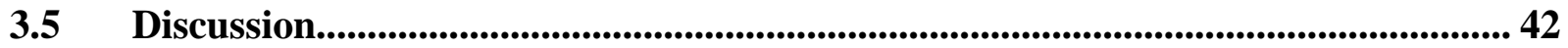

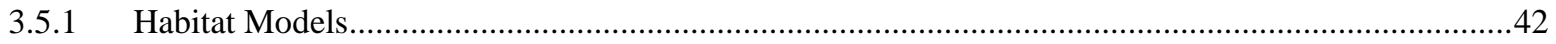

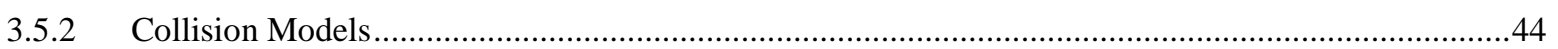

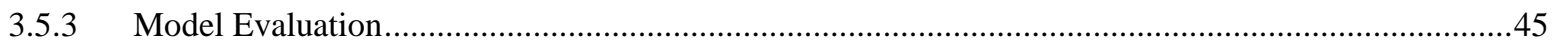

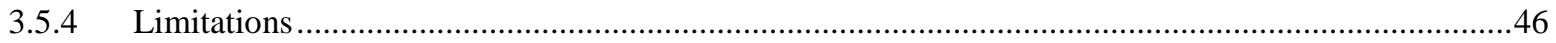




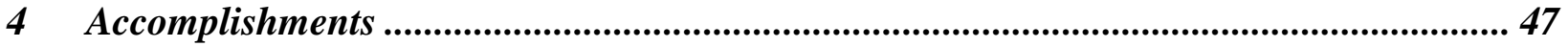

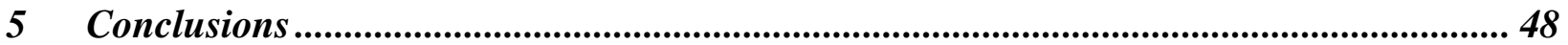

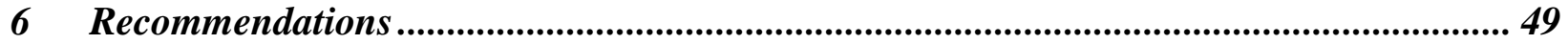

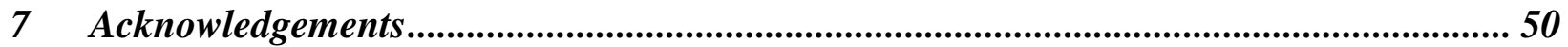

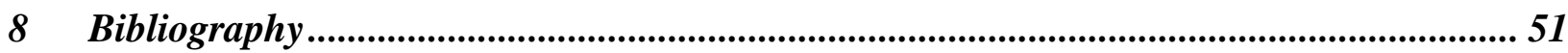

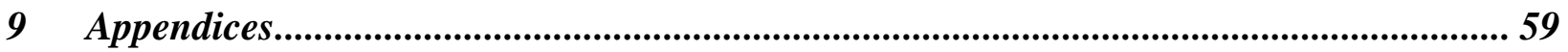

Appendix 1. Description of Land Use Classifications and Associated Metrics Used in the Habitat Analysis for Birds and Bats ....................................................... 59

Appendix 2. Focal Species Susceptible Behaviors and Habitat Preferences that were Used to Determine the Season-specific Models for each Species during Different Portions of their Annual Cycle......................................................... 61

Appendix 3. A Priori Habitat Models, Relevant Exposure Factors, and Final Seasonal Models for each Focal Species in the Study ................................... 66

Appendix 4. Model Scale and Explanatory Variables from the Best Subset of Models for each Bird Species in the US Bird Conservation Regions 11, 17, 18, and 19. Only Models within the $95 \%$ Confidence Set of Best Models are Included (Burnham and Anderson 2002). The Null Model (a Model Without Any Environmental Covariates) Was Included to Serve as a Comparison to Models Containing Environmental Variables

Appendix 5. Model-averaged standardized Parameter Values and Associated Confidence Intervals of Explanatory Variables in the Best Subset of Models for Explaining Bird Abundance in US Bird Conservation Regions 11, 17, 18, and 19 


\section{List of Figures}

Figure 2-1. Bird conservation regions in the central United States that will be used to predict bird and bat collision mortality.

Figure 3-1. Various buffer sizes surrounding Breeding Bird Survey routes and Christmas Bird Count circles. The background grid represents the sampling units used to quantify eBird bird and sampling event data.

Figure 3-2. Locations of wind farms with publically available mortality data on bird and bats.

Figure 3-3. Spatial distribution of predicted Horned Lark collision risk within the central United States. Shades of color represent relative predictions within a species; maps are not comparable among species.

Figure 3-4. Spatial distribution of predicted Red-eyed Vireo collision risk within the central United States. Shades of color represent relative predictions within a species; maps are not comparable among species.

Figure 3-5. Spatial distribution of predicted Mallard collision risk within the central United States. Shades of color represent relative predictions within a species; maps are not comparable among species.

Figure 3-6. Spatial distribution of predicted American Avocet collision risk within the central United States. Shades of color represent relative predictions within a species; maps are not comparable among species.

Figure 3-7. Spatial distribution of predicted Golden Eagle collision risk within the central United States. Shades of color represent relative predictions within a species; maps are not comparable among species.

Figure 3-8. Spatial distribution of predicted Whooping Crane collision risk within the central United States. Shades of color represent relative predictions within a species; maps are not comparable among species.

Figure 3-9. Spatial distribution of predicted red bat collision risk within the central United States. Shades of color represent relative predictions within a species; maps are not comparable among species.

Figure 3-10. Spatial distribution of predicted silver-haired bat collision risk within the central United States. Shades of color represent relative predictions within a species; maps are not comparable among species.

Figure 3-11. Spatial distribution of predicted hoary bat collision risk within the central United States. Shades of color represent relative predictions within a species; maps are not comparable among species.

Figure 3-12. Horned Lark model evaluation and sensitivity analysis showing scenarios of different weights applied to habitat and exposure variables. From left to right, habitat was given the following weights relative to exposure: $0.5,1$ (equal weighting), 2, 4, 8, and only habitat. 
Figure 3-13. Eastern red bat model evaluation and sensitivity analysis showing scenarios of different weights applied to habitat and exposure variables. From left to right, habitat was given the following weights relative to exposure: $0.5,1$ (equal weighting), 2, 4, 8, and only habitat.

Figure 3-14. Hoary bat model evaluation and sensitivity analysis showing scenarios of different weights applied to habitat and exposure variables. From left to right, habitat was given the following weights relative to exposure: $0.5,1$ (equal weighting), 2, 4, 8, and only habitat.

Figure 3-15. Silver-haired bat model evaluation and sensitivity analysis showing scenarios of different weights applied to habitat and exposure variables. From left to right, habitat was given the following weights relative to exposure: $0.5,1$ (equal weighting), 2, 4, 8, and only habitat. 


\section{List of Tables}

Table 3-1. Taxa and Focal Species Determined to be Susceptible to Collision Mortality with Wind Turbines in the Central US............................................................... 11

Table 3-2. Species-specific Seasonal Definitions of Breeding, Wintering, and Migratory Seasons for Avian Focal Species ................................................. 15

Table 3-3. Species-specific Seasonal Definitions of Summer, Wintering, and Migratory Seasons for Bat Focal Species .................................................................... 16 


\section{Acronyms and Abbreviations}

AKN Avian Knowledge Network

BCR Bird conservation region

CBC Christmas Bird Count

MW Megawatt

NABBS North American Breeding Bird Survey

NCDC National Climatic Data Center

NLCD National Land Cover Dataset

USFWS United State Fish and Wildlife Service 


\section{Introduction}

With increased wind development in the United States, concerns have been raised over the effects of collisions to birds and bats that co-occur in the areas where wind farm development is prevalent. Many small-scale site-specific studies have been conducted across the US on the species composition and the number of mortality events of birds and bats, but minimal research has been conducted on large-scale influences of bird and bat mortality at wind farms. Our project uses a spatial model to determine the relative influences of habitat, weather, and topography variables on bird and bat collisions with wind turbines in the central US. The model addresses a lack of knowledge in the area of large-scale influences on bird and bat collisions and provides mapped outputs that show the relative predicted collision risk for selected bird and bat species.

For birds, we adapted a hierarchical log-linear mixed-effects model for predicting abundance based on habitat to predicting collisions at wind facilities. The log-linear mixed-effects model considers habitat factors that influence bird presence and abundance in the area. The output is then modeled with spatial representations of weather variables thought to influence collision risk (i.e., visibility), topography, and behaviors that increase collision susceptibility; the final outputs are a predicted collision risk grid for each species for each season. Season-specific grids are combined to form a cumulative measure of collision risk across seasons.

For bats, the process is similar except there are no existing large-scale bat datasets from which to model abundance as a function of habitat. For bats, therefore, we created spatial grids of preferred bat habitat (identified from the literature), and used that as our basis for predicting bat presence by making the assumption that the presence of a greater number of preferred habitat variables would equate to a greater abundance of bats. The preferred habitat grids were combined with weather variables likely to affect bat collision risk (e.g., wind speed, temperature, and precipitation) and behavior information to form a grid of predicted collision probability with wind turbines. Collision grids for birds and bats were developed separately for each season given temporal differences in behavior and activity that would likely influence collision risk. Seasonspecific collision grids were weighted temporally based on the amount of time a given species spends in that part of its annual cycle.

Our model outputs have application to large-scale siting decisions and permitting. They are not to be used for micro-siting wind turbines. Limitations in the resolution of the datasets and classification inaccuracies in the habitat data constrain the interpretations of the models to a landscape scale. In addition, the relative risk values are only comparable within a species and not among species. Developers can use the model outputs to examine areas of possible wildlife issues early in the site-screening process, and researchers can use the models to better understand the effects of habitat, weather, and topography on collisions with wind turbines. Although we applied our models to the wind corridor of the central US, these models could be applied in other geographic regions of North America, assuming spatial data were available. Additional species could also be modeled, although species must be well represented by existing datasets for the modeling effort to be worthwhile.

Commercialization of the model is possible because much of the modeling process can be automated in statistical and GIS software such as R and ArcGIS, which were used for this project. Data can be fed into the model after being acquired from multiple internet sources and manipulated into the proper format. Mapped model outputs can be provided to clients in the form 
of images in a report or as grids which can be read into GIS software. We do not intend to commercialize this model at the current time.

We provide a web interface for accessing the models for this project which can be viewed at http://www.normandeau.com/pages/environment/services/WindWildlifeRiskMap/.

The web interface provides a basic viewing front end for examining the model outputs at various scales, navigating the view, and downloading the model output grids if desired.

\section{Background}

\subsection{Objectives}

Recognizing the benefits of wind energy, the United States Department of Energy (DOE) requested projects addressing a number of environmental concerns including developing largescale models for predicting collision mortality. Our project objective was to develop a tool characterizing mortality for bird and bat species that are potentially susceptible to collisions with wind turbines. Previous large-scale spatial models have not considered information about behaviors, habitat, weather, and other important parameters governing species' exposure to adverse impacts from wind facilities. Additionally, species that have been found to be susceptible to collisions have not been modeled over large areas with high potential for wind energy development.

This study develops a set of wind-wildlife collision mortality models for the central US, serving as a spatially explicit tool for modeling potential impacts of collisions into siting and other decision-making processes. Our models incorporate species distribution and relative abundance information along with weather and behavioral factors that influence species' susceptibility to collisions. Behavioral factors include flight height during various life stages (e.g., migratory flight height versus foraging flight height during breeding or wintering), tunnel vision, and hunting behavior. The result is a spatial model for each selected species, representing the predicted collision mortality from wind power facilities to the species.

While these models can be used in a decision-making framework when siting wind power facilities to help minimize the chance of avian and bat collisions, they should always be supplemented with ancillary field studies to validate the model results at the site-specific level. This approach can aid in siting decisions by providing regulatory agencies and developers with a tool that will assist in identifying areas of potentially higher collision mortality and thus minimizing wildlife impacts. This framework can be applied to species in our study area or applied to other species in different geographic regions (or bird conservation regions [BCRs]) in the country. Separate models would need to be developed in other geographic regions so they are both species and geographically specific.

This tool was developed for BCRs 11, 17, 18, and 19: the prairie potholes, the badlands and prairies, the shortgrass prairie, and the central and mixed grass prairie (Figure 2-1). These regions correspond to areas with a high potential for energy wind development. Although it will be applied to BCRs 11, 17, 18, 19, the tool will be designed so that the modeling process can be applied to other regions or locations. The datasets that we used are available for the entire US; therefore, models can be developed that are both species and geographically specific to any region. This adaptability is particularly important given the nationwide importance of avian and bat collisions with wind facilities. 


\subsection{Justification}

This modeling approach allows the DOE, regulatory agencies, the wind industry, and other environmental stakeholders to 1) predict relative collision mortality within a species of migratory birds and bats across a large extent, 2) assess potential impacts among wind projects in different locations on a species-specific basis, 3) identify geographic areas in need of additional research, and 4) reduce the current uncertainty in predicting the collision impacts to birds and bats from wind facilities. These goals address wildlife issues that have been specifically identified as near and midterm actions in the DOE report-20\% Wind Energy by 2030 (USDOE 2008).

\subsection{Qualifications}

Staff scientists at Normandeau Associates (Normandeau) are uniquely qualified to model collision risks of birds and bats in the central US. Greg Forcey, $\mathrm{PhD}$, is a senior avian ecologist with Normandeau, and completed his doctorate on landscape-level habitat and climate influences on wetland birds in the Prairie Potholes. His doctoral research involved species distribution modeling of wetland birds in the prairie potholes, research that has direct applicability to the landscape-level modeling being done on this project. Dr. Forcey's research experience and expertise includes spatial modeling, avian survey techniques, and statistics primarily using the ArcGIS and R software packages.

Christian Newman, MS, is a senior principal scientist and vice president at Normandeau. He has more than 18 years of experience is an expert in conducting avian and bat risk assessments, assessing avian and bat interactions with wind facilities during pre- and post-construction monitoring, and in evaluating technical publications and study plans related to wildlife, natural resources, and wildlife interactions with wind facilities.

James Newman, $\mathrm{PhD}$, is a senior principal scientist at Normandeau, and has more than 36 years of experience in managing and conducting research on the effects of energy generation (renewable and non-renewable energy sources) on wildlife in the US and internationally. He is an expert in ecological and avian risk assessment for wind and other energy projects.

Christine Sutter, MS, is a wildlife biologist with 17 years of experience in wildlife and habitat management on public and private lands, as well as considerable expertise in regulatory compliance. She has a broad knowledge of bat and avian ecology, and extensive experience with a variety of bat monitoring techniques. Her expertise includes avian and bat risk assessment for wind and conventional energy systems, including GIS modeling. 


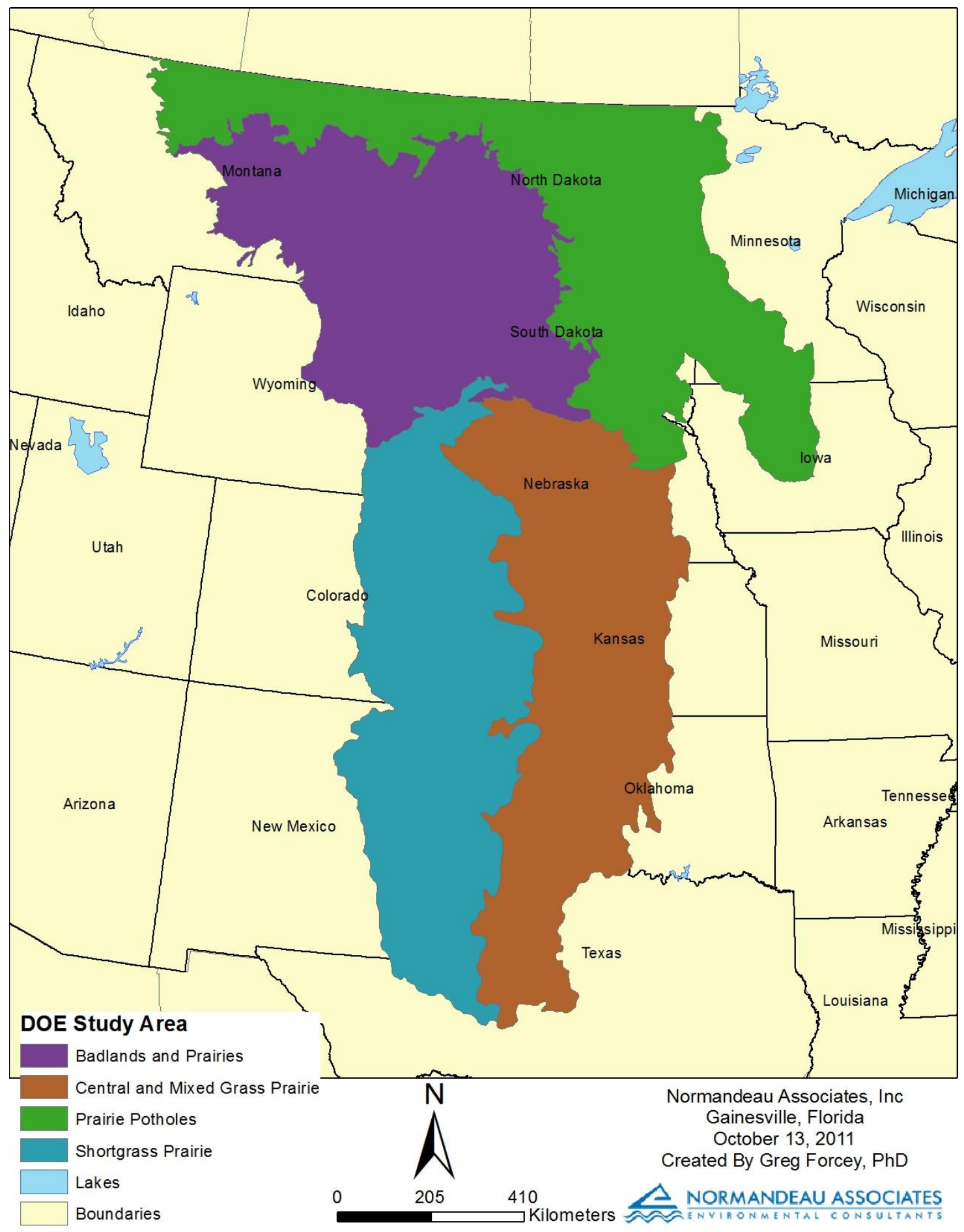

Figure 2-1. Bird conservation regions in the central United States that will be used to predict bird and bat collision mortality. 


\section{Results and Discussion}

\subsection{Literature Review}

Wind energy is a rapidly growing and relatively clean source of renewable energy, which can ultimately meet growing demands for electricity in the US (Manville 2005). Wind turbines harness energy from wind and turn it into electricity that can be fed into the existing electric grid. Despite the large potential for wind energy production in the US (AWEA 2009) and the industry's minimal carbon emissions, the proliferation of wind energy has some drawbacks, including land disturbance needed to install a wind facility, potential decline in aesthetics of a landscape, public acceptance, and threats to aerial and terrestrial wildlife (Kunz et al. 2007a; Kuvlesky et al. 2007).

Wind energy facilities pose two possible hazards to wildlife: the potential for mortality (i.e., collisions with wind turbines and associated lines) and the potential for habitat effects (Kuvlesky et al. 2007). These possible hazards are influenced by and can be understood from speciesspecific habitat preferences and behavioral characteristics. While both collisions and habitat effects can impact wildlife, this study will examine collision hazards only; other studies currently being funded by the DOE are examining habitat displacement effects.

\subsubsection{Wind Turbine Collisions and Wildlife}

Collisions occur when a bird or bat comes in contact with a utility structure and is impacted to some degree. Relative to collisions with communication towers and windows (e.g., Veltri and Klem 2005), collisions with wind turbines are a new area of active research. Wind turbinewildlife collision events are highly localized with some wind power facilities reporting higher than average fatality rates, while other facilities are reporting much lower rates. The national average mortality rate for birds at wind energy facilities is 2.11 fatalities/turbine/year and 3.04 fatalities/megawatt/year (Erickson et al. 2005). Although there are thousands of turbines currently operating in the US, the total annual predicted bird mortality from wind turbines (est. 20,000 to 37,000 ) is low compared to other sources of anthropogenic mortality including cats ( 100 million) and collisions with communication towers (est. 4 to 5 million) (Erickson et al. 2005; National Research Council 2007).

Unlike birds, bat fatalities at wind power facilities can be very high and are the highest source of bat mortality from any anthropogenic cause (Cryan and Barclay 2009). Bat mortality varies widely and is highly localized to different regions in the US. While some estimates for wind power facilities in the eastern US are as high as 20 to 70 bats/turbine/year, estimates for the central US are more modest, ranging from 0.1 to 7.8 bats killed/turbine/year at wind energy facilities in Minnesota, Wisconsin, and Iowa (Arnett et al. 2008).

Susceptibility to collisions is heavily influenced by exposure, which in turn, is influenced by behavior. The following is a list of behavioral factors contributing to higher (or lower) exposure of birds and bats to wind energy facilities. These factors all can influence the number of birds in the rotor swept area (RSA) over time.

\section{Higher exposure:}

- Courtship flights into the rotor swept zone (RSZ) and RSA

- Tunnel vision hunting behavior 
- Attraction to various microscale habitat features in a landscape (e.g., ridges, wetlands, patches of preferred vegetation types, areas of high food concentration such as crop fields with waste grain)

- Frequent high altitude flight (e.g., soaring and foraging)

- High sensitivity to and avoidance of areas with wind turbines or other tall structures, roads, human activity (habitat displacement)

- Migratory behavior

- Edge habitat preferences

\section{Lower exposure:}

- Preference for or restriction to low vegetation (ground, understory)

- High visual acuity

- High aerial maneuverability

- Low frequency of high altitude flight

- No habitat displacement from presence of wind turbines, roads, or human activity

- Prefer low-altitude flight

Predicted wildlife mortality can be calculated by multiplying the collision probability of a species by the number of individuals passing through the RSA, the area occupied by the turbine blades (Chamberlain et al. 2006). Collision probability (and ultimately mortality) is influenced by three different suites of variables: biological, environmental, and structural factors. Although not all collisions with wind turbines result in immediate death, most injured animals eventually die from their injuries.

\section{Biological}

Biological factors influencing species susceptibility to collisions include size, flight speed, wingspan, and behavior (Band et al. 2005; Drewitt and Langston 2006). Behavior such as courtship flights and hunting can increase the probability of collisions because attention is diverted away from the turbine blades. Avoidance behavior (most often observed in birds) can often dramatically reduce the probability of collision with turbine blades. Avoidance behavior is a major influence in rates of collision mortality as most estimates of avoidance for birds are very high (> 0.95) (Chamberlain et al. 2006). The large impact of avoidance behavior on collision mortality makes this a required consideration in any study estimating collision mortality mathematically because small changes in avoidance rate estimates can have large influences on collision mortality (Chamberlain et al. 2006).

There are two main hypotheses attempting to explain bird collisions: 1) birds divide their attention between flying and watching the surface for food causing them not to notice the turbines and 2) motion smear (reduced visibility of the blades turning at high speed) makes the blades less visible to birds in flight (Hudos 2003). Birds that frequent the RSZ because of foraging or courtship behavior are far more susceptible than terrestrial dwelling birds, which are less exposed to the RSZ. In addition, many raptors often fly low over an area and within the RSZ when hunting and are more susceptible than raptors that fly at a high altitude above the RSZ or that hunt by perching.

Bat mortality at wind power facilities occurs by one of two main causes: 1) a direct collision with the moving blades or 2) barotrauma, where bats are exposed to pressure changes at the tips of turbine blades (Baerwald et al. 2008). Some hypotheses suggest that direct collisions and 
barotrauma often occur because of a possible attraction to wind turbine blades. Several hypotheses exist as to why bats may be attracted to wind turbines including 1) the sound of moving blades, 2) blade motion, 3) insect aggregations, 4) turbines as potential roost structures, and 5) turbines as mating locations (Cryan and Barclay 2009).

\section{Environmental}

Environmental variables such as habitat, topography, and weather also influence the collision mortality of birds and bats in relation to wind turbines. Bird species that live in areas with large differences in topography may be more susceptible to collisions from reduced visibility and from lift caused by rising air currents (Alerstam 1990). Birds may also lower their flight height when crossing ridges therefore coming in closer proximity to tall structures such as wind turbines (Richardson 2000). Species favoring edge habitat may also be vulnerable as the construction of a wind power facility often creates substantial edge habitat, which may attract higher numbers of birds.

Adverse weather, both storms and cold weather, can cause high mortality events for bird migrants (Newton 2007). Storms can cause large migratory fallouts in unfamiliar locations with poor shelter. Cold weather can cause bird mortality directly through exposure and indirectly through a decrease in food availability. Adverse weather such as rain and fog can also influence susceptibility to wind turbine collisions by reducing visibility (Erickson et al. 2001).

Current research suggests that larger scale environmental factors have a greater influence than within-site factors such as vegetation or turbine density (Arnett et al. 2008). Little information is known about how weather affects migrating bats (Cryan and Brown 2007), although Arnett et al. (2008) observed increases in the number of bat fatalities during the passage of storm fronts. Some hypotheses also suggest bats may be funneled into windy places by mountain ridges and river valleys, which could influence the chance of collisions (Cryan and Barclay 2009). Wind speed does appear to influence bat activity with increased levels of bat activity occurring during nights of low wind speed (Arnett et al. 2006). Increasing the wind turbine cut-in speed (the wind speed that turbines begin to generate electricity into the grid) can decrease bat mortality significantly. Arnett et al. (2009) found that increasing wind turbine cut-in speed can reduce bat mortality by a factor between 1.23 and 4.68 .

\section{Structural}

Structural variables that can also influence collision mortality include the number of blades, tower height, size of the RSA, rotation speed, and lighting (Winkelman 1992; Thelander et al. 2003; Band et al. 2005; Drewitt and Langston 2006). In general, fatality rates are greater for turbines using smaller and faster spinning rotors compared to larger, slower spinning rotors, although this difference may be more because of geographic differences than structural differences (National Research Council 2007). Although there are no documented cases of passerines impacting the stationary turbine monopole, they have been known to impact stationary communication towers and smokestacks (Erickson et al. 2001). Artificial lighting has been known to influence collision mortality at other artificial structures and may play a role in collision rates with wind turbines. Kerns and Kerlinger (2004) found 33 passerines dead at a wind power facility, although this appears to be an isolated case of high bird mortality due to lighting. The current recommendation for wind turbine lighting is the use of red flashing lights, which appear to decrease risk compared to steady constant lighting (Kerlinger et al. 2010). 
Location of the structures in relation to high-activity use areas, such as nesting colonies, can also increase the chance of collisions (Henderson et al. 1996).

Little is known about the influence of structural variables on bat mortality at wind power facilities. The majority of large bat kills at wind power facilities occur at facilities with 1 to 1.5 MW turbines mounted on large monopoles (National Research Council 2007). Barclay et al. (2007) found that while diameter of the turbine rotor had little effect on bird or bat mortality, the number of bat kills increased significantly with increasing tower height. Some theories suggest that bats may be attracted to the ultrasonic sounds emitted by wind turbines (National Research Council 2007), although other studies have not found bat affinities for wind turbines (Jain 2005). Unlike birds, bats do not appear to be directly attracted by lighting that is installed on turbines (Horn et al. 2008). Lighting on turbines has been known to attract insects; therefore, there may be some indirect attraction to the insect aggregations (Kunz et al. 2007b).

\subsubsection{Spatial Modeling and Mapping}

Geographic Information Systems (GIS) provide a powerful tool for examining large-scale wildlife relationships with their environment. Common applications of GIS in wildlife research include habitat mapping, predicting relative abundance through modeling, and determining areas to target conservation and management actions. The use of GIS technology also allows studies to be conducted at large spatial scales that are not feasible with traditional field studies. Large-scale datasets, such as the North American Breeding Bird Survey (NABBS) (Sauer et al. 2011) and the National Land Cover Dataset (NLCD) (Homer et al. 2007), provide opportunities to examine large-scale bird-habitat relationships. There are presently no large-scale, long-term datasets available for bats in the US; therefore, much of what is known about bats is from incidental sightings and small-scale studies.

While small-scale habitat studies are still common, the number of larger scale habitat studies is growing because of the wide availability of readily accessible data via the internet, powerful GIS software, increased information on modeling theory, and greater computer processing speed. GIS software has become capable of more complex analyses at larger scales in recent years concomitant with increases in computing power (Greenberg et al. 2002). These technologies have allowed scientists to collect and analyze data across broad geographic areas, permitting habitat-related studies at larger scales.

A relatively new approach to wildlife studies is to examine environmental influences at a multistate level. Because political boundaries are not ecologically meaningful, biologists often evaluate multistate bird-environment relationships within one or more BCR(s). BCRs are ecologically unique areas with similar avian communities and are used to foster a large-scale approach to bird conservation and management (NABCI 2012). Sauer et al. (2003) examined NABBS data in North America and found BCRs to be useful strata for analyses of avian population trends. Thogmartin et al. (2004) modeled Cerulean Warbler abundance as a function of land use and climatic influences in the Prairie-Hardwood Transition BCR (BCR23). BCRs were also effective strata for mapping predicted abundances of five grassland bird species as a function of land use and climate variables (Thogmartin et al. 2006).

In addition to the NABBS, CBC count data and eBird data have used in several different modeling studies. Link et al. (2008) combined NABBS data with CBC data to model population changes in Northern Bobwhite (Colinus virginianus). Link et al. (2006) used the CBC data to 
model population change of American Black Duck (Anas rubripes) and found similar results to models performed with the Midwinter Waterfowl Inventory. Fink et al. (2010) used eBird data to model seasonal changes in distribution of Tree Swallows (Tachycineta bicolor) and Northern Cardinals (Cardinalis cardinalis) within their range.

To our knowledge, bat studies have not been conducted using BCRs as strata, but several largescale modeling efforts have occurred through state gap modeling. Additionally Rodhouse et al. (2012) used a large-scale distribution model to assess bat population trends in the northwestern United States.

Large-scale spatial models in conjunction with modern GIS software and computers present a powerful approach to modeling bird and bat collision mortality in BCRs across North America. A high-resolution spatial tool for predicting collision mortality can be developed for wind energy decision making based on a combination of habitat mapping, relative abundance predictions, and incorporating an exposure index into the model.

Collision risk models have been applied to wind farms to predict wildlife mortality based on field data inputs, wind farm characteristics, and a probabilistic model. Tucker (1996) created a probabilistic model based on bird anatomy, flight characteristics, avoidance rates, and turbine characteristics to output a turbine-specific collision probability. Similarly Band et al. (2005) designed a probabilistic model using bird field data, flight characteristics, and wind turbine dimension as inputs and outputted a predicted collision probability considering scenarios with and without avoidance behavior. Another probabilistic model designed by Bolker (2006) uses similar inputs to that of Tucker (1996) and Band et al. (2005), and estimates average number of turbine encounters but does not include avoidance behavior in the calculation. Many additional probabilistic models have been designed using one of these models as its base. These variant models often have improvements or were modified to address specific questions.

The inclusion of spatial habitat and exposure parameters in collision models is a novel addition to the field of collision risk modeling. Eichhorn et al. (2012) created a virtual landscape and simulated proportions of different land use types as inputs for a collision model for raptors at wind farms. This model was limited in that it did not consider a real world landscape-only a simulated one. A spatially explicit Bald Eagle model has also been developed to predict total transits within a site boundary over the course of the year. Predicted transits, wind turbine structural information, and ancillary field data are used to predict the number of eagles that will be killed by wind turbines on a project-specific basis (Normandeau Associates, unpublished data).

\subsection{Study Area}

The study area for this project includes the four BCRs in the central US: the prairie potholes (BCR11), the badlands and prairies (BCR 17), the shortgrass prairie (BCR 18), and the central and mixed grass prairie (BCR19). Together, these regions encompass a large range of grassland songbird, waterbird, and raptor avifauna and cover much of the central migratory flyway, which is used heavily by songbirds, shorebirds, and waterfowl. Topographically this flyway is relatively homogeneous, and most of the birds make direct north and south flights from their breeding and wintering grounds (NABCI 2012). 
These four BCRs also contain much of the potential wind capacity in the lower 48 states (AWEA 2009). The potential wind capacity, combined with the bird and bat fauna in the area, underscores the importance of selecting these regions for our study area.

The prairie potholes region (BCR 11) contains both mixed grass and tallgrass prairies interspersed with shallow pools and lakes. These bodies of water were formed after glaciers from the last ice age receded and left behind shallow depressions. This region is known for its extensive waterfowl production and has the highest density of breeding waterfowl in North America. BCR 11 has a defined precipitation gradient with the driest conditions occurring in the northwest and the wettest in the southeast part of the region (Euliss et al. 1999) (Figure 2-1).

The badlands and prairies region (BCR 17) is more arid than the prairie potholes and contains some of the largest continuous tracts of grassland in the US (NABCI 2012). Several distinct habitats occur in this region including eroded clay slopes, large tracts of grassland, and scattered low shrub vegetation (Stewart 1975). This region is a transition zone from the even more arid shortgrass prairie in the west to the tallgrass prairie to the east (Figure 2-1).

The shortgrass prairie (BCR 18) is a primarily dry region with limited plant diversity but contains habitat for many grassland birds including Mountain Plover (Charadrius montanus), Burrowing Owl (Athene cunicularia), and Lesser Prairie-Chicken (Tympanuchus pallidicinctus). This region is dominated by two warm-season grasses that survive under intensive grazing: blue gramma (Bouteloua gracillis) and buffalo grass (Bouteloua dactyloides) (Samson et al. 1998) (Figure 2-1).

As its name suggests, the mixed-grass prairie (BCR 19) is an ecotone between the shortgrass and tallgrass prairies in the central US This BCR typically contains warm season grasses in the western portion of the region and cool and warm season grasses in the eastern portion of the region. This region has the highest plant diversity of all the prairie habitats (Samson et al. 1998); however, habitats in this region are threatened by heavy disturbances from agriculture. This BCR provides habitat for sensitive species such as the Greater Prairie-Chicken (Tympanuchus cupido) and Interior Least Terns (Sterna antillarum athalassos) (NABCI 2012) (Figure 1).

There are no defined ecoregions for bats in the US that are analogous to what the BCRs have defined for birds. Given the similar ecology and vegetation structure of the BCRs, these regions should also provide adequate delineations for studying bats in this region.

\subsection{Methods}

\subsubsection{Species Selection}

We selected a representative species from each of seven taxa of birds and bats for a total of nine focal species. The focal species in our study were chosen based on one or more of the following factors: 1) occurrence in the study area, 2) having behaviors that predispose the species to higher exposure, and in theory, higher collision mortality, 3) previously reported mortality at other wind power facilities, 4) high conservation status in the study region (endangered, threatened, species of special concern, etc.), 5) can serve as a representative surrogate for other species in the same taxa, and 6) is conspicuous to observers when doing surveys and, therefore, the species is well represented by existing datasets (Table $3-1$ ). 
Table 3-1. Taxa and Focal Species Determined to be Susceptible to Collision Mortality with Wind Turbines in the Central US.

\begin{tabular}{|c|c|c|c|c|}
\hline Taxa & $\begin{array}{l}\text { Common } \\
\text { Name }\end{array}$ & $\begin{array}{l}\text { Scientific } \\
\text { Name }\end{array}$ & Reasons for Inclusion & Source(s) \\
\hline $\begin{array}{l}\text { Grassland } \\
\text { Passerine }\end{array}$ & $\begin{array}{l}\text { Horned } \\
\text { Lark }\end{array}$ & $\begin{array}{l}\text { Eremophila } \\
\text { alpestris }\end{array}$ & $\begin{array}{l}\text { Previously reported mortality at } \\
\text { other wind power facilities, } \\
\text { courtship behavior increases } \\
\text { exposure to blades (territorial } \\
\text { fights involve aerial combat); } \\
\text { conspicuous and well } \\
\text { represented by existing datasets }\end{array}$ & $\begin{array}{l}\text { Beason 1995; } \\
\text { Kingsley and } \\
\text { Whittam 2007; } \\
\text { National } \\
\text { Research } \\
\text { Council } 2007\end{array}$ \\
\hline $\begin{array}{l}\text { Neotropical } \\
\text { Woodland } \\
\text { Passerine }\end{array}$ & $\begin{array}{l}\text { Red-eyed } \\
\text { Vireo }\end{array}$ & $\begin{array}{l}\text { Vireo } \\
\text { olivaceus }\end{array}$ & $\begin{array}{l}\text { Previously reported mortality at } \\
\text { other wind power facilities, } \\
\text { neotropical migrants have a high } \\
\text { conservation status; conspicuous } \\
\text { and well represented by existing } \\
\text { datasets }\end{array}$ & $\begin{array}{l}\text { Cimprich et al. } \\
\text { 2000; Kingsley } \\
\text { and Whittam } \\
\text { 2007; National } \\
\text { Research } \\
\text { Council } 2007\end{array}$ \\
\hline Waterfowl & Mallard & $\begin{array}{l}\text { Anas } \\
\text { platyrhynchos }\end{array}$ & $\begin{array}{l}\text { Previously reported mortality at } \\
\text { other wind power facilities, } \\
\text { traveling between nesting and } \\
\text { foraging grounds may increase } \\
\text { exposure to blades; conspicuous } \\
\text { and well represented by existing } \\
\text { datasets }\end{array}$ & $\begin{array}{l}\text { Drilling et al. } \\
\text { 2002; Kingsley } \\
\text { and Whittam } \\
\text { 2007; National } \\
\text { Research } \\
\text { Council } 2007\end{array}$ \\
\hline Shorebirds & $\begin{array}{l}\text { American } \\
\text { Avocet }\end{array}$ & $\begin{array}{l}\text { Recurvirostra } \\
\text { americana }\end{array}$ & $\begin{array}{l}\text { Previously reported mortality at } \\
\text { other wind facilities (albeit very } \\
\text { low); migratory behavior may } \\
\text { increase exposure to turbine } \\
\text { blades }\end{array}$ & $\begin{array}{l}\text { Page and Gill } \\
\text { 1994; Kingsley } \\
\text { and Whittam } \\
\text { 2007; National } \\
\text { Research } \\
\text { Council } 2007\end{array}$ \\
\hline Raptors & $\begin{array}{l}\text { Golden } \\
\text { Eagle }\end{array}$ & $\begin{array}{l}\text { Aquila } \\
\text { chrysaetos }\end{array}$ & $\begin{array}{l}\text { Previously reported mortality at } \\
\text { other wind facilities }\end{array}$ & $\begin{array}{l}\text { Kingsley and } \\
\text { Whittam 2007; } \\
\text { National } \\
\text { Research } \\
\text { Council } 2007\end{array}$ \\
\hline Cranes & $\begin{array}{l}\text { Whooping } \\
\text { Crane }\end{array}$ & $\begin{array}{l}\text { Grus } \\
\text { americana }\end{array}$ & $\begin{array}{l}\text { Slow flying behavior may } \\
\text { increase exposure to turbine } \\
\text { blades; high conservation status; } \\
\text { considered susceptible by US } \\
\text { FWS }\end{array}$ & Lewis 1995 \\
\hline
\end{tabular}




\begin{tabular}{|l|l|l|l|l|}
\hline Taxa & $\begin{array}{l}\text { Common } \\
\text { Name }\end{array}$ & $\begin{array}{l}\text { Scientific } \\
\text { Name }\end{array}$ & Reasons for Inclusion & Source(s) \\
\hline $\begin{array}{l}\text { Migratory } \\
\text { Tree Bats }\end{array}$ & $\begin{array}{l}\text { Red bat, } \\
\text { hoary bat, } \\
\text { and silver- } \\
\text { haired bats }\end{array}$ & $\begin{array}{l}\text { Lasiurus } \\
\text { cinereus, } \\
\text { Lasiurus } \\
\text { borealis, and } \\
\text { Lasionycteris } \\
\text { noctivagans }\end{array}$ & $\begin{array}{l}\text { Comprise the majority (86\%) of } \\
\text { reported mortality; high } \\
\text { conservation status because high } \\
\text { mortality rates could have } \\
\text { population-level effects }\end{array}$ & $\begin{array}{l}\text { Erickson et al. } \\
2002 ; \text { Kuvlesky } \\
\text { et al. 2007 }\end{array}$ \\
\hline
\end{tabular}

\subsubsection{Existing Datasets}

Modeling collision mortality over BCRs 11, 17, 18, and 19 was performed using pre-existing large-scale (and in several cases temporally long-term) datasets. These datasets include the primary and gray literature, North American Breeding Bird Survey (NABBS), Christmas Bird Counts (CBC), eBird, Landfire.gov Elevation Dataset, National Landcover dataset, and weather data from the National Climate Data Center. These datasets contain information covering the entire study area in the US and are commonly used for modeling large-scale bird-habitat relationships (e.g., Thogmartin et al. 2006; Forcey et al. 2007, 2011).

\section{Literature Sources}

Because of the large size of the study area and the infeasible nature of collecting field data over the large area, much of the life history and habitat preference data on the focal species were extracted from the literature. The primary sources for life history information on birds are the Birds of North America species accounts (Poole 2005). These accounts are a collection of information of each bird species in North America compiled and written by those with expertise on the specific species. Accounts are frequently updated and are available online at http://birds.cornell.edu. Because no equivalent source exists for bats, we relied on the International Union for Conservation of Nature (IUCN) Red List database for life history and habitat information. The IUCN Species Programme has been ranking the conservation status of species for more than four decades and provides detailed habitat and conservation information for species across the world (IUCN 2010). Other literature sources include primary and gray literature, books, and professional expertise.

\section{North American Breeding Bird Survey}

The NABBS is a long-term survey effort to monitor the status of bird population trends on a continental scale. Breeding bird survey routes are randomly assigned along roadsides across North America and are surveyed every year during late May and June by volunteer scientists of varying experience. Each route is $39.4 \mathrm{~km}$ in length, and there are 50 stops — one approximately every $0.8 \mathrm{~km}$ along the route. At each stop, an observer conducts a three-minute point count and records all birds seen or heard within a 400-m radius. Individual routes are surveyed by the same observer each year, when possible, with a consistent method and only under suitable weather conditions (i.e., low wind and minimal precipitation) where bird detection probabilities are not likely to be affected. Attempts to minimize variability in NABBS data ensure that data are as unbiased as possible and that real variation in trends can be detected over time (Sauer et al. 2011). 


\section{Christmas Bird Count}

The Audubon CBC is the largest wildlife survey in the world and also the oldest (Butcher 1990). The CBC started in 1900, and currently has more than 1,500 count circles in North, Central, and South America. Each count circle is $24.1 \mathrm{~km}$ in diameter and is counted for a one-day period by varying numbers of volunteers within two weeks of 25 December (Butcher 1990). Unlike the NABBS, the level of observer effort varies considerably among CBC count circles depending on the number of volunteers and time spent in the field. These nuisance effects must be addressed in the analysis before meaningful comparisons can be made among count circles. Past counts have been standardized to the units of number of birds per party hour (Sauer et al. 1996).

\section{eBird}

eBird is an online collection of bird observation data collected by scientists, birders, and other interested parties across the world. Started in 2002, this database contains historical and recent observations of bird collected during both incidental observations, stationary counts (e.g., point counts), and traveling surveys (e.g., transect counts). In addition to data on bird species, abundance and location, this database has extensive metadata documentation on the type of survey, observer effort, and internal quality control mechanisms. eBird data is reviewed by local partner conservation organization, which targets local expertise and knowledge of bird fauna to ensure that aberrant bird records receive the necessary scrutiny (Munson et al. 2009).

\section{National Land Cover Dataset}

Land use information and metrics were derived from the 2001 NLCD distributed by the US Geological Survey. Land use data from the NLCD represent conditions in the US in the early 2000s and are currently the most recent version of these data (Homer et al. 2007). The NLCD was derived from Landsat 5 and Landsat 7 imagery and provides a characterization of the land cover for every 30-m cell in the US This characterization consists of 16 land cover classes including different vegetation, urban, and water classifications (Homer et al. 2007). This classification was simplified into a modified Anderson et al. (1976) classification to reduce classification inaccuracies that can occur when differentiating among similar land use types.

\section{Landfire Spatial Data}

The Landfire program is an interagency program within the federal government that is dedicated to using mapping techniques to understand fire and fuel potential at a spatial level. We used three data layers provided by Landfire: topography, forest canopy coverage, and forest biomass. The topography layer identifies the level of slope through the study area and was derived from the National Elevation Data and 7.5 minute quadrangle topographic data.

Vegetation height and biomass data were generated using a predictive model using Landsat imagery and calculated height values derived from field data (Landfire 2012). Both vegetation height data and biomass data were used to derive an index of forest stand age (important for tree bats). Relative amounts of forest stand age were derived from low (low biomass and low canopy coverage) to high (high biomass and high canopy coverage).

\section{National Climate Data Center Weather Data}

The National Climatic Data Center (NCDC) archives 99\% of the weather data from the National Oceanic and Atmospheric Administration (NCDC 2011). Sources of archival data include satellites, radar, remote sensing systems, and aircraft. We used hourly data on temperature, 
visibility, wind speed, and precipitation data to understand the variation in these covariates across space and time.

\section{Whooping Crane Migration Corridor}

USFWS maintains records of Whooping Cranes sighted during their migration from Aransas National Wildlife Refuge in Texas to Wood Buffalo National Park in Alberta. From these records, an approximate migration corridor has be created that encompasses $>90 \%$ of the Whooping Crane observations during migration (USFWS 2009). The migration corridor provides an approximate area where Whooping Cranes are most likely to occur during their migration in the US.

\section{Bats}

There are currently no long-term, large-scale datasets available on bat distribution and abundance. Because of this paucity of bat data, we relied on known habitat preferences cited in the literature to map preferred breeding, wintering, and migratory habitats for bats in the study region.

\subsubsection{General Analysis Approach Birds}

Relative predicted collision risk was determined based on a combination of abundance and exposure information specific to each species for each season throughout the year. For the breeding, winter, and migratory seasons, relative abundance of each focal species was modeled as a function of land use variables to predict relative abundance over the landscape. Spatial representations of weather and topography, which can influence collision susceptibility with wind turbines (Erickson et al. 2001), were used with abundance predictions to compute a mapped output of predicted collision risk for each species for each season. Season-specific predictions of collision mortality were summed and weighted according to 1) the number of months a species spends in that part of its annual cycle, and 2) the occurrence of behavior that would increase susceptibility to collisions (e.g., aerial courtship displays).

Because of temporal differences across seasons in bird abundance, distribution, and behavior, separate models were warranted for the summer, winter, and migratory seasons. None of the focal species occur in the same range year round, so models must account for temporal differences in abundance and distribution across the study area. For example, the American Avocet occurs in the study region during the breeding season but not during the winter season (Robinson et al. 1997). In addition, behavior also differs temporally among seasons. During the summer breeding season, birds are establishing territories, performing courtship rituals, and feeding young, whereas on the wintering grounds birds often occur in conspecific and mixedspecies flocks and spend the majority of their time foraging for food. For example, Horned Larks often travel in flocks during the winter time in search of food (Beason 1995). During spring and fall migration, birds travel great distances and often through unfamiliar areas as they travel between wintering and breeding grounds. These temporal differences can have a large impact on abundance and exposure in a given area.

A final reason that warrants constructing season-specific models for breeding, wintering, and migratory periods involves temporal limitations of the existing datasets. The NABBS data are only collected in May and June so that only breeding individuals are recorded. It is uncommon that migrants are recorded during this survey, and thus interpretations from this dataset must be 
limited to the breeding season. Similarly, the CBC is restricted to the time period within two weeks before or after 25 December, which limits temporal variation in this dataset. eBird are available year round; however, these data were used for migration information as other more comprehensive, systematic datasets (NABBS and CBC) are available for the other time periods. Timing of migration varies considerably across the focal species and our analyses of migration will correspond with the times that each species normally migrates (Table 3-2).

Table 3-2. Species-specific Seasonal Definitions of Breeding, Wintering, and Migratory Seasons for Avian Focal Species

\begin{tabular}{|l|l|l|l|l|}
\hline Species & Breeding $^{1}$ & Wintering & Migratory & Source \\
\hline $\begin{array}{l}\text { Lorned } \\
\text { through June }\end{array}$ & $\begin{array}{l}\text { Late May } \\
\text { Early January }\end{array}$ & $\begin{array}{l}\text { March to May; mid- } \\
\text { September through } \\
\text { mid-November }\end{array}$ & Beason 1995 \\
\hline $\begin{array}{l}\text { Red-eyed } \\
\text { Vireo }\end{array}$ & $\begin{array}{l}\text { Late May } \\
\text { through June }\end{array}$ & $\begin{array}{l}\text { Does not occur in study } \\
\text { area }\end{array}$ & $\begin{array}{l}\text { Mid-April to May; } \\
\text { September to October }\end{array}$ & $\begin{array}{l}\text { Cimprich et al. } \\
2000\end{array}$ \\
\hline Mallard & $\begin{array}{l}\text { Late May } \\
\text { through June }\end{array}$ & $\begin{array}{l}\text { Late December through } \\
\text { Early January }\end{array}$ & $\begin{array}{l}\text { Mid-February to } \\
\text { March; September to } \\
\text { November }\end{array}$ & $\begin{array}{l}\text { Drilling et al. } \\
2002\end{array}$ \\
\hline $\begin{array}{l}\text { American } \\
\text { Avocet }\end{array}$ & $\begin{array}{l}\text { Late May } \\
\text { through June } \\
\text { area }\end{array}$ & $\begin{array}{l}\text { Does not occur in study } \\
\text { Late February to early } \\
\text { April; mid-July to mid- } \\
\text { September }\end{array}$ & $\begin{array}{l}\text { Robinson et al. } \\
1997\end{array}$ \\
\hline $\begin{array}{l}\text { Golden } \\
\text { Eagle }\end{array}$ & $\begin{array}{l}\text { Late May } \\
\text { through June }\end{array}$ & $\begin{array}{l}\text { Late December through } \\
\text { Early January }\end{array}$ & $\begin{array}{l}\text { March to April; } \\
\text { October to December }\end{array}$ & $\begin{array}{l}\text { Kochert et al. } \\
2002\end{array}$ \\
\hline $\begin{array}{l}\text { Whooping } \\
\text { Crane }\end{array}$ & $\begin{array}{l}\text { Does not } \\
\text { occur in study } \\
\text { area }\end{array}$ & $\begin{array}{l}\text { Does not occur in study } \\
\text { area }\end{array}$ & $\begin{array}{l}\text { April to May; October } \\
\text { to mid-November }\end{array}$ & Lewis 1995 \\
\hline
\end{tabular}

${ }^{1}$ Breeding season is assumed to coincide with the period when the NABBS is conducted.

${ }^{2}$ Wintering season is assumed to coincide with the period when the $\mathrm{CBC}$ is conducted.

\section{Bats}

Currently no large-scale, long-term datasets that record breeding, wintering, and/or migratory information on bats exists. Because of this paucity of bat data, we could not model bat abundance as a function of habitat variables and create a prediction of abundance as we did for birds. Instead, we reviewed the literature on preferred bat habitat and identified those habitat features preferred by bats in the landscape. The greater the number of preferred habitat features, the greater the habitat quality. Bat habitat preferences were assumed to be the same across seasons as there is insufficient information in the literature to differentiate habitat preferences among the summer, winter, and migratory seasons.

Unlike habitat preferences, bat behavioral patterns differ across seasons to the point that exposure was considered separately for each season. During migration, bats travel through unfamiliar areas and may have increased potential exposure to turbines. Migration is a particularly vulnerable time for bats with most reported bat mortality at wind power facilities occurring during the fall (Arnett et al. 2008). Bat activity is also higher during the summer and 
minimal during the winter seasons given the warmer temperatures and increased insect abundance. Given the differences in bat behavior across seasons, our exposure variables depicting weather were specific to each season (

Table 3-3). A final step in the modeling process was to incorporate the habitat models with the exposure models for a final prediction of collision mortality.

Table 3-3. Species-specific Seasonal Definitions of Summer, Wintering, and Migratory Seasons for Bat Focal Species

\begin{tabular}{|l|l|l|l|l|}
\hline Species & Summer & Wintering & Migratory & Source \\
\hline $\begin{array}{l}\text { Eastern } \\
\text { red bat }\end{array}$ & $\begin{array}{l}\text { Early June to } \\
\text { Late July }\end{array}$ & $\begin{array}{l}\text { Mid-September to } \\
\text { April }\end{array}$ & $\begin{array}{l}\text { May to early June; } \\
\text { late July to mid- } \\
\text { September }\end{array}$ & $\begin{array}{l}\text { Nationwide } \\
\text { Acoustic Surveys; } \\
\text { Normandeau } \\
\text { Associates, Inc. } \\
\text { Unpublished Data }\end{array}$ \\
\hline Hoary bat & $\begin{array}{l}\text { Early June to } \\
\text { Late July }\end{array}$ & $\begin{array}{l}\text { Mid-September to } \\
\text { April }\end{array}$ & $\begin{array}{l}\text { May to early June; } \\
\text { late July to mid- } \\
\text { September }\end{array}$ & $\begin{array}{l}\text { Nationwide } \\
\text { Acoustic Surveys; } \\
\text { Normandeau } \\
\text { Associates, Inc. } \\
\text { Unpublished Data }\end{array}$ \\
\hline $\begin{array}{l}\text { Silver- } \\
\text { haired bat }\end{array}$ & $\begin{array}{l}\text { Early June to } \\
\text { Late July }\end{array}$ & $\begin{array}{l}\text { Mid-September to } \\
\text { April }\end{array}$ & $\begin{array}{l}\text { May to early June; } \\
\text { late July to mid- } \\
\text { September }\end{array}$ & $\begin{array}{l}\text { Nationwide } \\
\text { Acoustic Surveys; } \\
\text { Normandeau } \\
\text { Associates, Inc. } \\
\text { Unpublished Data }\end{array}$ \\
\hline
\end{tabular}

\subsubsection{Relative Abundance Modeling-Birds}

We used NABBS, CBC, and eBird data between the years 1990 and 2009 because this timeframe evenly overlaps the time when NLCD land use data were derived from satellite imagery during the early 2000s (Homer et al. 2007). Within BCRs 11, 17, 18, and 19, there are 472 NABBS routes and 141 active $\mathrm{CBC}$ count circles. A separate sampling dataset for both NABBS and CBC counts was incorporated with the bird data to account for routes and circles that were sampled but birds of a given species were not observed.

\section{eBird Data Processing and Quality Control}

Because eBird data are represented as point data, we converted point data to polygon data so that counts would represent a defined area, where land use could be quantified, and related back to the bird abundance in that area. We created a 100,000-ha cell size vector grid with 1,724 total cells across the entire study area. Smaller sampling units were not examined with eBird data because they would not cover an area sufficient to obtain an adequate number of counts within the sampling unit; eBird data is generally sparse in our study region compared with more populated areas. The vector grid was created with the xTools Pro extension for ArcGIS 10.

eBird data are provided as two separate datasets: count data and sampling event data. The count data represent the total number of birds observed during each count, which represents positive 
observations only. The sampling effort data indicates every count survey that was conducted regardless of what species were observed. Using the count data with the sampling effort data allowed us to correct for differences in sampling effort across sampling units. Sampling effort correction was done by dividing the number of birds observed of each species in each sampling unit (each 100,000 ha grid cell) during a given time period by the number of surveys occurring in that grid cell during that time period. Final values within each sampling block represent the number of birds observed per survey; this is specific to each species and each season within the analysis. Timeframes vary across species given that spring and fall migration times are specific to each of the focal species.

Because the eBird dataset encompasses different types of counts ranging from stationary to traveling counts, we performed a quality control procedure at multiple levels for the sampling event data (survey data) and count data. This procedure removed data that was questionable or unreliable by the standards detailed below.

1) Remove Incomplete Checklists-Complete checklists represent a total count of all birds seen or heard within a defined area, and the absence of a species or individual can be assumed to be a true zero value. Incomplete checklists do not represent all species, and therefore the absence of individuals or species do not necessarily represent a true zero value but could mean that birds were present but not counted. Removal of incomplete checklists minimizes this bias.

2) Remove Invalid Observations - Cornell Lab of Ornithology performs its own independent verification process on data submitted to the Avian Knowledge Network $(\mathrm{AKN})$. Observations are reviewed for credibility and whether the number of birds for each species fits within a defined range that is acceptable for a given time period and location. Every AKN observation is classified into one of four categories: 1) valid and reviewed, 2) valid but not reviewed, 3) not valid but reviewed, and 4) not valid and not reviewed. For our analyses, we removed observations that were "not valid but reviewed" and "not valid and not reviewed". Observations that were classified as valid regardless of whether or not they were reviewed were included in our analyses.

3) Remove Long Traveling Counts and Large Exhaustive Area Counts-Two of the count types present within the eBird database are traveling counts and exhaustive area counts. These types of counts involve collecting data over large areas. Although the surveys may cover large spatial extents, traveling counts and exhaustive area counts are still recorded as single points in the database. This problem is mitigated to a degree in the eBird database by attempting to ensure that the single point chosen for the observation is located near the center of the actual spatial extent surveyed; however, it is often unclear where certain birds were observed within the large areas covered by these types of surveys. To reduce spatial imprecision with the eBird point data, we excluded long traveling counts (> $30 \mathrm{~km})$ and large exhaustive area counts (> 1,200 ha).

\section{Land Use Quantification}

Land use patterns were evaluated at three spatial scales around each NABBS route by creating three sizes of buffers: $0.1 \mathrm{~km}(\sim 1,000 \mathrm{ha}), 1 \mathrm{~km}(\sim 10,000 \mathrm{ha})$, and $10 \mathrm{~km}(\sim 100,000 \mathrm{ha})$. Land use patterns around CBC circles were evaluated similarly although only at two scales. These scales are 50,000 ha (the approximate scale of the count circle) and 100,000 ha (similar to one of the scales used in the NABBS analyses). A smaller scale was not used for CBC data because it would be smaller than the sampling unit (the count circle), and therefore unjustified. Land use 
quantification associated with bird migration data was performed using the same 100,000 ha grid that was used to quantify the eBird data (Figure 3-1). Land use metrics were quantified within each buffer size around each route/circle/grid cell using ArcGIS v10 GIS software (ESRI 2012) and FRAGSTATS (McGarigal et al. 2002) (Appendix 1). 


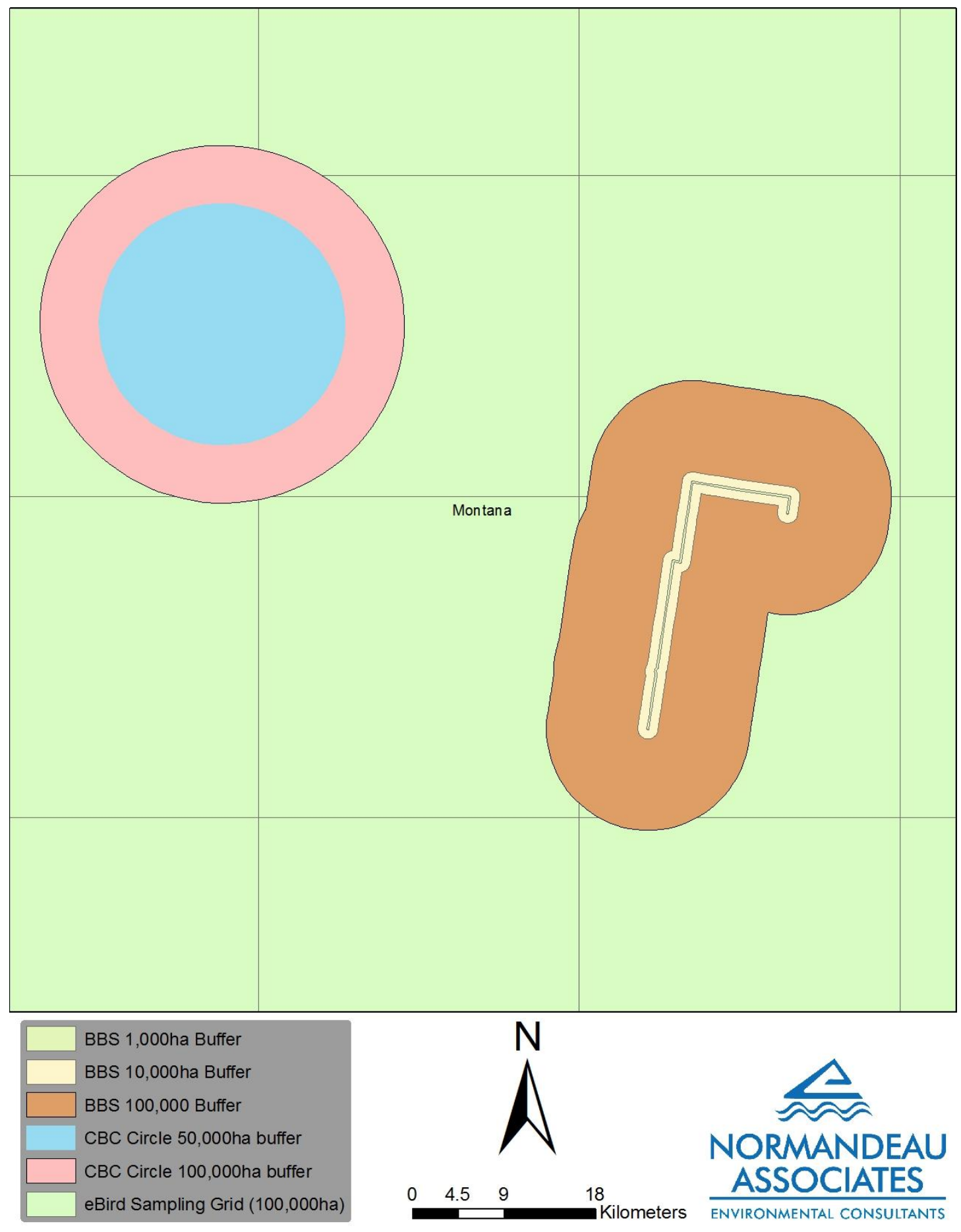

Figure 3-1. Various buffer sizes surrounding Breeding Bird Survey routes and Christmas Bird Count circles. The background grid represents the sampling units used to quantify eBird bird and sampling event data. 


\section{Habitat Variable Selection}

The number of environmental variables that can be measured through remote sensing is large relative to the sample sizes in this study. Because of chances associated with finding spurious effects when examining a large number of covariates (Anderson et al. 2001), variables that were thought to be important descriptors of bird abundance were selected a priori. We reviewed published habitat associations and life histories for focal species in this study to determine which environmental variables would be likely to have the most effect on abundance (Appendix 2). These variables were used to construct candidate sets of models at each spatial scale for each focal species (Appendix 3). Spearman's rank correlations were calculated for environmental covariates; covariates with a correlation coefficient $>0.5$ were not included in the same $a$ priori model.

\section{Bird modeling approach}

Bird abundance from the BBS, CBC, and eBird was modeled as a function of land use variables and "nuisance effects" (i.e., survey year, observer bias, and specific survey location) using a hierarchical log-linear mixed-effects model. Hierarchical models are useful for this modeling effort because they acknowledge correlation among multiple observational units that are present in the survey design (Link et al. 2002). Temporal correlation in counts is present among years, and spatial correlation is present among routes and count circles. Temporal correlation occurs when count similarity is tied to survey chronology; spatial correlation is when count similarity is tied to geographical proximity.

The response variable in the breeding (BBS) and winter (CBC) modeling is the total number of birds for each species across the entire route/circle for each year. The response variable in the migratory (eBird) modeling is the total number of birds for each species within each grid cell across all years (1990 to 2009), and observers corrected for sampling effort (birds observed divided by sampling effort). Nuisance effects were incorporated into the models at three levels. A year effect was included to account for inherent temporal variation in bird abundance occurring as populations naturally fluctuate. Year effects were included in both breeding and winter modeling, but not migratory modeling; bird migration data were pooled across all years to boost sample sizes in each sampling unit to better estimate spatial patterns in population abundance. To account for variation across space, route, circle, and grid cell effects were also included in the breeding, winter, and migratory models, respectively.

Another level in the model hierarchy is the observer due to differences in bird counting experience among observers; failure to accommodate for this effect can substantially bias analyses (Sauer et al. 1994). Two observer effects were included in the breeding models: one accounted for differences in surveying abilities among observers (Sauer et al. 1994) and the other accounted for inexperience (a first-time observer effect). The first-time observer effect was a binary variable, which was 0 if it was an observer's first time surveying a route and 1 if the observer had surveyed the route previously. The first-time effect accounts for improvements in observer bird identification over time, increased surveying efficacy, and associating certain species with individual stops (Kendall et al. 1996). Observer effects cannot be accommodated with the $\mathrm{CBC}$ count data as multiple observers conduct counts in the same sampling unit simultaneously and are not assigned a unique identification number. We standardized the number of birds observed by party-hour, which corrected for differences in the number of observers among count circles (Sauer et al. 1996). Although observer information is collected for eBird data, we lost this information when point observations were pooled across each sampling unit 
and across years to provide a total abundance of birds of each species in each sampling unit. Observer effects were not incorporated into migratory models.

Models were constructed with covariates at a common scale; we did not have sufficient a priori information available to warrant constructing multiscale models. Poisson regression was used to model bird abundance as a function of environmental covariates in the study region because counts are typically discrete positive values and are often Poisson distributed. Counts from CBC and eBird data that were standardized per unit effort were rounded up to create integer values suitable for Poisson regression. All environmental variables were standardized to have mean of 0 and standard deviation of 1 so comparisons could be made among covariates in the model results.

The construction for breeding models is as follows: Counts, environmental covariates, and nuisance effects all occur across space (s). Lambda $(\lambda)$ represents the count of a species on a route for a given year. Beta parameters $\left(\beta_{k}\right)$ represent the coefficients for environmental effects $\left(x_{k}\right)$. Year $\left(\gamma_{k}\right)$ and observer $\left(\omega_{\mathrm{k}}\right)$, route $\left(Z_{k}\right)$, and overdispersion effects $\left(\varepsilon_{\mathrm{k}}\right)$ were treated as random effects in the model. Novice effects $(\eta I)$ were treated as fixed indicator variables. The final model we used was

$$
\log [\lambda(s)]=\sum_{k=1}^{n} \beta_{k} x_{k}(s)+Z_{k}(s)+\omega_{k}(s)+\eta I(s)+\gamma_{k}(s)+\varepsilon_{k}
$$

Where $k$ represents year-specific counts for 1 through n years.

Because observer information is not present within the $\mathrm{CBC}$ count data and multiple observers survey a count circle, the model that was used was modified from above, omitting the observer effects:

$$
\log [\lambda(s)]=\sum_{k=1}^{n} \beta_{k} x_{k}(s)+Z_{k}(s)+\gamma_{k}(s)+\varepsilon_{k}
$$

Because year effects were removed from the migration modeling by combining data across years to increase the sampling effort and sample size, the model that was used was modified from the winter model above, omitting the year effect:

$$
\log [\lambda(s)]=\sum_{k=1}^{n} \beta_{k} x_{k}(s)+Z_{k}(s)+\varepsilon_{k}
$$

Models were ranked as to how well they fit the data by comparing the Akaike's Information Criteria among models and ranking them accordingly (Burnham and Anderson 2002). Model weights were calculated to assess the relative importance of each model and model-averaged parameters were compared among each other to assess the relative strength of the effects of the covariates.

Mapped abundance models were based on model-averaged beta parameters in each model within the subset of best models (Burnham and Anderson 2002). Land cover layers in the GIS were standardized to have a mean of 0 and a standard deviation of 1 before creating maps of relative bird abundance. The standardization process removes the units and places all covariates on the same scale. Abundance mapping was performed by creating four sizes of regular lattices over the study area. The four sizes corresponded to the spatial extents examined in the breeding, winter, 
and migration modeling: 1,000 ha (finest scale for the NABBS), 10,000 ha (intermediate scale for the NABBS), 50,000 ha (intermediate scale for the CBC), and 100,000 ha coarsest scale for the NABBS, CBC, and eBird). FRAGSTATS was used to quantify each land use variable in the analysis in each of the cells of the different sized regular lattices. Calculations determined by FRAGSTATS were joined back into each vector grid. This resulting vector grid contains multiple columns of attribute data with each column representing a different land use metric calculated by FRAGSTATS. Vector grids were converted to raster grids, with each raster grid representing a different land use metric. The vector to raster conversion was necessary so that land use grids could be used in raster algebraic equations.

For each bird species, environmental covariates were modeled in the maps at the scale(s) at which they were determined to be important. Variables were included in the raster algebraic equation if they were included in the $95 \%$ confidence interval of best models (Burnham and Anderson 2002). Land use variables were weighted in the raster algebraic equation based on the model-averaged values of the beta parameters for each species for each season. This process outputs ESRI ArcGrids of predicted relative abundance for each focal species for each season (breeding, winter, and migratory).

\subsubsection{Habitat Modeling-Bats}

Unlike birds, there are currently no pre-existing large-scale bat datasets that systematically record bats in the study area during breeding, winter, or migration. To predict relative abundance for bats, we identified areas of preferred habitat from the NLCD based on known habitat associations described in the literature (IUCN 2010). Creating high-resolution habitat models for bats involved 1) a review of the literature for habitat information on bats (Appendix 2) and 2) a landscape-level moving window analysis that identified the important habitat described in the literature review. Habitats that the bats are known to avoid (e.g., developed areas) were also considered.

We used a 2-km and 10-km moving window to quantify land use metrics within the study region. A 2-km moving window was used to quantify red bat and silver-haired bat, while a 10-km moving window was used to quantify hoary bat habitat. The larger moving window size was used for hoary bats because this species is thought to move longer distances within the course of night due to its larger size, widespread range, and swift and direct flight (Barbour and Davis 1969). Moving window analyses quantify landscape metrics within a specified radius from each pixel in the raster grid. A moving window analysis takes a raster grid of multiple land use types and reduces to a specific measurement of one land use type. For example, a moving window analysis of percent forest takes a land use grid showing multiple land use types and outputs a grid where each grid cell reflects the percent forest within a given radius of the cell. These analyses typically result in millions of repeated calculations and are therefore highly computationally intensive. Moving window analyses output a separate ArcGrid for each landscape variable determined to influence occupancy of bats (Appendix 3). Values of a specific grid cell represent a summary of all the grid cells of that particular land use type within an area the size of the moving window. Grids were added together using raster algebra to create a final spatial representation of habitat suitability for bats, and all different habitat variables were weighted evenly. All habitat variables were standardized to a mean of 0 and standard deviation of 1 so that all layers would be in the same units and directly comparable when being added together. Given the lack of information about the variability of bat habitat requirements among 
seasons, we used the same variables to assess habitat suitability for bats in the spring, summer, fall, and winter. Spring and fall migration were modeled separately because of large differences in bat mortality between spring and fall (Arnett et al. 2008).

\subsubsection{Exposure Modeling}

Because abundance is one of several factors that can influence collision mortality (Erickson et al 2001), a measure of exposure and those variables that influence exposure must also be incorporated into the final collision model outputs. Exposure represents a measure of contact with one or more stressors (USEPA 1998). Based on known behaviors and expert opinion, we incorporated variables into the collision model that were thought to be influential on exposure to wind turbines (hereafter referred to exposure variables). Exposure variables that were used were specific for each species for each time period in the analysis (summer, winter, fall, and winter). Temporal specificity is necessary because behavior varies widely among seasons, especially during migration. In our study, exposure to wind turbines can be influenced by a variety of factors including courtship, foraging, and perching behaviors; visibility; wind speed; temperature; and topography.

\section{Weather Variables}

Weather variables that likely influence bird and bat exposure to wind turbines include visibility for birds (Martin 2010) and temperature, precipitation, and wind speed for bats (Weller and Baldwin 2011). Spatial grids of visibility were derived separately for each bird species. We used life history information to estimate when each species of bird is likely to be breeding, wintering, and migrating, and derived measures of visibility for those time periods (Appendix 2). For Horned Lark, Red-eyed Vireo, Mallard, and American Avocet we derived the average number of daylight hours having less than 0.5 mile visibility (Appendix 3). For Golden Eagle and Whooping Crane we derived the average number of daylight hours with $>1$ mile visibility. Both Golden Eagle and Whooping Crane spend a large portion of their time in the air, and are more likely to be active during periods of greater visibility; and increased activity likely increases collision risk (Lewis 1995, Kochert et al. 2002). For bats, we derived weather variables based on three factors: temperature, wind speed, and precipitation. Eastern red bat and silver-haired bat variables for each season included average number of night hours with $<7 \mathrm{~m} / \mathrm{s}$ wind, average number of night hours with no rain, and average number of nights with $>50$ degree temperatures. Hoary bat variables were similar, except we derived the average number of night hours with $<10 \mathrm{~m} / \mathrm{s}$ wind speed (Appendix 3 ) to account for the fact that hoary bats seem to be more tolerant of moderate wind speeds because they are larger, stronger fliers than the other two tree bat species.

We obtained hourly weather data from 156 weather recording stations within the study area. From each weather station we assembled data from 1998, 2002, and 2006, which overlap temporally with the landcover data. Hourly data from each year were assembled in a GIS and the krieging function of the ArcGIS spatial analyst extension (ESRI 2012) was used to generate spatial layers of weather data for each of the weather variables we evaluated in our study (Appendix 3). Krieging is a method of surface interpolation where data from known locations are used to estimate values of a given metric at unknown locations. Weather data were average across the three years before krieging to smooth out interannual variability among years. 


\section{Topography}

Topography is relatively homogeneous in the central US as compared to the east or western regions. Among our focal species, we hypothesized that the Golden Eagle would be the only species where exposure would be influenced by topography. In areas of variable topography, Golden Eagles commonly hunt using short contour flights with short gliding flights to surprise prey (Kochert et al. 2002). In addition topography focuses air currents conducive to soaring, which can increase exposure to turbine blades. We used the slope function of the spatial analyst to derive the slope from 0 to 90 based on elevation data (Landfire 2012).

\subsubsection{Collision Modeling}

The final stage of the collision model involved adding the seasonal models and weighting them according to 1) the amount of time the species spends in each seasonal portion of its annual cycle and 2) a weight for the presence of behaviors that may increase susceptibility to collisions. Each seasonal model assumes that the species occurs throughout the study region during a given season.

\section{Behavior}

Behavior is a difficult metric to quantify spatially, but at a large scale is more temporally important. Many behaviors may increase or decrease susceptibility to wind turbine collisions, and should be factored into overall measure of collision risk. We addressed behavior in our collision models by weighting seasons according to the presence and number of risky behaviors, which normally occur in the season. For example, the Mallard breeding model received a weight of 3 given that the species has three susceptible behaviors during the breeding season: male-male interactions, flights between feeding and nesting areas, and low flight maneuverability. Seasons with 0 or 1 susceptible behavior did not receive a behavioral weight to minimize the chance of overweighting a season where it was not warranted. Our behavioral weighting approach allows us to place more importance on time periods where potentially susceptible behaviors occur, and provides a means to incorporate behavior into the overall collision risk prediction.

\section{Temporal Weighting}

Total time spent within a season can influence the level of exposure of birds and bats to wind turbines, and therefore was weighted in the model for each season. We weighted each seasonal model according to the number of months that was spent breeding, wintering, or migrating. For example, Golden Eagles have a prolonged migratory period and can spend up to seven months of the year in migration; a weight of 7 was applied to the Golden Eagle migratory model to reflect this amount of time. Temporal weighting was considered independently for each species for each season and was in addition to behavioral weighting described previously.

\section{Final Collision Model}

The final collision model was a summation of the all the season-specific grids weighted both temporally and spatially. The final collision grid values were standardized using a natural long transformation so that the range of values would be similar among grids.

\subsubsection{Model Evaluation}

\section{Comparison Against Independent Sources of Mortality}

Evaluating model performance is a critical step in the modeling process and necessary to understand how models perform under a range of input values. We evaluated the performance of 
our models using data collected from publically available mortality studies available within the study area. We reviewed existing studies for data on reported mortality of our focal species, the number of megawatts of the wind facility, and the duration of the study (Figure 3-2). Publically available studies included Buffalo Ridge Phases 1, 2 (Johnson et al. 2000, Tierney 2009), and 3, Top of Iowa (Koford and Jain 2004, Koford 2005), Judith Gap (TRC Environmental Corporation 2008), Ainsworth (Derby et al. 2007), and the Oklahoma Wind Energy Center (Piorkowski 2006). We standardized all the reported mortalities to number of birds and bats killed per turbine per year, which allowed for meaningful comparisons among wind facilities. Among the published studies we reviewed, only Horned Lark, red bat, hoary bat, and silver-haired bat had adequate sample sizes to be validated. For the species that could be validated, we plotted the predicted mortality against the observed and evaluated Spearman's rank correlations (Zar 1999) to see how well models predicted relative mortality. 


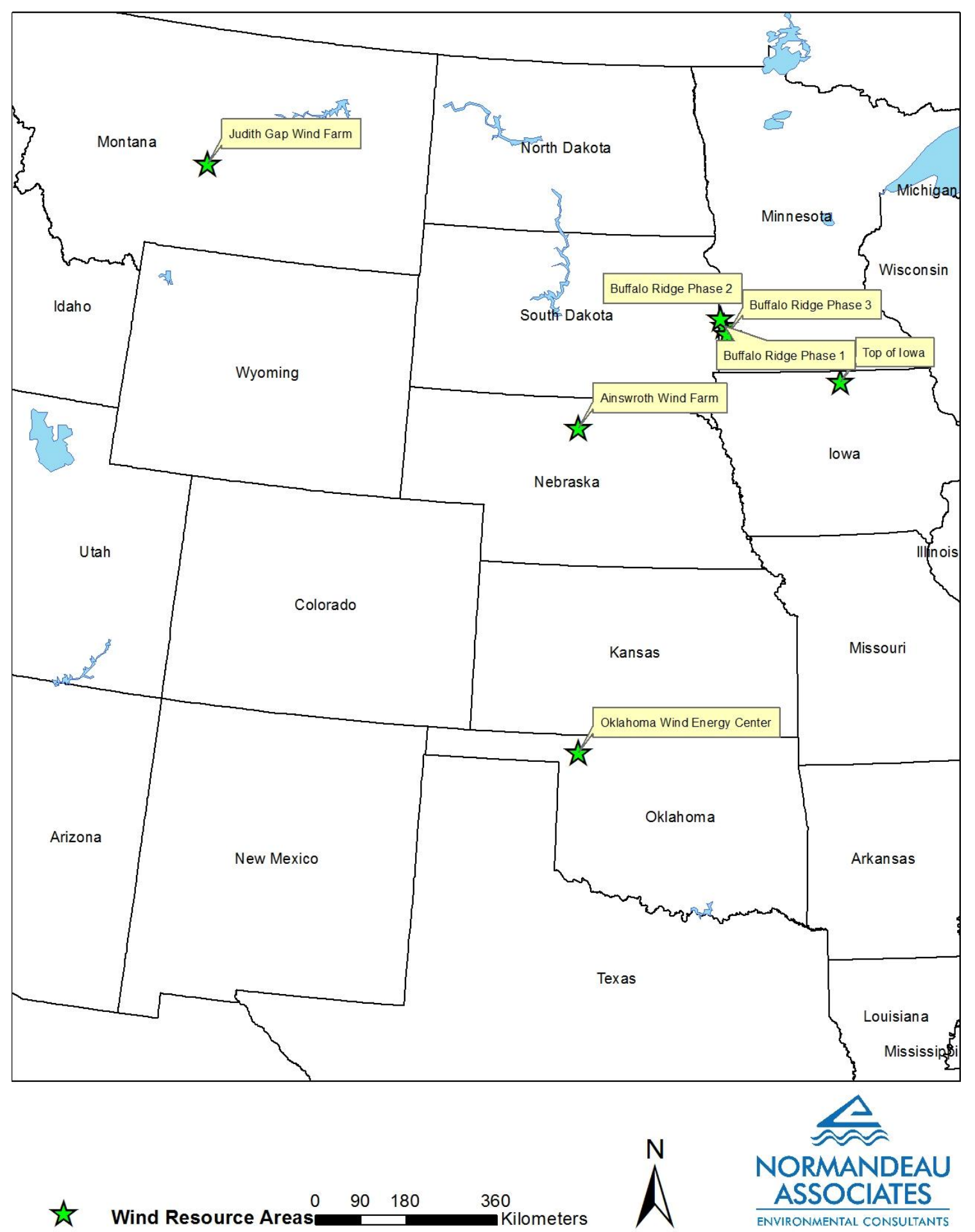

Figure 3-2. Locations of wind farms with publically available mortality data on bird and bats.

\section{Sensitivity Analyses}

One area of uncertainty in our modeling was the extent to which habitat and exposure influence collisions with wind turbines. Because little research exists in this area, we performed a 
sensitivity analysis examining the outcome of six different scenarios-weighting habitat and exposure factors differently and examining the resulting collision predictions. We applied the following weights to the abundance grid relative to the exposure variables to assess how the collision predictions differed among scenarios: 0.5, 1 (equal weight), 2, 4, and 8. Each scenario was assessed by comparing the Spearman's Rank Correlation Coefficients in a scatterplot matrix (Heiberger 2012). The scenario that provided the strongest positive correlation was the one used for mapping and what is presented in this report. For species where no validation data were available, we weighted habitat and exposure equally when generating collision risk maps because no a priori information was available to suggest other weighting would be more appropriate.

\subsection{Results}

\subsubsection{Habitat Modeling}

Across all species, the intermediate and coarsest scale had the most influence on bird abundance in the study region. All best models for all bird species included variables either at the coarsest or intermediate scale. Only the American Avocet and Golden Eagle had models in the best subset that contained variables at the finest scale. Across all species and seasons, model uncertainty was generally low to moderate with Golden Eagle having the most model uncertainty with eight models being in the best subset for the winter season. Habitat variables improved the model fit over the null model in almost all cases with the exception of the migratory models for Red-eyed Vireo and Golden Eagle (Appendix 4).

Model selection uncertainty was low for Horned Larks in the breeding and winter seasons, and moderate during the migratory season (Appendix 4). Horned Larks were influenced by variables mostly at the coarsest scale, although the intermediate scale also played a moderate role in influencing abundance. Across all seasons, Horned Larks were found to be positively influenced the most by cultivated crops and herbaceous vegetation and the strength of these effects were similar across scales. A strong negative relationship between Horned Larks and forest was found during the breeding season, but this relationship was weaker during winter and migration (Appendix 5).

Model selection uncertainty was low for Red-eyed Vireo during the breeding season and moderate during the migratory season; this species does not occur in the study area during winter (Appendix 4). Red-eyed Vireo abundance was mostly driven by positive relationships with forest metrics, especially forest edge density and forest percentage. The strongest effects were forest edge density and the intermediate and coarsest scale during the breeding season. There were not any strong effects of habitat ( $95 \%$ confidence interval not overlapping zero) found during the migratory season (Appendix 5).

During breeding and migration, model selection uncertainty was low for Mallard and moderate during the winter. Mallard abundance was driven slightly more at the intermediate scale than at the coarsest scale, but the strength of the effects was similar across scales indicating that scale played a minimal role for this species (Appendix 4). Nearly all habitat effects during breeding and winter were found to be strong positive predictors of Mallard abundance; during migration open water and emergent vegetation were the strongest predictors. A negative relationship was found with shrubland habitat during the breeding season (Appendix 5). 
For American Avocet, model selection uncertainty was low with only three models in the best subset for breeding, and 5 models in the best subset for migration. During breeding, fine and intermediate scales were the most influential in predicting abundance; models with coarse scale variables were not present in the best subset of models (Appendix 4). Percentage of open water and emergent wetlands were the strongest positive influences on abundance during breeding and open water was the strongest effect during migration. No strong negative relationships with habitat were found (Appendix 5).

Model selection uncertainty was moderate for Golden Eagles across all seasons, and abundance was influenced by habitat variables at all scales of the analysis (fine, intermediate, and coarse) (Appendix 4). The percentage of herbaceous land in the landscape was the strongest positive influence on abundance during breeding and winter. During breeding, percentage of shrubland and open water interspersion with other habitats were also strong positive predictors. During winter, forest percentage was a strong positive predictor of Golden Eagle abundance; open water interspersion and shrubland were strong negative predictors of abundance. No environmental variables were shown to be strong predictors of Golden Eagle abundance during migration. (Appendix 5)

Whooping Cranes only occur within the study area during migration, and therefore we only modeled abundance as a function of habitat variables during this time frame. Model selection uncertainty was low for Whooping Crane with only 1 model being in the best subset and being a much better fit to the data than the null model (Appendix 4). Whooping Crane abundance was positively associated with open water edge density and emergent vegetation interspersion with other land use types; a negative association occurred between Whooping Crane abundance and cultivated crops interspersed with other land use types (Appendix 5).

We did not have adequate bat data to model bat abundance as a function of habitat variables; therefore, our habitat models were based on extracting the habitat from the landscape that bats are known to prefer. Habitat for red bat, silver-haired bat, and hoary bat were heavily weighted toward forested areas, open water, and stream and river corridors.

\subsubsection{Collision Risk Mapping}

Mapped outputs provided a representation of relative collision risk for each species across the study area. These outputs incorporate habitat, weather, topographic, and behavioral variables into the relative risk prediction. The relative prediction is limited in that it can only be compared within a map, so it is only possible to make statements that a certain area is a higher or lower risk to a given species than another area. Maps cannot be compared among species because cases of previously reported mortality and overall susceptibility to collisions are not considered.

Horned Lark collision predictions were based solely on habitat given that the sensitivity analysis showed that the collision risk grid using only habitat provided the best correlations with observed mortality (Section 3.4.3). Collisions were expected to be highest in the northwest, westerncentral, and southwest portions of the study area. Low collision rates were expected in the forested portions of the study region and intermediate levels of risk were expected elsewhere (Figure 3-3). Red-eyed Vireo collision risk was highest in the eastern portions of the study area and in the forested habitats of the western portion of the study area. Collision risk was much lower elsewhere (Figure 3-4). Predicted Mallard collision risk was expected to be highest in the prairie pothole region of eastern North Dakota, South Dakota, western Minnesota, and northern 
Iowa. Areas of higher collision risk were also found in eastern Montana, Wyoming, and Colorado (Figure 3-5). Similar to Mallard, American Avocet predicted collision risk was concentrated in the prairie pothole habitats of the eastern Dakotas and isolated areas where lower visibility was found during this species' breeding and migratory season (Figure 3-6). Golden Eagle risk model outputs showed that risk was primarily concentrated in the western mountainous and forested portion of the study area. Minimal risk was found in the eastern portion of the study area, and intermediate risk levels were predicted elsewhere (Figure 3-7). Whooping Crane predicted collision risk was highest within their migratory flight corridor, and much lower outside the corridor with few exceptions (Figure 3-8).

Bat predicted collision risk was driven by habitat and weather variables and the extent that each contributed to the final predicted collision risk was dependent on the results of the model evaluation and sensitivity analysis. Bat mortality for all three species was predicted to be highest in forested habitat and in areas close to water, especially river corridor habitat. Areas of higher mortality were also predicted in the southern portion of the study area (Figure 3-9, Figure 3-10, and Figure 3-11). 


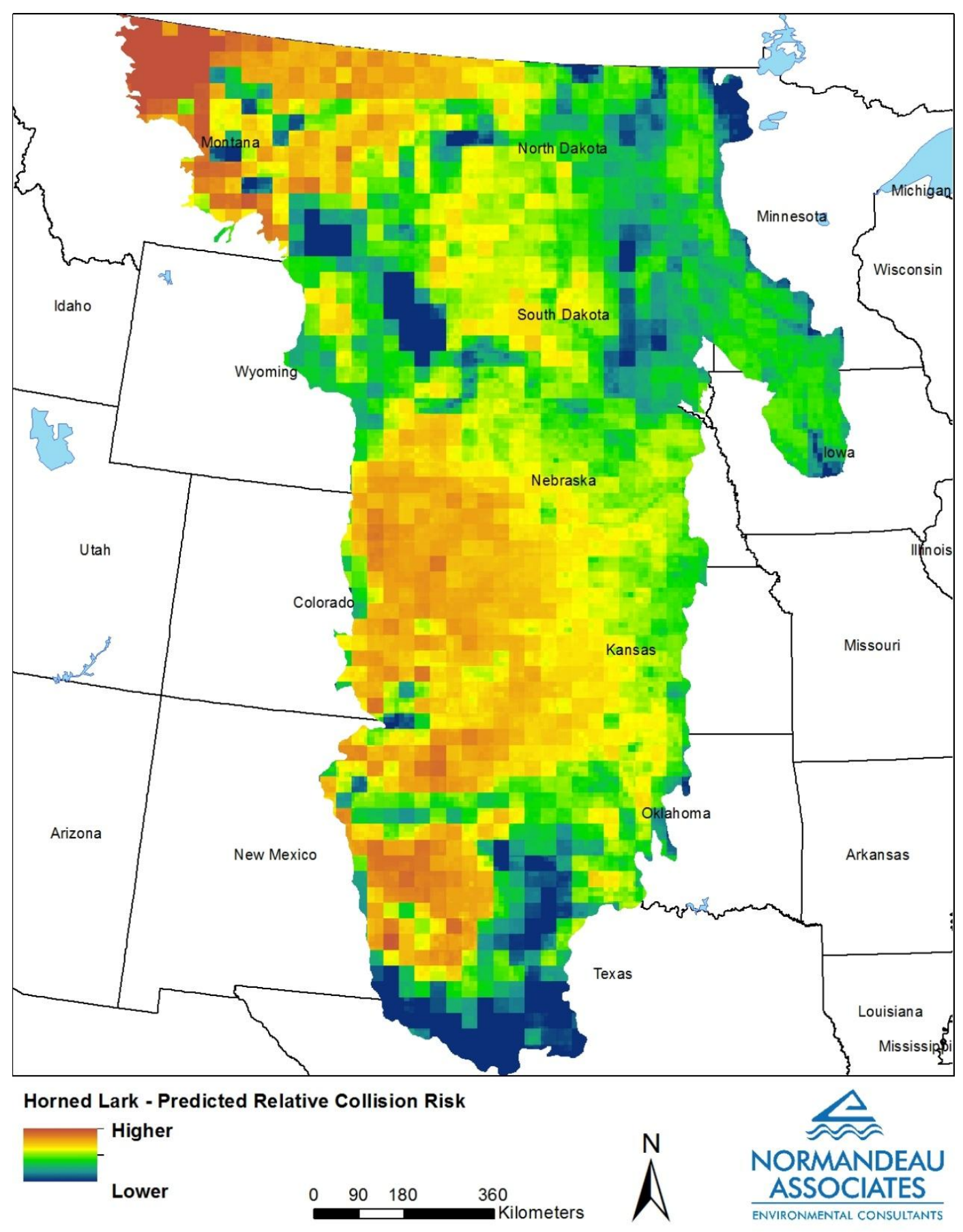

Figure 3-3. Spatial distribution of predicted Horned Lark collision risk within the central United States. Shades of color represent relative predictions within a species; maps are not comparable among species. 


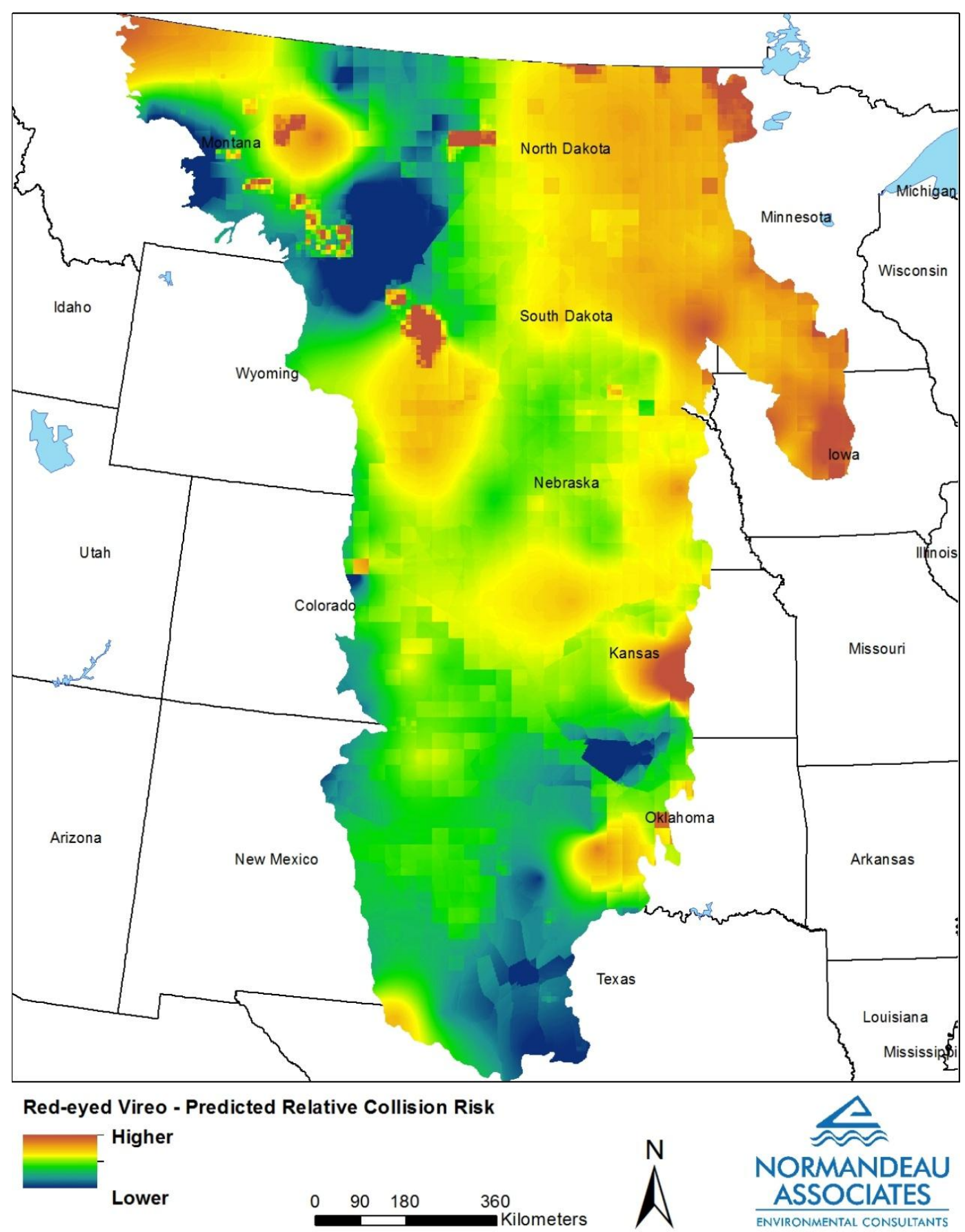

Figure 3-4. Spatial distribution of predicted Red-eyed Vireo collision risk within the central United States. Shades of color represent relative predictions within a species; maps are not comparable among species. 


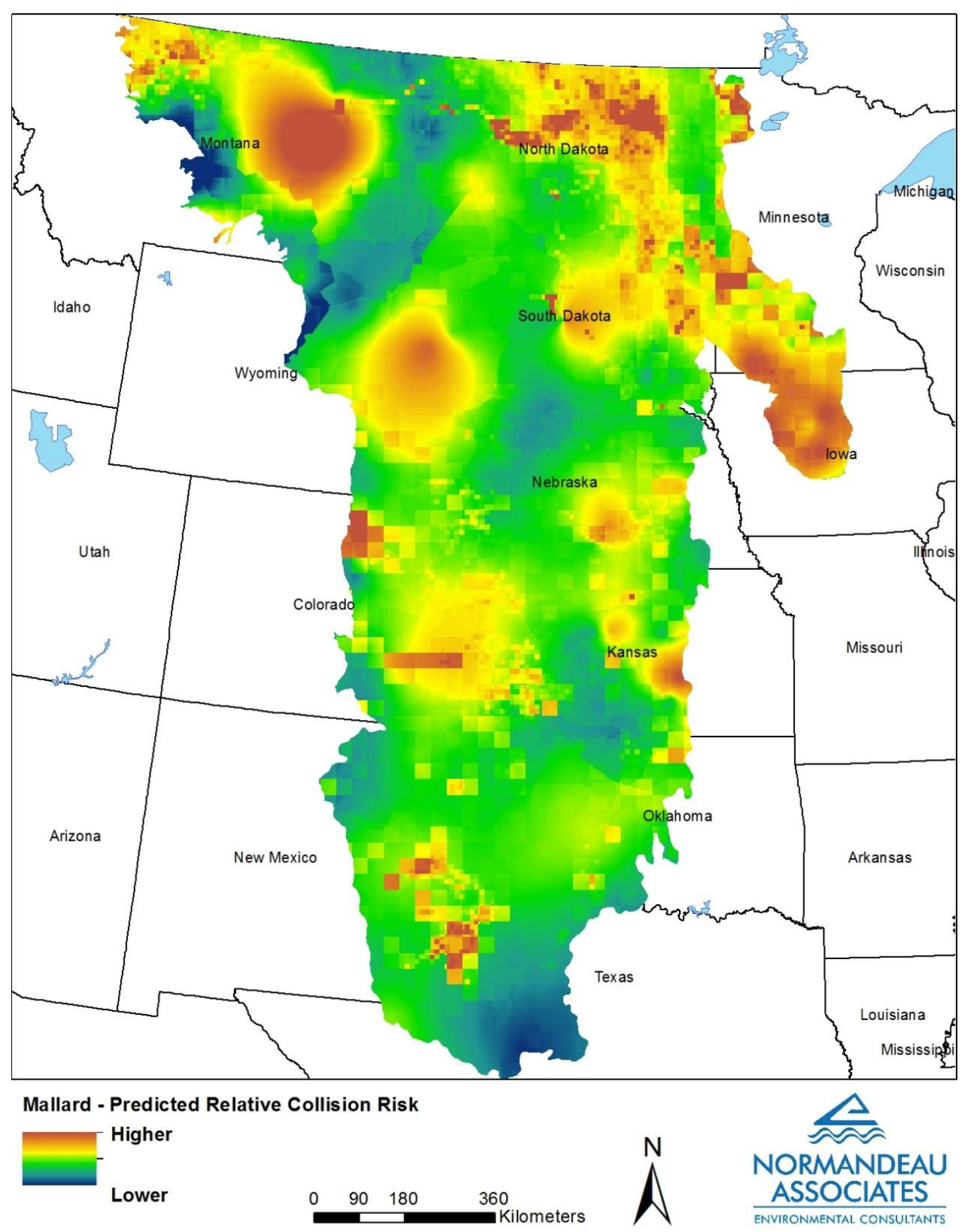

Figure 3-5. Spatial distribution of predicted Mallard collision risk within the central United States. Shades of color represent relative predictions within a species; maps are not comparable among species. 


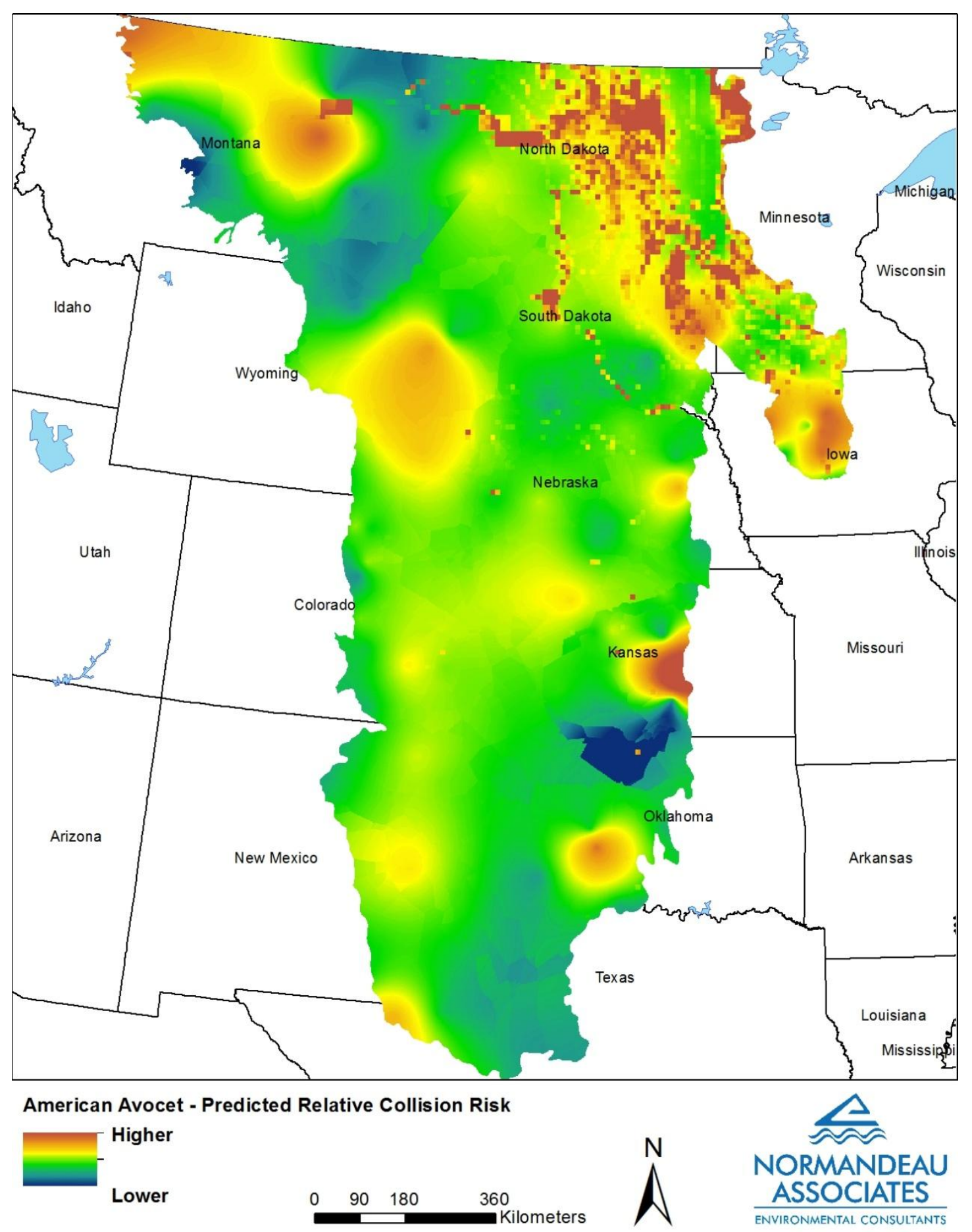

Figure 3-6. Spatial distribution of predicted American Avocet collision risk within the central United States. Shades of color represent relative predictions within a species; maps are not comparable among species. 


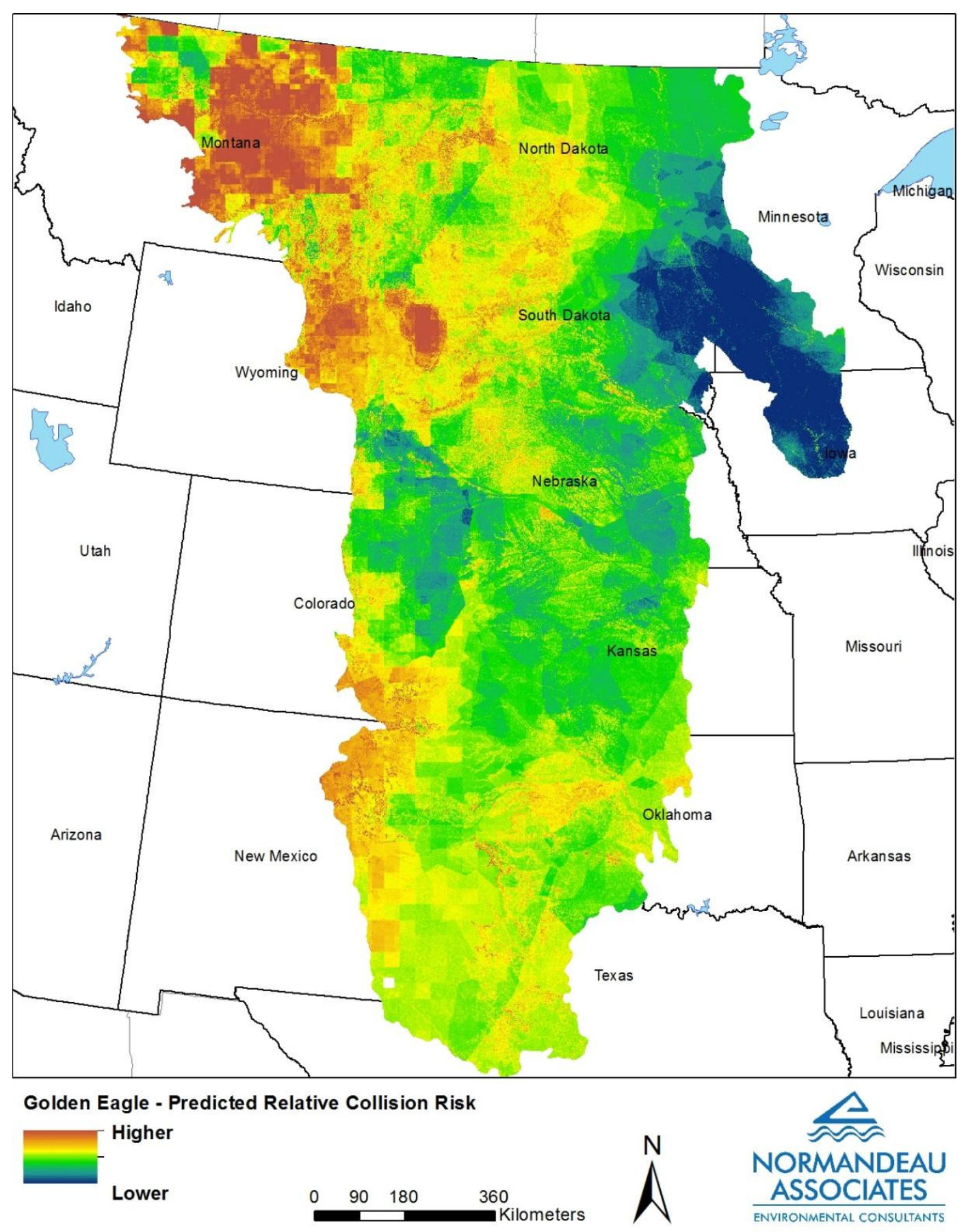

Figure 3-7. Spatial distribution of predicted Golden Eagle collision risk within the central United States. Shades of color represent relative predictions within a species; maps are not comparable among species. 


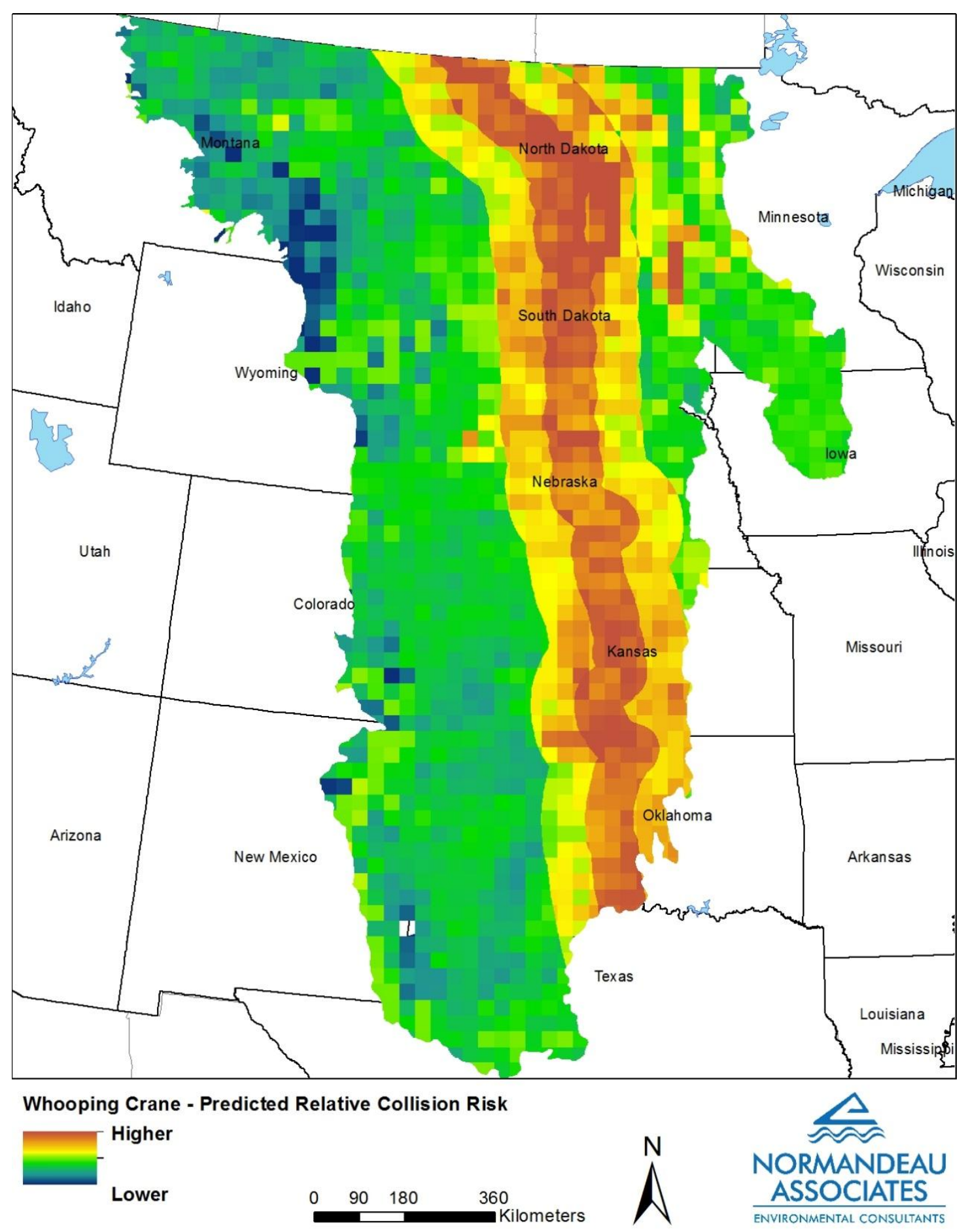

Figure 3-8. Spatial distribution of predicted Whooping Crane collision risk within the central United States. Shades of color represent relative predictions within a species; maps are not comparable among species. 


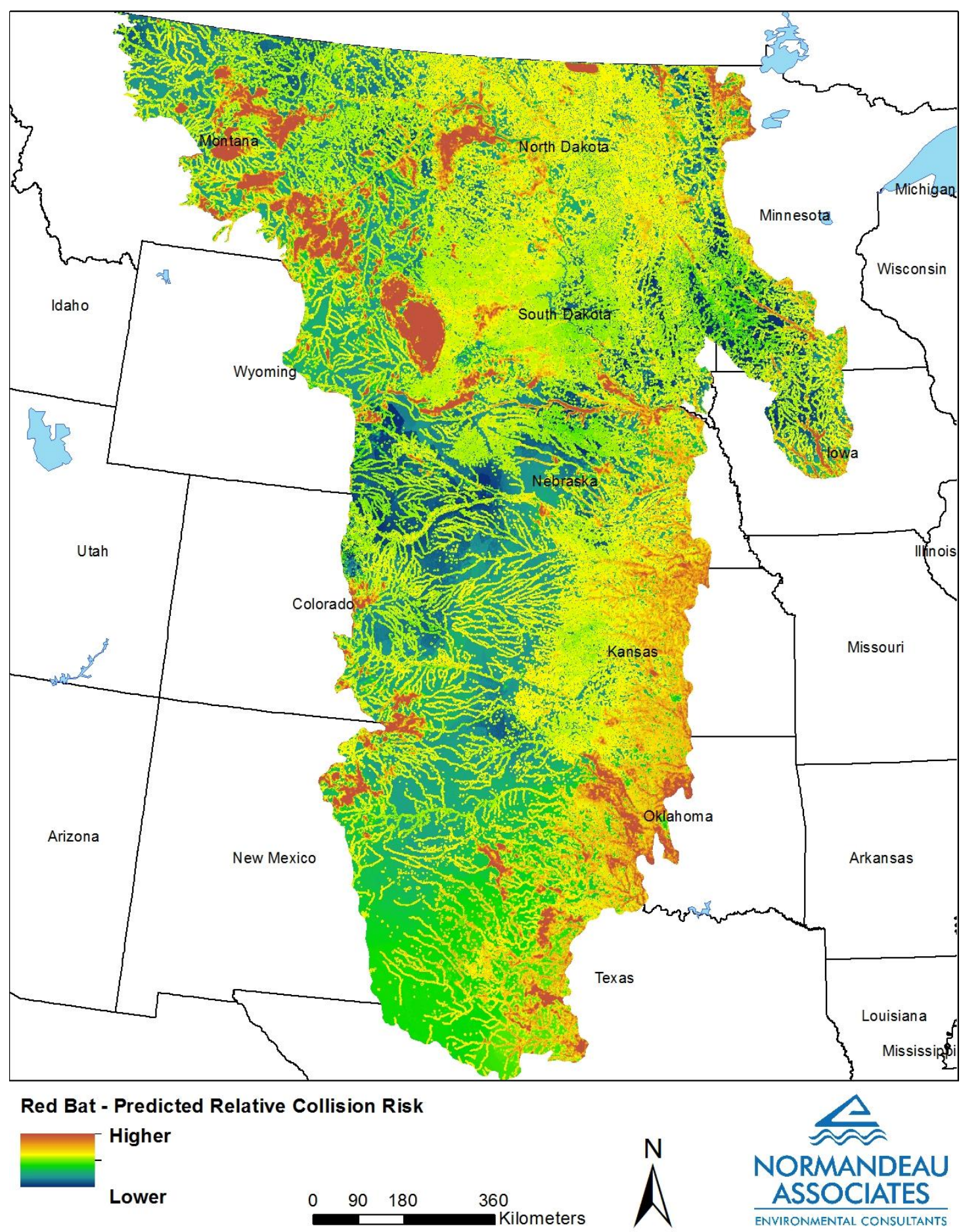

Figure 3-9. Spatial distribution of predicted red bat collision risk within the central United States. Shades of color represent relative predictions within a species; maps are not comparable among species. 


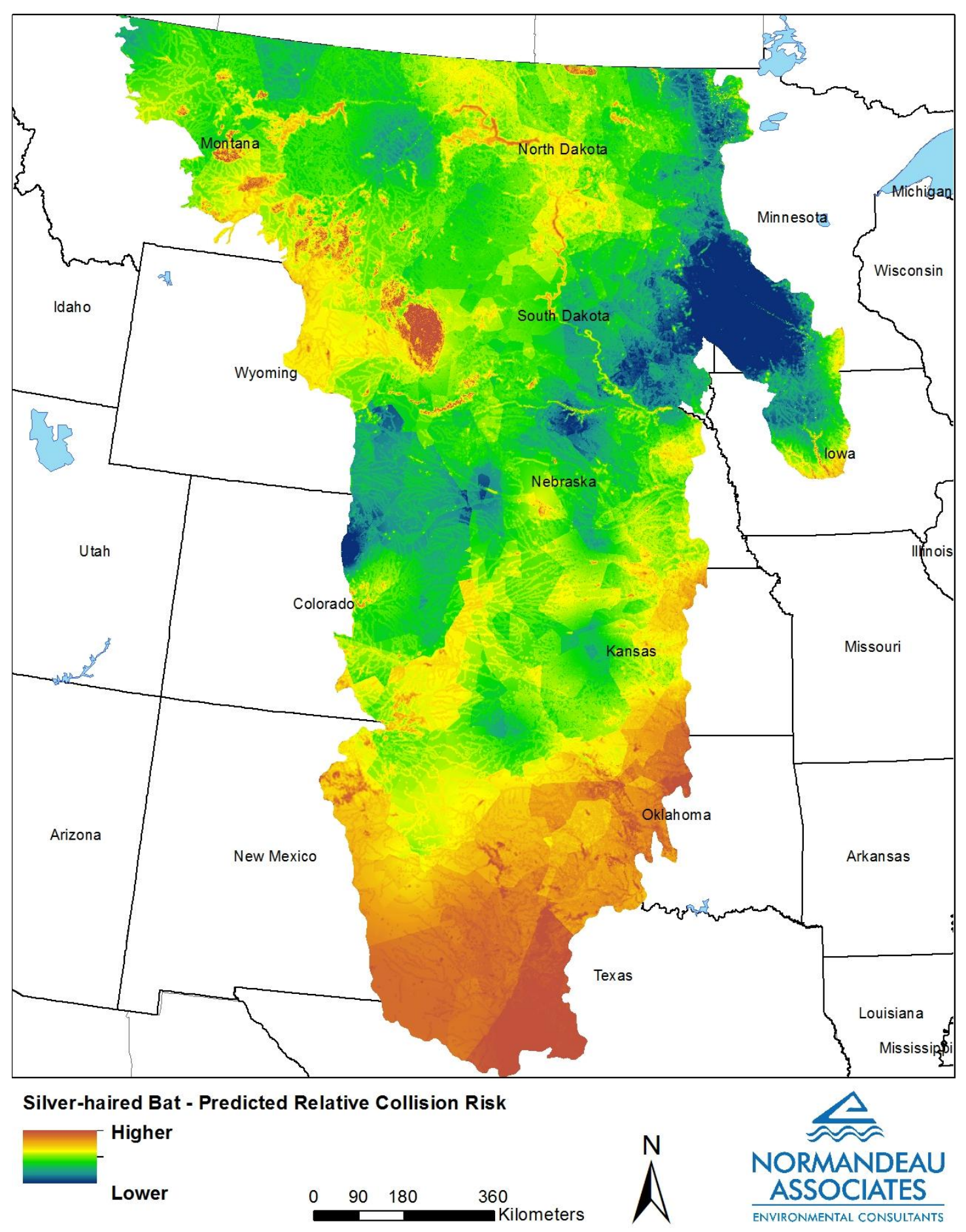

Figure 3-10.Spatial distribution of predicted silver-haired bat collision risk within the central United States. Shades of color represent relative predictions within a species; maps are not comparable among species. 


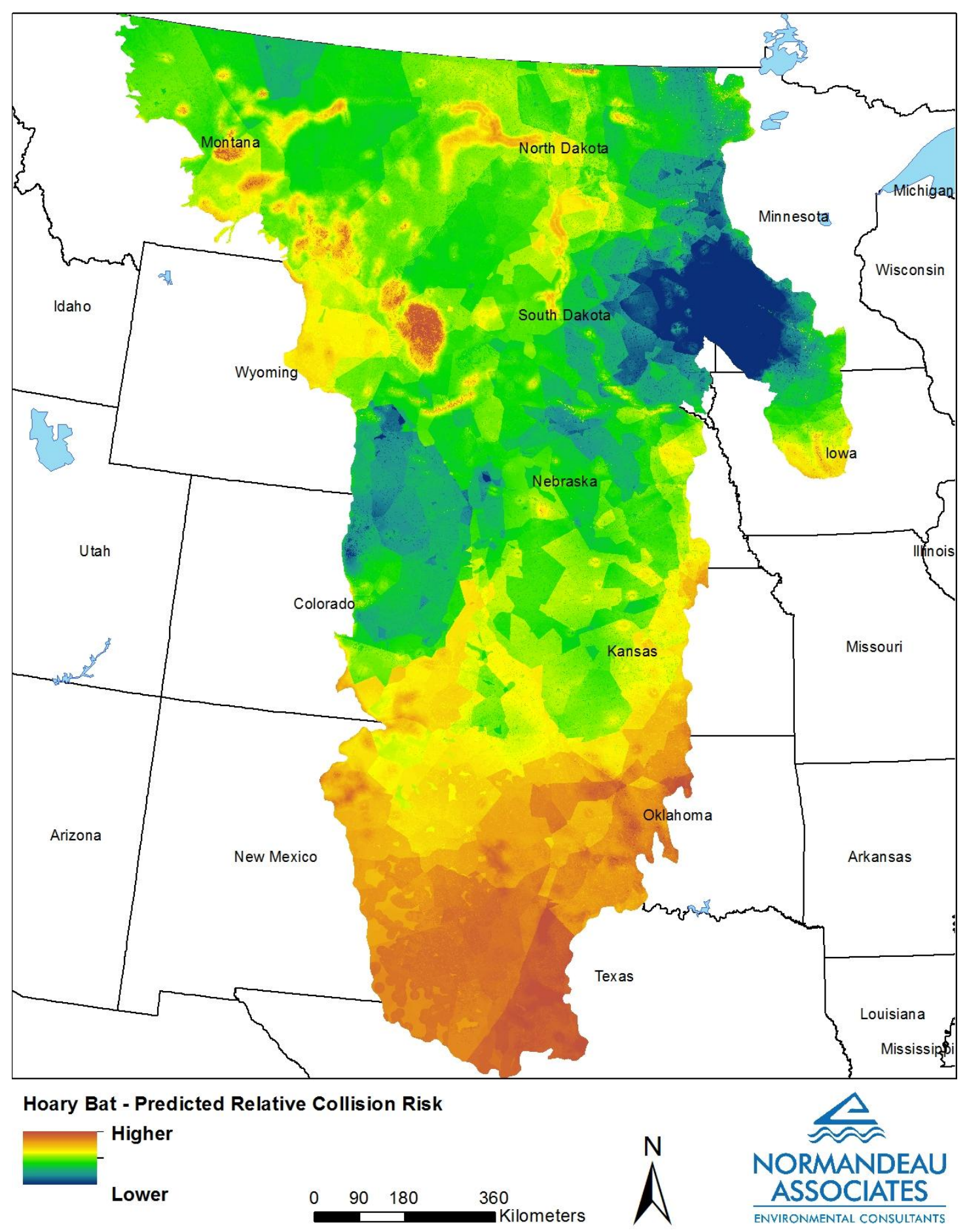

Figure 3-11.Spatial distribution of predicted hoary bat collision risk within the central United States. Shades of color represent relative predictions within a species; maps are not comparable among species.

\subsubsection{Model Evaluation}

Model evaluation procedures revealed that the best models in the sensitivity analyses fit the data well to very well. Sensitivity analyses showed that habitat and exposure influenced collision 
mortality differently among species. For Horned Lark the best habitat versus exposure weighting occurred when exposure was not considered and only habitat was used to predict collisions. A moderate correlation $(\mathrm{r}=0.55)$ was noted between observed and predicted mortality with this model (Figure 3-12). For Eastern red bat, the best habitat model weighting occurred with the scenario when abundance was weighted by a factor of 8 over exposure (Figure 3-13). Under this scenario, a strong correlation $(\mathrm{r}=0.89)$ was observed between predicted and observed mortality. The opposite trend was observed with hoary bats where a scenario weighting abundance half as much as exposure provided the best correlation $(\mathrm{r}=0.85)$ between observed versus predicted mortality (Figure 3-14). Silver-haired bats were affected by weather and habitat similar to hoary bats with the best scenario occur when habitat was weighted half as much as exposure variables (Figure 3-15). Under this scenario, a strong correlation $(\mathrm{r}=0.91)$ was observed between observed and predicted mortality. Model performance of other focal species could not be validated because little to no data exists from publically available studies in the study region. For these species habitat and exposure were weighted equally in the collision outputs, because there was not strong reason to weight them otherwise.

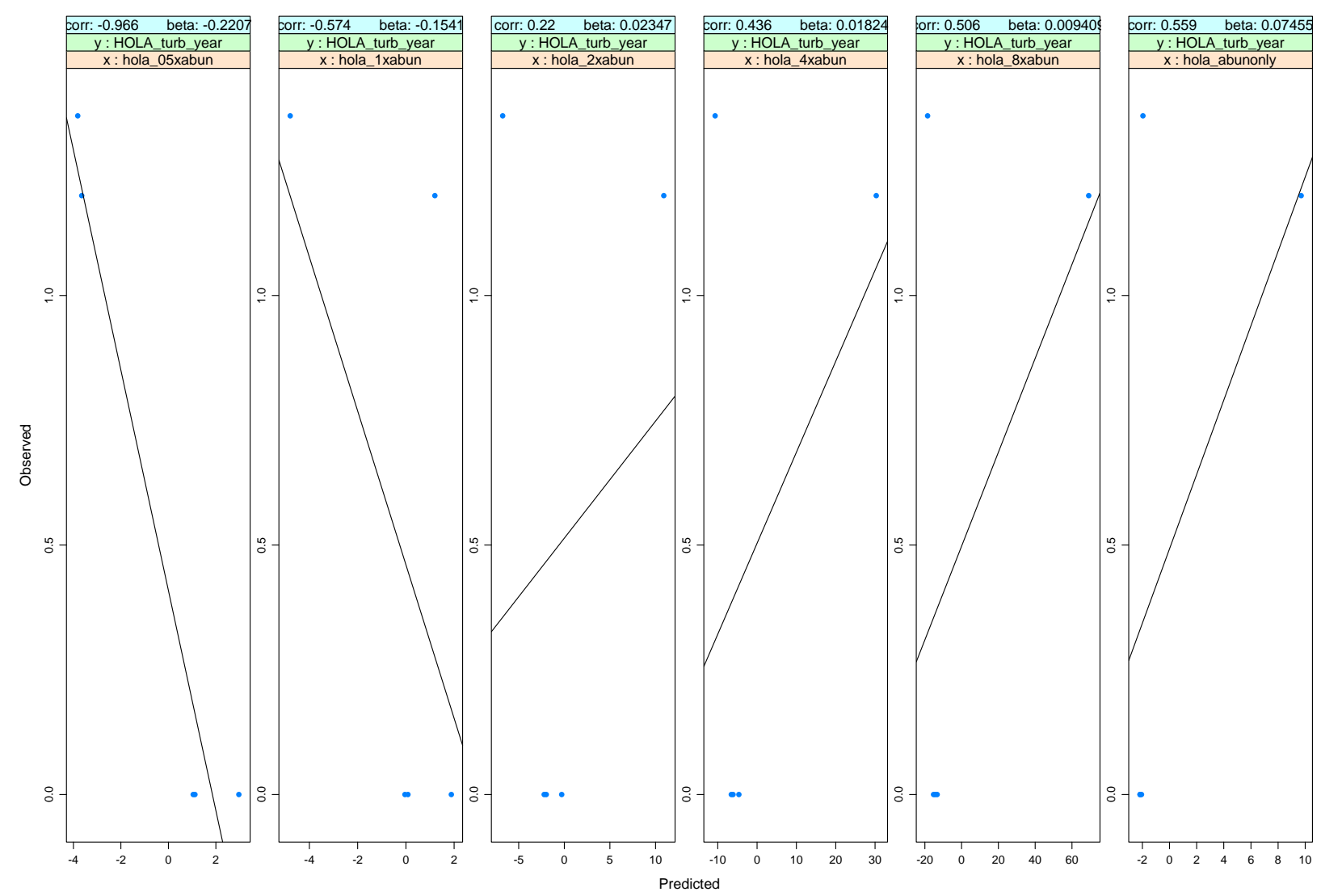

Figure 3-12. Horned Lark model evaluation and sensitivity analysis showing scenarios of different weights applied to habitat and exposure variables. From left to right, habitat was given the following weights relative to exposure: $0.5,1$ (equal weighting), $2,4,8$, and only habitat. 

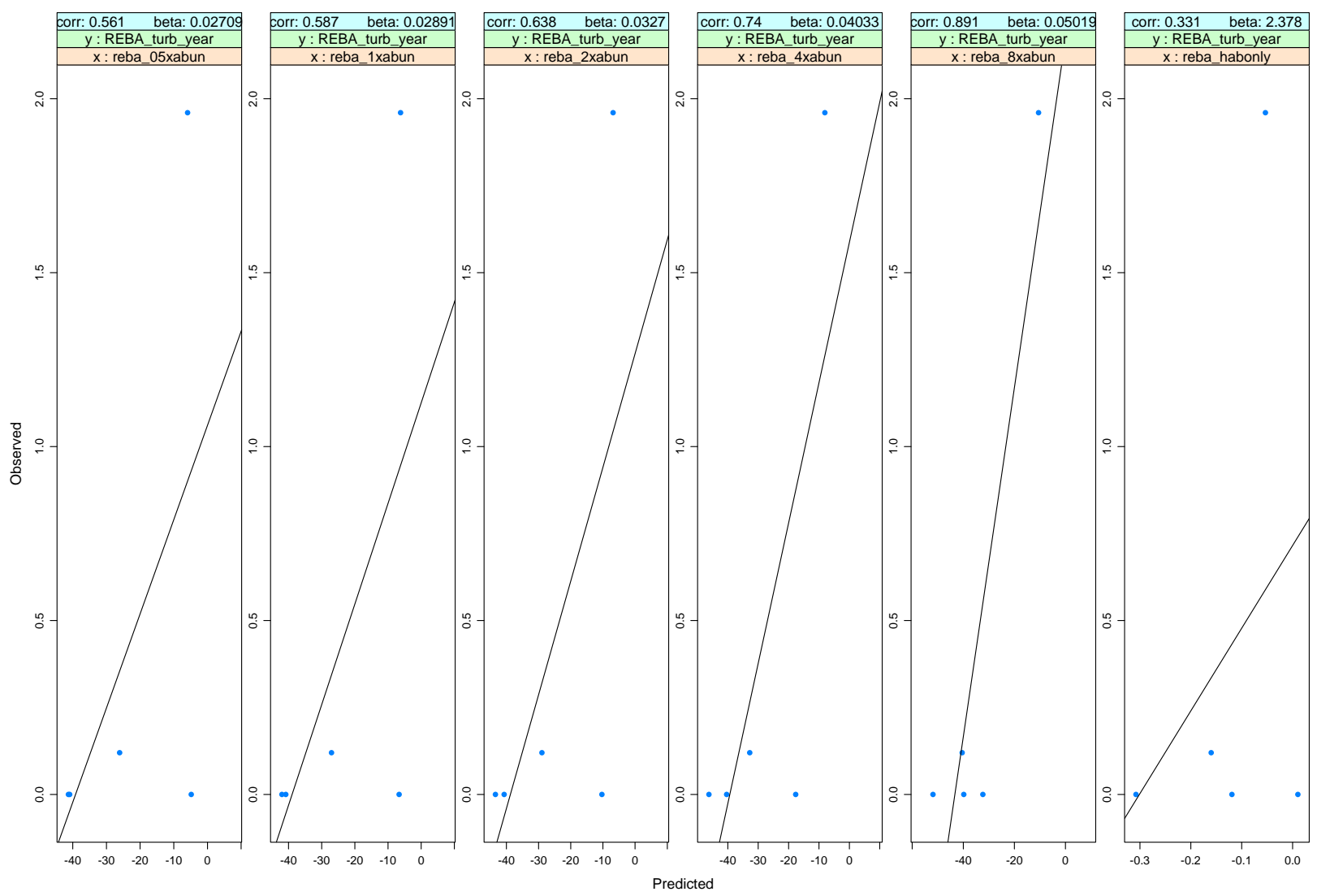

Figure 3-13. Eastern red bat model evaluation and sensitivity analysis showing scenarios of different weights applied to habitat and exposure variables. From left to right, habitat was given the following weights relative to exposure: $0.5,1$ (equal weighting), $2,4,8$, and only habitat. 


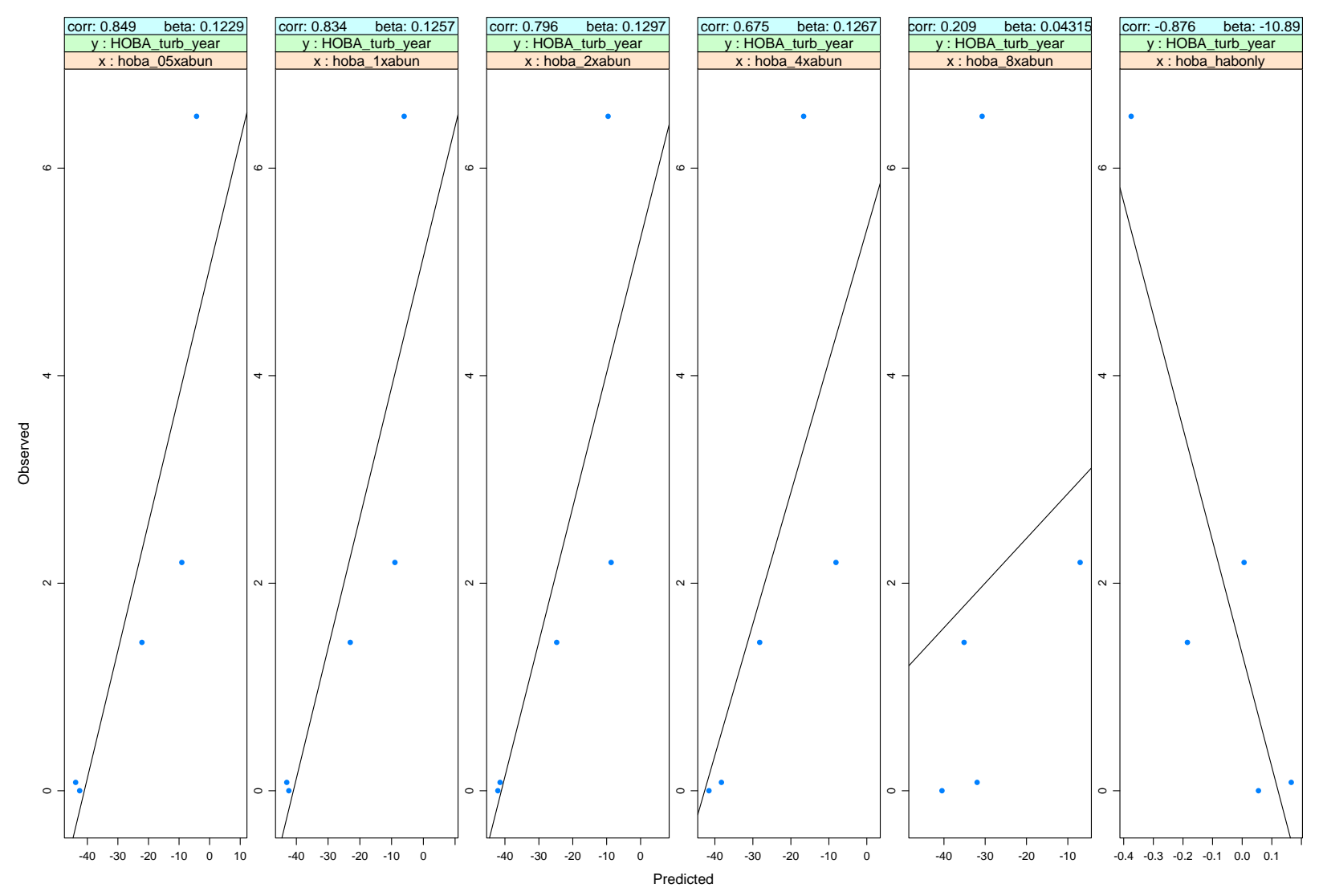

Figure 3-14. Hoary bat model evaluation and sensitivity analysis showing scenarios of different weights applied to habitat and exposure variables. From left to right, habitat was given the following weights relative to exposure: $0.5,1$ (equal weighting), $2,4,8$, and only habitat. 

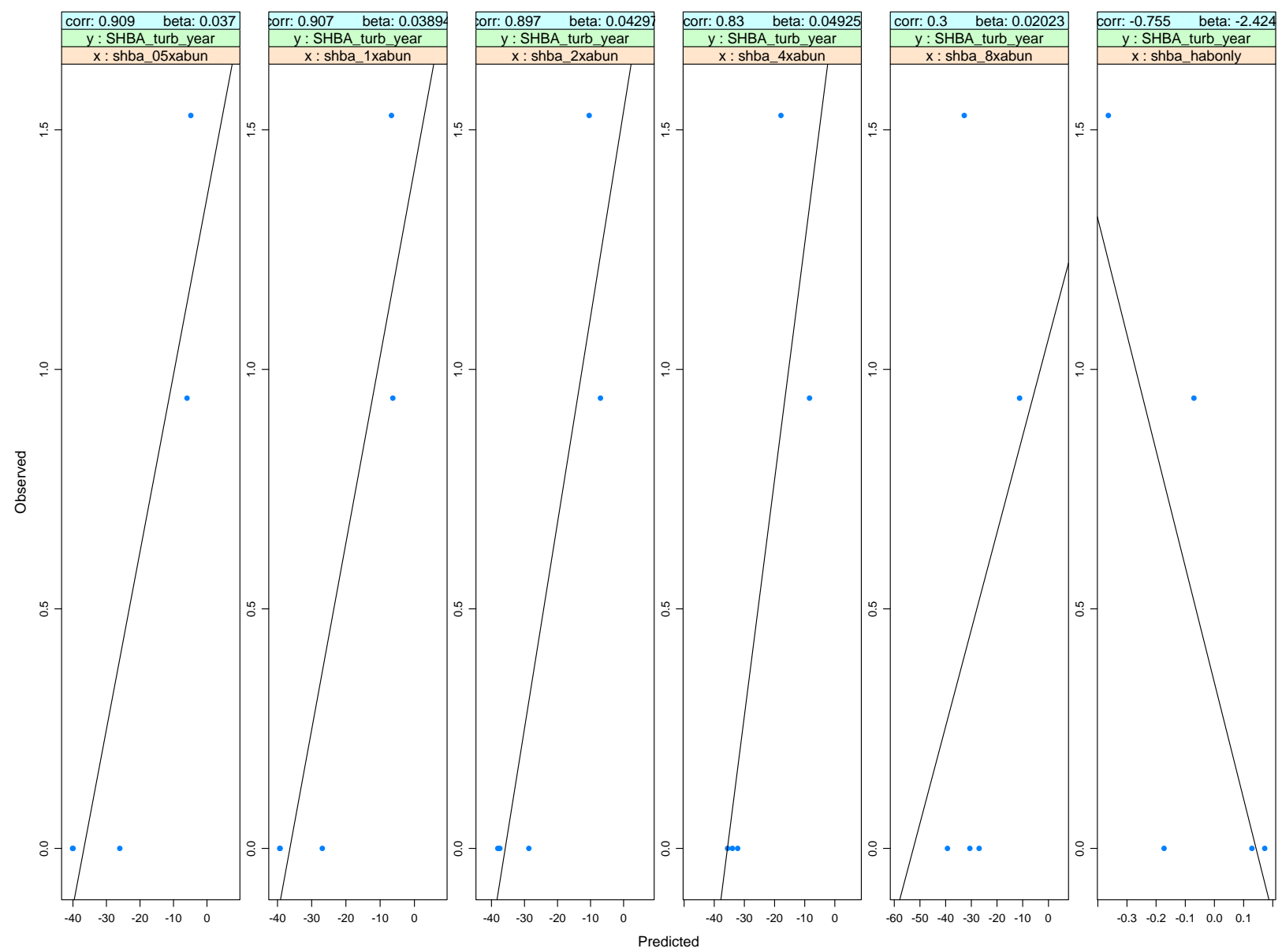

Figure 3-15. Silver-haired bat model evaluation and sensitivity analysis showing scenarios of different weights applied to habitat and exposure variables. From left to right, habitat was given the following weights relative to exposure: $0.5,1$ (equal weighting), 2, 4, 8, and only habitat.

\subsection{Discussion}

\subsubsection{Habitat Models}

Habitat modeling for birds revealed many relationships between landscape habitat variables and abundance from BBS, CBC, and eBird data. In general, the strongest relationships were found in breeding and winter modeling and weaker with the migratory models. Fewer significant habitat relationships during migration may be due to 1) birds having more general habitat preferences during migration as opposed to during breeding and winter, 2) the paucity of migratory data from the study region, 3) the spatial imprecision of the eBird data (although steps were taken to minimize this), and 4) the effects of habitat on birds during migration may be operating at scales other than what were used in the analysis. Assessing each of these hypotheses was outside the scope of this project, but worth noting as the habitat models are one of the key components of the collision models. While habitat relationships were weaker during migration, the direction of the association (positive or negative) was similar to what was reported in the literature and usually found in other seasons thus supporting eBird as a reputable source for bird data. Multiple studies 
have used eBird data to study large-scale bird population dynamics and have found it to be useful in understanding large-scale trends (e.g., Hochachka et al. 2012, Hurlbert and Liang 2012).

Horned Larks were positively associated with cultivated crops and herbaceous vegetation at all scales and seasons throughout the year. This is not surprising given that habitat preferences of this species differ little among seasons (Beason 1995). A strong positive association with bare ground was not found during any season, which was not expected given preferences for this habitat type, especially in nonagricultural lands (Appendix 5). Horned Larks were influenced mostly by habitat variables at the coarsest scale in all seasons, which can be somewhat explained by their characteristic nomadic behavior, which causes them to cover large areas, especially in winter (Rotenberry and Wiens 1976).

A strong relationship between forest edge density was found for Red-eyed Vireo during the breeding season, but not during migration. This was expected as Red-eyed Vireos commonly occur in forested habitats with small openings and understory in the forest (Cimprich et al. 2000) (Appendix 5). The effect of scale appeared similar between the intermediate and coarsest scale, although no models in the finest scale were in the best subset of models (Appendix 4). A lack of any strong habitat effects during migration was also not surprising given that habitat requirements are much more flexible during this time (Cimprich et al. 2000).

The influence of habitat for Mallard was mostly consistent across seasons with strong positive effects of emergent wetlands, cultivated crops, and open water. These relationships were expected as mallards are heavily associated with wetland habitat throughout their range and usually nest in upland habitat (Drilling et al. 2002). Positive habitat relationships were mostly influenced by habitat at the intermediate scale during breeding, and similarly between the intermediate and coarsest scale during winter (Appendix 5). Forcey et al. (2011) found Mallards to be mostly influenced at the coarsest scale, though that study only looked at the effects in BCR 11 and not BCRs 17, 18, and 19, suggesting that Mallards may be affected differently at varying scales among ecoregions. This also suggests that species distribution models need to be performed specifically for each region of interest as findings from one region may not be directly transferrable to another.

American Avocets were strongly associated with open water and emergent wetlands at the finest and intermediate scales during breeding (Appendix 5). This species is known for its association with wetland habitat for foraging and nesting (Robinson et al. 1997), so its association at the larger landscape scale was not unexpected. The models in the best subset only contained variables from the finest and intermediate scales, which suggest the largest scale effects are not influential to this species (Appendix 4). No data were available on home range size to support this finding (Robinson et al. 1997).

The effect of scale was negligible for Golden Eagles, as models at all scales were included in the best subset of models (Appendix 4). Golden Eagles prefer mountainous open areas with grasslands for foraging and cliffs for nesting (Kochert et al. 2002). Our modeling effort found similar trends with strong positive effects of herbaceous vegetation and shrub/scrub which commonly occur in open areas. A strong positive effect of open water interspersion with other habitats was found during breeding, but the influence was found to be strongly negative during winter (Appendix 5). Our literature review did not find strong evidence for an association with water except that during winter Golden Eagles will occur near areas with high waterfowl concentrations (Kochert et al. 2002). Although this would not explain the negative association 
with water, it is possible that in winter many of our study area's standing water bodies are frozen, and do not offer the foraging opportunities that they do in other geographic areas.

Whooping Cranes only occur in the study area during migration, and we only modeled at the coarsest scale (Appendix 4). Our modeling did show a strong positive effect of open water edge and emergent wetland interspersion with other habitats; a negative association occurred with cultivated crop interspersion with other habitats (Appendix 5). Whooping Cranes commonly use small wetlands for roosting, so it is not unexpected that they were associated with wetland habitat (Lewis 1995, Austin and Richert 2005). A negative association with cultivated crop interspersion was not expected given that Whooping Cranes commonly forage in these habitats during migration. It is likely that our models operating at a 100,000-ha scale were not able to detect positive habitat associations, which likely occur at smaller scales given that most roosting sites are within $1 \mathrm{~km}$ of a feeding site (Lewis 1995, Austin and Richert 2005).

Bat statistical habitat modeling was not performed given that bat abundance and occurrence data do not exist at a large scale within the region.

\subsubsection{Collision Models}

Collision model outputs across species were based on which scenario performed the best in the sensitivity analysis. For species that could not be validated because of a lack of mortality data, we weighted habitat and exposure variables equally to compute the final collision model because we did not have any a priori information to suggest an alternative weighting approach. Model outputs provide a relative collision risk prediction and are not comparable among species; collision predictions are only comparable within a species.

The Horned Lark predicted collision risk grid was weighted exclusively toward habitat—given the best scenario from the sensitivity analysis was the one where only habitat was considered as a predictor of collision risk. Given the strong influence of habitat, the highest risk was predicted in the areas where the most suitable habitat is located, including areas with a high percentage of cultivated and herbaceous habitat. The area in the extreme northwestern portion of the study area contained the highest predicted collision risk levels, and this was likely because of a strong positive relationship with latitude and a strong negative relationship with longitude, as well as preferred habitat. The very low risk predictions in the southern part of the study area are also likely the result of abundance relationship with latitude. The coarse map resolution of the grid was due to the fact that variables at the coarsest scale were the most influential throughout the year.

Red-eyed Vireo collision risk was driven both by habitat and visibility conditions as both were weighted equally in the final model output. A strong positive longitudinal effect was responsible for generally higher risk predictions in the east and lower in the west, but this effect only occurred during breeding and not during migration. This finding agrees with the accepted range of the Red-eyed Vireo because the species only occurs in isolated areas within the western portion of the study area (Cimprich et al. 2000). Other areas of higher risk coincide with forested habitat and areas with poor visibility.

Like Red-eyed Vireo, habitat and exposure were weighted equally for Mallard. Mallards are attracted to wetland habitat for foraging and upland habitat for nesting, and the pothole region in the northern portion of the study area had the overall higher levels of collision risk. Other areas in the study region with higher risk included areas of low visibility. 
The predicted risk for American Avocet closely mirrored the map for Mallard, which was expected given their preference for wetland habitats, especially those habitats in the pothole region of the study area. The habitat model placed higher risk in the pothole region of the study area; isolated areas of lower visibility in the western portion of the region also increased risk. Although the collision risk map closely mirrors that of the Mallard, the map resolution is finer due to the strong influence of habitat variables at the finest and intermediate scales for American Avocet.

The Golden Eagle primarily occurs in the western portions of the study area, which corresponds to where the highest predicted collision risk occurs. In the western portion of the study area, the topography layer in addition to habitat and exposure are the factors driving the collision risk prediction. While Golden Eagles have been killed in numbers at west coast wind facilities, we did not find any mortality reported in the publically available studies that we reviewed. Risk is negligible in the eastern portion of the study area, where the species rarely occurs.

The final Whooping Crane collision grid showed the strong influence of the USFWS's migratory corridor layer. This layer was derived from a database of incidental sightings collected over several decades. The center boundary of the migratory corridor contains $75 \%$ of the observations of migrating Whooping Cranes, and thus a strong weight was applied to this region. A few small isolated areas outside the migratory corridor were found to be higher levels of predicted risk, which was driven by preferred habitat. Otherwise outside the migratory corridor, the predicted levels of collision risk were low.

The collision map for Eastern red bat was influenced heavily by the predicted habitat grid, as determined from the sensitivity analysis. The sensitivity analysis indicated that weighting the habitat grid by a factor of 8 over the exposure variables produced the best prediction of collision avoidance. The strong influence of habitat is evident within the collision grid as fine areas of forested habitat and areas in close proximity to water are well defined. Migratory flight corridors in riverine habitats are also well defined.

The silver-haired bat and hoary bat collision models were similar because both models were based on the scenario where habitat was weighted 0.5 times as much as exposure variables as determined by the sensitivity analysis. The only difference between the collision predictions involves the habitat grids. The silver-haired bat moving window analysis was done at the $2-\mathrm{km}$ scale, and the hoary bat moving window analysis was done at the $10-\mathrm{km}$ scale. The effect of this difference is a smoothing effect of the hoary bat model as compared to the silver-haired bat and reflects the larger home range size thought to be used by hoary bats. Other than the scale of analysis, this model outputs are identical and emphasize the effects of weather variables in affecting the collision risk of these species. This is particularly evident from the higher risk predicted in the southern latitudes of the study area, which is primarily being driven by the greater number of night hours of $>50$ degree temperatures. We are not aware of any studies linking bat collision risk with latitude, but Cryan (2003) found higher numbers of tree bat museum records in southern latitudes compared to more northern areas, suggesting that this effect could play a role in collision risk.

\subsubsection{Model Evaluation}

Model evaluation and sensitivity analyses were possible on four of the focal species: Horned Lark, Eastern red bat, silver-haired bat, and hoary bat. Other focal species were not found in 
publically available mortality studies; therefore, it was not possible to evaluate model performance against an independent dataset. Under the best scenario for each species, models generally predicted collision mortality moderately well to very well for each species $(\mathrm{r}=0.55-$ 0.91). Bat collision models generally had a stronger correlation with observed collision mortality than the Horned Lark collision model. This finding may be due to the more generalist habitat preferences of Horned Larks versus the three tree bat species examined in this study. Horned Larks will commonly inhabit a variety of agricultural, nonagricultural, and barren habitats (Beason 1995), whereas tree bats are tightly associated with forest cover for roosting and foraging (Barbour and Davis 1969). The stronger associations with habitat for bats likely make it easier to elucidate relationships between bats and habitat associations.

Habitat influences appeared to be the predominant factor affecting Horned Lark collision mortality with the best scenario only including habitat as a predictor; inclusion of visibility made the morality prediction worse. Visibility may have minimal bias on Horned Lark mortality because of the species' tendency to remain at or near ground level (Beason 1995); and agonistic interactions between males typically occur at heights of $<15 \mathrm{~m}$ (Beason 1970), which is below the rotor swept zone of turbine blades.

Eastern red bat, silver-haired bat, and hoary bat differ in their reaction to the influence of habitat and weather variables. While Eastern red bats appear to be more affected by habitat than weather conditions, hoary bat and silver-haired bat collision mortality is much more affected by weather variables than by habitat. The strong influence of weather on hoary bat and silver-haired bat mortality was expected as weather variables are known to be highly influential on bat activity. Weller and Baldwin (2011) noted that weather variables (especially wind speed and temperature) were important predictors of bat activity in California. In addition Silver-haired Bats are among the slowest flying North American bats (Barbour and Davis 1969); therefore, they may be more intolerant of poor foraging conditions. The stronger influence of habitat on Eastern red bats was not expected, especially because this is the smallest of the three bat species examined in this study (Barbour and Davis 1969) and may be less tolerant of marginal weather conditions.

While our ability to evaluate our collision models with adequate sample sizes is limited by available data, model evaluation will become increasingly feasible as more publically available studies become available. Additional fatality datasets from post-construction mortality monitoring can easily be added to our validation dataset to increase the sample size and, hopefully, relevance of our model evaluation.

\subsubsection{Limitations}

Several limitations in our analysis limited or precluded us from making more precise conclusions about avian and bat collision risk. The first limitation of our collision predictions is that they are only comparable within a species and not among species. General susceptibility to collision across species is not considered in our models. In order to making collision comparisons across species, we would need sufficient collision data from pre-existing studies to use as the measurement variable in our models. Although these datasets do not exist currently in sufficient number or availability, it is possible that over time this will change as more post-construction mortality studies are done and made available. Sufficient post-construction mortality data may be available in other regions of the country (e.g., east and west coasts) where more stringent regulations necessitate more rigorous post-construction mortality monitoring. 
The paucity of available data also limited our ability to evaluate the performance of the models, and conduct a sensitivity analyses to evaluate the importance of habitat and exposure variables. Greater numbers of studies with post-construction mortality data would likely have allowed us to evaluate the model performance of more of our focal species. For some species, mortality at wind farms is likely to always be low either because of low susceptibility or because of natural rarity in the environment.

One factor not considered in our models was the currently installed wind facilities in the study area and how the presence of turbines would influence risk. We chose to build our models irrespective the presence of existing turbines for two reasons: 1) the wind turbine landscape is constantly changing and any modeling effort would need to be constantly updated to reflect this change; this constant updating is not feasible to do on an ongoing basis and we wanted the models to be applicable in the future, and 2) models were intended to evaluate the influence of habitat, weather, topography, and behavior regardless of the presence of turbines. Including installed wind turbines in the model would have confounded the effects of environmental variables on collision risk.

A final limitation of our models is that they can reliably be applied only to birds and bats at a large scale. The resolution of the input data, potential classification errors, and possible errors with the weather variable surface interpolation preclude the models from being applied to the level of the wind facility. Our models are designed be used for large-scale siting, and should always be evaluated with ancillary field data when siting wind facilities at smaller scales.

\section{Accomplishments}

Several key products have been created as a result of our modeling effort and findings. Most of the outputs from this project have come in the form of quarterly and final reports and conference presentations. We have presented both preliminary and final results and findings at the following conferences:

- National Wind Coordinating Collaborative 2010 (Presentation and Poster)

- National Wind Coordinating Collaborative 2011 (Webinar)

- US Department of Energy Project Update 2011 (Webinar)

- American Wind Energy Association Windpower 2012 Conference (Poster)

- National Wind Coordinating Collaborative 2012 (Abstract Submitted for Presentation)

In addition to our research products, we also have created an online web-based interface to allow the model outputs to be accessed via the internet within a user friendly interface. This interface was built on the foundation of ArcGIS Server and allows anyone with a web browser and internet access to view the model outputs of each species, navigate within the map, and zoom in and out to different scales. The mapping interface also includes the ability to download the native grids in ArcGRID format, which are suitable for opening in the ArcGIS application for closer examination. The mapping interface includes some text describing how to interpret the model outputs, how they can be used, and some of the limitations. Complete documentation is not included but can be found in this final report. The mapping interface can be found at the following link:

http://www.normandeau.com/pages/environment/services/WindWildlifeRiskMap/. 


\section{Conclusions}

Our model outputs have elucidated habitat and exposure relationships with collision mortality for select bird and bat species in the central US. These models have provided insight into bird and bat habitat relationships as well as relationships with collision mortality, habitat, and exposure parameters. Not only have we identified relationships with collision mortality, we have mapped the relative risk of mortality of our focal species. The maps provide relative predictions of mortality within a species, but the values of the mortality predictions cannot be compared among species.

Our findings our not surprising in that bird and bat collisions are predicted to be highest where their preferred habitat is ideal and where weather conditions put them at increased levels of exposure. Salient results from our study indicate the relative differences habitat and exposure parameters have on Horned Lark, Eastern red bat, hoary bat, and silver-haired bat. Horned Lark collisions appear to be mostly influenced by habitat with little influence from weather variables. A similar trend was observed with Eastern red bat, where habitat played a much stronger role than exposure parameters in influencing collisions with this species. Hoary and silver-haired bats showed an opposite trend where weather variables played a larger role than habitat in influencing collisions. Although our number of independent datasets used to evaluate the models was small, these findings are the first of their kind (to our knowledge) that provide insight as to macroscale variables and the extent that they influence collision mortality.

Application of our models is best at scales of the multicounty level or larger. The US FWS recently released voluntary land-based wind energy guidelines for assessing impacts of a wind facility to wildlife using a tiered approach. The tiered approach uses an iterative approach for assessing impacts to wildlife in levels of increasing detail from landscape-level screening to sitespecific field studies (USFWS 2012). The models presented in this report would be applicable to be used as tools to conduct screening at the tier 1 level, and would not be appropriate to complete smaller scale tier 2 and tier 3 level studies.

We expect to publish this research in a peer-reviewed journal, either within the wildlife or renewable energy areas. No commercialization is planned for this model or its outputs. All outputs will be provided for free via the interactive web-interface described previously in section 4. 


\section{Recommendations}

We recommend additional research using this type of modeling approach to examine the landscape-level influences of collisions on other species in other geographic areas. Using other species in other areas (particularly the east and west coasts) has the advantage of a greater sample size, both in model inputs and post construction mortality data for validation. We chose our study area in the central US primarily because of the wind development potential and species of concern present in the area. Study areas along the western or eastern US may be better choices if the study goals are to perform more intensive model evaluation or modeling using mortality data instead of habitat data as a surrogate. Modeling collision mortality directly would have been ideal for our study, but the paucity of available data precluded us from using this approach. Additional modeling and validation in geographic areas with greater data availability would provide a better assessment of how our models perform with regard to both predicting collision risk and their use as a planning tool for developers and regulators. 


\section{Acknowledgements}

Many valuable contributions have been made by multiple parties for this study. We thank the members of the technical advisory group for their insight and comments on this study: Wayne Thogmartin, Ted Weller, Jane Ledwin, and Kevin Martin. Other contributors to this study included GIS Associates, Matt Krogh, and Tyson Waldo. Nick Johnson, Melissa Luken, and Patrick Gilman from the US Department of Energy provided project guidance and administrative support. We thank the US Department of Energy for providing funding for this research. 


\section{Bibliography}

Alerstam, T. 1990. Bird Migration. Cambridge University Press, Cambridge, United Kingdom.

American Wind Energy Association (AWEA). 2009. American Wind Energy Association Annual Wind Industry Report. American Wind Energy Association.

Anderson, J. R., E. E. Hardy, J. T. Roach, and R. E. Witmer. 1976. A land-use and land cover classification system for use with remote sensor data. US Department of the Interior, Geological Survey, Geological Survey Professional Paper 964.

Anderson, D. R., K. P. Burnham, W. R. Gould, and S. Cherry. 2001. Concerns about finding effects that are actually spurious. Wildlife Society Bulletin 29:311-316.

Arnett, E. B., J. P. Hayes, and M. M. P. Huso. 2006. Patterns of pre-construction bat activity at a proposed wind facility in south-central Pennsylvania. An annual report submitted to the Bats and Wind Energy Cooperative. Bat Conservation International, Austin, Texas.

Arnett, E. B., M. Schirmacher, M. P. Huso, and J. P. Hayes. 2009. Effectiveness of changing wind turbine cut-in speed to reduce bat fatalities at wind facilities - Annual report prepared for the bats and wind energy cooperative and the Pennsylvania Game Commission. Bat Conservation International, Austin, Texas.

Arnett, E. B., W. K. Brown, W. P. Erickson, J. K. Fiedler, B. L. Hamilton, T. H. Henry, A. Jain, G. D. Johnson, J. Kerns, R. R. Koford, C. P. Nicholson, T. J. O’Connell, M. D. Piorkowski, and R. D. Tankersley, Jr. 2008. Patterns of bat fatalities at wind energy facilities in North America. Journal of Wildlife Management 72:61-78.

Arroyo-Cabrales, J., B. Miller, F. Reid, A. D. Cuarón, and P. C. de Grammont. 2008a. Lasionycteris noctivagans. In: IUCN 2010. IUCN Red List of Threatened Species. Version 2010.1. 〈www.iucnredlist.org>. Downloaded on 05 April 2010.

Arroyo-Cabrales, J., B. Miller, F. Reid, A. D. Cuarón, and P. C. de Grammont. 2008b. Lasiurus borealis. In: IUCN 2010. IUCN Red List of Threatened Species. Version 2010.1. <www.iucnredlist.org>. Downloaded on 05 April 2010.

Austin, J. E., and A. L. Richert. 2005. Patterns of habitat use by Whooping Cranes during migration: Summary from 1977-1999 site evaluation data in Proceedings of the North American Crane Workshop International Crane Foundation.

Baerwald, E. F., G. H. D’ Amours, B. J. Klug, and R. M. R. Barclay. 2008. Barotrauma is a significant cause of bat fatalities at wind turbines. Current Biology 18:695-696.

Band, W., M. Madders, and D. P. Whitfield. 2005. Developing field and analytical methods to assess avian collision risk and wind farms. In: M. De Lucas, G. Janss, and M. Ferrer, editors. Birds and Wind Power. Lynx Edicions, Barcelona, Spain.

Band, W., M. Madders, and D. P. Whitfield. 2007. Developing field and analytical methods to assess avian collision risk at wind farms in M. de Lucas, G. F. E. Janss, and M. Ferrer, editors Birds and Wind Farms Risk Assessment and Mitigation, First Edit. Quercus.

Barbour, R. W., and W. H. Davis. 1969. Bats of America. The University of Kentucky Press, Lexington, Kentucky, USA. 
Barclay, R. M. R. 1984. Observations on the migration, ecology, and behavior of bats at Delta Marsh Manitoba. Canadian Field-Naturalist. 98. 331-336.

Barclay, R. M. R., E. F. Baerwald, and J. C. Gruver. 2007. Variation in bat and bird fatalities at wind energy facilities: assessing the effects of rotor size and tower height. Canadian Journal of Zoology 85:381-387.

Barclay, R. M. R. 1984. Observations on the migration, ecology, and behavior of bats at Delta Marsh Manitoba. Canadian Field-Naturalist. 98. 331-336.

Beason, R. C. 1970. The annual cycle of the Prairie Horned Lark in west-central Illinois. Master's Thesis. Western Illinois Univ. Macomb.

Beason, R. C. 1995. Horned Lark (Eremophila alpestris), The Birds of North America Online (A. Poole, Ed.). Cornell Lab of Ornithology. <http://bna.birds.cornell.edu.bnaproxy.birds.cornell.edu/bna/species/195>.

Beason, R. C. 1995. Horned Lark (Eremophila alpestris), The Birds of North America Online (A. Poole, Ed.). Cornell Lab of Ornithology. <http://bna.birds.cornell.edu.bnaproxy.birds.cornell.edu/bna/species/195>.

Bellrose, F. C. 1980. Ducks, geese, and swans of North America. 3rd ed. Stackpole Books, Harrisburg, PA.

Betts, B. J. 1998. Roosts used by maternity colonies of silver-haired bats in northeastern Oregon. Journal of Mammalogy 79: 643-650.

Bolker, E. D., J. J. Hatch, and C. Zara. 2006. Modeling bird passage through a windfarm. Boston, Massachusetts ; :1-16.

Brown, M. J., E. Linton, and E. C. Rees. 1992. Causes of mortality among wild swans in Britain. Wildfowl 43:70-79.

Burnham, K. P., and D. R. Anderson. 2002. Model selection and multimodel inference: a practical information-theoretic approach. Second edition. Springer-Verlag, New York, New York.

Butcher, G. S. 1990. Audubon Christmas Bird Counts. Pp. 5-13 in J. R. Sauer and S. Droege, eds. Survey designs and statistical methods for the estimation of avian population trends. Biological Report 90(1). US Fish and Wildlife Service.

Chamberlain, D. E., M. R. Rehfisch, A. D. Fox, M. Desholm, and S. J. Anthony. 2006. The effect of avoidance rates on bird mortality predictions made by wind turbine collision risk models. Ibis 148:198-202.

Cimprich, D. A., F. R. Moore and M. P. Guilfoyle. 2000. Red-eyed Vireo (Vireo olivaceus), The Birds of North America Online (A. Poole, Ed.). Cornell Lab of Ornithology. <http://bna.birds.cornell.edu.bnaproxy.birds.cornell.edu/bna/species/527>.

Cryan, P. M. 2003. Seasonal Distribution of Migratory Tree Bats (Lasiurus and Lasionycteris) in North America. Journal of Mammalogy 84:579-593.

Cryan, P. M, and A. C. Brown. 2007. Migration of bats past a remote island offers clues toward the problem of bat fatalities at wind turbines. Biological Conservation 139:1-11. 
Cryan, P. M., and R. M. R. Barclay. 2009. Causes of bat fatalities at wind turbines: hypotheses and predictions. Journal of Mammology 90:1330-1340.

Derby, C., A. Dahl, W. Erickson, K. Bay, and J. Hoban. 2007. Post Construction Monitoring Report for Avian and Bat Mortality at the NPPD Ainsworth Wind Farm. Cheyenne, Wyoming. 24pp.

Drewitt, A. L., and R. H. W. Langston. 2006. Assessing the impacts of wind farms on birds. Ibis 148:29-42.

Drilling, N., R. Titman, and F. Mckinney. 2002. Mallard (Anas platyrhynchos), The Birds of North America Online (A. Poole, Ed.). Cornell Lab of Ornithology. <http://bna.birds.cornell.edu.bnaproxy.birds.cornell.edu/bna/species/658>.

Eichhorn, M., K. Johst, R. Seppelt, and M. Drechsler. 2012. Model-Based Estimation of Collision Risks of Predatory Birds with Wind Turbines. Ecology and Society 17:1.

Environmental Systems Research Institute [ESRI]. 2012. ArcGIS 10 Software. Redlands, California, USA.

Erickson, W. P., G. D. Johnson, and D. P. Young, Jr. 2005. A summary and comparison of bird mortality from anthropogenic causes with an emphasis on collisions. USDA Forest Service General Technical Report. PSW-GTR-191.

Erickson, W. P., G. D. Johnson, D. Young, M. D. Strickland, R. Good, M. Bourassa, K. Bay, and K. Sernka. 2002. Synthesis and comparison of baseline avian and bat use, raptor nesting and mortality information from proposed and existing wind developments. Report prepared for Bonneville Power Administration, Portland, Oregon, USA.

Erickson, W. P., G. D. Johnson, M. D. Strickland, D. P. Young, K. J. Sernja Jr., and R. E. Goodl. 2001. Avian collisions with wind turbines: a summary of existing studies and comparisons to other sources of avian collision mortality in the United States. Western EcoSystems Technology Inc., National Wind Coordinating Committee Resource Document. <http://www.nationalwind.org/publications/avian.htm>.

Euliss, N. H., Jr., D. M. Mushet, and D. A. Wrubleski. 1999. Wetlands of the Prairie Pothole Region: Invertebrate Species Composition, Ecology, and Management. Pages 471-514 in D. P. Batzer, R. B. Rader and S. A. Wissinger, eds. Invertebrates in Freshwater Wetlands of North America: Ecology and Management, Chapter 21. John Wiley \& Sons, New York. Jamestown, ND: Northern Prairie Wildlife Research Center. Version 02SEP99Online. <http://www.npwrc.usgs.gov/resource/wetlands/pothole/index.htm>.

Fink, D., W. M. Hochachka, B. Zuckerberg, D. W. Winkler, B. Shaby, M. A. Munson, G. Hooker, M. Riedewald, D. Sheldon, and S. Kelling. 2010. Spatiotemporal exploratory models for broad-scale survey data. Ecological applications 20:2131-47.

Forcey, G. M., G. M. Linz, W. E. Thogmartin, and W. J. Bleier. 2007. Influence of land use and climate on wetland breeding birds in the Prairie Pothole region of Canada. Canadian Journal of Zoology 85:421-436.

Forcey, G. M., W. E. Thogmartin, G. M. Linz, W. J. Bleier, and P. C. McKann. 2011. Land use and climate influences on waterbirds in the Prairie Potholes. Journal of Biogeography 38: 1694-1707. 
Gonzalez, E., R. Barquez, R. J. and Arroyo-Cabrales, J. 2008. Lasiurus cinereus. In: IUCN 2010. IUCN Red List of Threatened Species. Version 2010.1. <www.iucnredlist.org>. Accessed 05 April 2010.

Greenberg, J. D., M. G. Logsdon, and J. F. Franklin. 2002. Introduction to geographic information systems (GIS). Pages 17-31 in S. E. Gergel and M. G. Turner, editors. Learning landscape ecology: a practical guide to concepts and techniques. SpringerVerlag, New York, New York.

Henderson, I. G., and R. H. W. Langston, and N. A. Clark. 1996. The response of common terns (Sterna hirundo) to power lines: an assessment of risk in relation to breeding commitment, age, and wind speed. Biological Conservation 77:195-192.

Heiberger, R. M. 2012. HH: Statistical analysis and Data Display: Heiberger and Holland. R Package version 2.3-15. http://CRAN.R-project.org/package $=\mathrm{HH}$

Hochachka,W.M., D. Fink, R.A. Hutchinson, D. Sheldon, W-K Wong, S. Kelling. 2012. Dataintensive science applied to broad-scale citizen science, Trends in Ecology \& Evolution: 27 (2): 130-137. 10.1016/j.tree.2011.11.006

Homer, C., J. Dewitz, J. Fry, M. Coan, N. Hossain, C. Larson, N. Herold, A. McKerrow, J. N. VanDriel, and J. Wickham. 2007. Completion of the 2001 National Land Cover Database for the Conterminous United States, Photogrammetric Engineering and Remote Sensing, Vol. 73, No. 4, pp 337-341.

Horn, J.W., E. B. Arnett, and T. H. Kunz. 2008. Behavioral responses of bats to operating wind turbines. Journal of Wildlife Management 73:123-132.

Hudos, W. 2003. Minimization of motion smear: reducing avian collisions with wind turbines. Technical Report DE-AC36-99-GO10337. National Renewable Energy Laboratory, Golden, Colorado.

Hurlbert, A.H., Liang, Z. 2012. Spatiotemporal Variation in Avian Migration Phenology: Citizen Science Reveals Effects of Climate Change. PLoS ONE 7(2): e31662. doi:10.1371/journal.pone.0031662

IUCN. 2010. IUCN Red List of Threatened Species. Version 2010.1. <http://www.iucnredlist.org>. Accessed 11 March 2010.

Jain, A. A. 2005. Bird and Bat Behavior and Mortality at a Northern Iowa Windfarm. Thesis, Iowa State University, Ames, IA. 107 pp.

Johnson, G. D., W. P. Erickson, M. D. Strickland, M. F. Shepherd, and D. A. Shepherd. 2000. Avian Monitoring Studies At The Buffalo Ridge, Minnesota Wind Resource Area: Results Of A 4-year Study. Cheyenne, Wyoming. 273pp.

Kendall, W. L., B. G. Peterjohn, and J. R. Sauer. 1996. First-time observer effects in the North American Breeding Bird Survey. Auk 113:823-829.

Kerlinger, P., J. L. Gehring, W. P. Erickson, R. Curry, A. Jain, and J. Guarnaccia. 2010. Night Migrant Fatalities and Obstruction Lighting at Wind Turbines in North America. The Wilson Journal of Ornithology 122:744-754. 
Kerns, J., and P. Kerlinger. 2004. A Study of Bird and Bat Collision Fatalities at the Mountaineer Wind Energy Center, Tucker County, West Virginia: Annual Report for 2003. Prepared for FPL Energy and Mountaineer Wind Energy Center Technical Review Committee.

Kingsley, A., and B. Whittam. 2007. Wind turbines and birds: a background review for environmental assessment. Environment Canada, Catineau, Quebec, Canada.

Kochert, M. N., K. Steenhof, C. L. Mcintyre and E. H. Craig. 2002. Golden Eagle (Aquila chrysaetos), The Birds of North America Online (A. Poole, Ed.). Cornell Lab of Ornithology. <http://bna.birds.cornell.edu.bnaproxy.birds.cornell.edu/bna/species/684>.

Koford, R. 2004. Avian Mortality Associated with the Top of Iowa Wind Farm. Ames, IA. 9pp.

Koford, R. R., and A. Jain. 2005. Bird and Bat Mortality Associated with the Top of Iowa Wind Farm Top of Iowa Wind Farm. Ames, Iowa. 92pp.

Kunz, T.H., and M. B. Fenton 2003. Bat Ecology. The University of Chicago Press, Chicago, IL.

Kunz, T. H., E. B. Arnett, B. M. Cooper, W. P. Erickson, R. P. Larkin, T. Mabee, M. L. Morrison, M. D. Strickland, and J. M. Szewczak. 2007a. Assessing Impacts of WindEnergy Development of Nocturnally Active Birds and Bats: A Guidance Document. Journal of Wildlife Management 71:2449-2486.

Kunz, T. H., E. B. Arnett, W. P Erickson, A. R. Hoar, G. D. Johnson, R. P. Larkin. M. D. Srickland, R. W. Thresher, and M. D Tuttle. 2007b. Ecological impacts of wind energy development on bats: questions, research, needs, and hypothesis. Frontiers in Ecology and the Environment 5:315-324.

Kuvlesky, W. P., L. A. Brennan, M. L. Morrison, K. K. Boydston, B. M. Ballard, and F. C. Bryant. 2007. Wind Energy Development and Wildlife Conservation: Challenges and Opportunities. Journal of Wildlife Management 71:2487-2498.

Landfire. 2012. Landfire data products. <http://landfire.cr.usgs.gov/viewer/> Accessed 31 September 2012.

Lewis, J. C. 1995. Whooping Crane (Grus americana), The Birds of North America Online (A. Poole, Ed.). Cornell Lab of Ornithology. <http://bna.birds.cornell.edu.bnaproxy.birds.cornell.edu/bna/species/153>.

Link, W. A., E. Cam, J. D. Nichols, and E. G. Cooch. 2002. Of BUGS and birds: Markov chain Monte Carlo for hierarchical modeling in wildlife research. Journal of Wildlife Management 66:277-291.

Link, W., J. Sauer, and D. Niven. 2006. A hierarchical model for regional analysis of population change using Christmas Bird Count data, with application to the American Black Duck. The Condor 108:13-24.

Link, W. a., J. R. Sauer, and D. K. Niven. 2008. Combining Breeding Bird Survey and Christmas Bird Count Data to Evaluate Seasonal Components of Population Change in Northern Bobwhite. Journal of Wildlife Management 72:44-51.Lusk, J. J., F. S. Guthery, R. R. George, M. J. Peterson, and S. J. DeMaso. 2002. Relative abundance of bobwhites in relation to weather and land-use. Journal of Wildlife Management 66:1040-1051. 
Manville, A. M., II. 2005. Bird strikes and electrocutions at power lines, communication towers, and wind turbines: state of the art and state of the science - next steps toward mitigation. In: Proceedings of the 3rd International Partners in Flight Conference, Vol 2; 2002 (C. J. Ralph and T. D. Rich, editors). March 20-24; Asilomar, CA. General Technical Report, PSW-GTR-191. Pacific Southwest Research Station, USDA Forest Service <www.fs.fed.us/psw/publications/documents/psw_gtr191/Asilomar >. Accessed 11 Jun 2007.

Martin, G. R. 2010. Bird collisions : a visual or a perceptual problem ? in BOU proceedings Climate Change and Birds. University of Birmingham, Edgbaston, Birmingham

McGarigal, K., S. A. Cushman, M. C. Neel, and E. Ene. 2002. FRAGSTATS: Spatial pattern analysis program for categorical maps. <http://www.umass.edu/landeco/research/fragstats/fragstats.html>. Accessed 2010 March 22.

Mormann, B.M., and L. W. Robbins, L.W. 2007. Winter Roosting Ecology of Eastern Red Bats in Southwest Missouri. Journal of Wildlife Management. 71(1):213-217.

Munson, M. Arthur, K. Webb, D. Sheldon, D. Fink, W. M. Hochachka, M. Iliff, M. Riedewald, D. Sorokina, B. Sullivan, C. Wood, and S. Kelling. 2009. The eBird Reference Dataset. Cornell Lab of Ornithology and National Audubon Society, Ithaca, NY, USA. <http://www.avianknowledge.net/content/features/archive/eBird_Ref> Accessed 28 August 2012

National Climate Data Center [NCDC]. 2011. World's Largest Archive of Climate Data. http://www.ncdc.noaa.gov/oa/ncdc.html. Accessed 2012 July 30.

National Research Council. 2007. Environmental impacts of wind-energy projects. The National Academies Press, Washington D.C..

Newton, I. 2007. Weather-related mass-mortality events in migrants. Ibis 149:453-467.

North American Bird Conservation Initiative [NABCI]. 2012 May. Bird Conservation Regions. <http://www.nabci-us.org/bcrs.html>. Accessed 2012 August 27.

Page, G. W., and R. E. Gill, Jr. 1994. Shorebirds in western North America: late 1800s to late 1900s. Studies in Avian Biology 15:147-160.

Piorkowski, M. D. 2006. Breeding Bird Habitat Use And Turbine Collisions Of Birds And Bats Located At A Wind Farm In Oklahoma Mixed-grass Prairie. Masters Thesis. 112pp.

Poole, A. (Editor). 2005. The Birds of North America Online: http://bna.birds.cornell.edu.bnaproxy.birds.cornell.edu/BNA/. Cornell Laboratory of Ornithology, Ithaca, NY.

Richardson, W. J. 2000. Bird Migration and wind turbines: migration timing, flight behavior, and collision risk. Proceedings of the National Avian-Wind Power Planning Meeting II, 132140. <http://nationalwind.org/Publications/Avian.htm>.

Robinson, Julie A., Lewis W. Oring, Joseph P. Skorupa, and Ruth Boettcher. 1997. American Avocet (Recurvirostra americana), The Birds of North America Online (A. Poole, Ed.). Cornell Lab of Ornithology.

<http://bna.birds.cornell.edu.bnaproxy.birds.cornell.edu/bna/species/275>. 
Rodhouse, T. J., P. C. Ormsbee, K. M. Irvine, L. A. Vierling, J. M. Szewczak, and K. T. Vierling. 2012. Assessing the status and trend of bat populations across broad geographic regions with dynamic distribution models. Ecological Applications 22:10981113. http://dx.doi.org/10.1890/11-1662.1

Rotenberry, J. T. and J. A. Wiens. 1976. A method for estimating species dispersion from transect data. Am. Midl. Nat. 95:64-78.

Samson, F. B., F. L. Knopf, and W. R. Ostlie. 1998. Grasslands. In: M. J. Mac, P. A. Opler, C. E. Puckett Haecker, and P.D. Doran, eds. Status and Trends of the Nation's Biological Resources, Vol. 2. Version 21JAN2000. Northern Prairie Wildlife Research Center Online. <http://www.npwrc.usgs.gov/resource/habitat/grlands/index.htm>.

Sauer, J. R., B. G. Peterjohn, and W. A. Link. 1994. Observer differences in the North American Breeding Bird Survey. Auk 111:50-62.

Sauer, J. R., J. E. Fallon, and R. Johnson. 2003. Use of North American Breeding Bird Survey data to estimate population change for bird conservation regions. Journal of Wildlife Management 67:372-389.

Sauer, J. R., J. E. Hines, and J. Fallon. 2011. The North American Breeding Bird Survey, Results and Analysis 1966-2010. Version 12.07.2011. USGS Patuxent Wildlife Research Center, Laurel, MD.

Sauer, J. R., S. Schwartz, and B. Hoover. 1996. The Christmas Bird Count Home Page. Version 95.1. Patuxent Wildlife Research Center, Laurel, MD

Stewart, R. E. 1975. Breeding Birds of North Dakota. Tri-College Center for Environmental Studies, Fargo, ND. Jamestown, ND: Northern Prairie Wildlife Research Center Online. Version 06JUL2000. <http://www.npwrc.usgs.gov/resource/birds/bbofnd/index.htm>.

Thelander, C. G., K. S. Smallwood, and L. Rugge. 2003. Bird Risk Behaviors and Fatalities at the Altamont Pass Wind Resource Area. Report to the National Renewable Energy Laboratory Colorado.

Thogmartin, W. E., J. R. Sauer, and M. G. Knutson. 2004. A hierarchical spatial model of avian abundance with application to cerulean warblers. Ecological Applications 14:1766-1779.

Thogmartin, W. E., M. G. Knutson, and J. R. Sauer. 2006. Predicting regional abundance of rare grassland birds with a hierarchical spatial count model. Condor 108:25-46.

Tierney, R. 2008. Buffalo Gap 2 Wind Farm Avian Mortality Study July 2007-December 2008 Final Survey Report. Albuquerque, New Mexico. 49pp.

TRC Environmental Corporation. 2008. Post-construction avian and bat fatality monitoring and grassland bird displacement surveys at the Judith Gap Wind Energy Project, Wheatland County, Montana. Laramie, Wyoming. 65pp.

Tucker, V. A. 1996. A Mathematical Model of Bird Collisions With Wind Turbine Rotors. Journal of Solar Energy Engineering 118:253-269.

United States Department of Energy [USDOE]. 2008. 20\% wind energy by 2030 - increasing wind energy's contribution to U.S. Electricity Supply. <http://www.nrel.gov/docs/fy08osti/41869.pdf> Accessed 24 August 2012. 
United States Environmental Protection Agency [USEPA]. 1998. Guidelines for Ecological Risk Assessment. Federal Register 63:26846-26924.

United States Fish and Wildlife Service [USFWS]. 2009. Whooping Cranes and Wind Development - an issue paper.

<ftp://wiley.kars.ku.edu/windresource/Whooping_Crane_and_Wind_Development_FWS _\%20April\%202009.pdf> Accessed 30 July 2012.

U.S. Fish and Wildlife Service [USFWS]. 2012. U . S . Fish and Wildlife Service Land-Based Wind Energy Guidelines. Arlington, VA, USA. 82pp.

Veltri, C. J., and D. Klem Jr. 2005. Comparison of fatal bird injuries from collisions with tower and windows. Journal of Field Ornithology 76:127-133.

Weller, T. J., and J. a. Baldwin. 2011. Using echolocation monitoring to model bat occupancy and inform mitigations at wind energy facilities. The Journal of Wildlife Management 9999:1-13.

Winkelman, J. E. 1992. The impact of the Sep wind park near Oosterbierrum, the Netherlands on birds 3: flight behavior during daylight. RIN rapport 92/4 Arnhem: Rijksintituut voor Natuurbeheer.

Zar, J. H. 1999. Biostatistical Analysis. Fourth Edition. Prentice Hall, Upper Saddle River, New Jersey, USA. 


\section{Appendices}

\section{Appendix 1. Description of Land Use Classifications and Associated Metrics Used in the Habitat Analysis for Birds and Bats}

Land Use Classifications modified similar to Anderson et al. (1976)

Open Water-All areas of open water, generally with less than $25 \%$ cover of vegetation or soil. Developed

- Areas with a mixture of some constructed materials, but mostly vegetation in the form of lawn grasses. Impervious surfaces account for less than $20 \%$ percent of total cover. These areas most commonly include large-lot single family housing units, parks, golf courses, and vegetation planted in developed settings for recreation, erosion control, or aesthetic purposes

- Areas with a mixture of constructed materials and vegetation. Impervious surfaces account for $20 \%$ to $49 \%$ of total cover. These areas most commonly include single family housing units.

- Areas with a mixture of constructed materials and vegetation. Impervious surfaces account for $50 \%$ to $79 \%$ of the total cover. These areas most commonly include single family housing units.

- Highly developed areas where people reside or work in high numbers. Examples include apartment complexes, row houses, and commercial/industrial developments. Impervious surfaces account for 80 to $100 \%$ of the total cover.

Barren Land (Rock/Sand/Clay) - Barren areas of bedrock, desert pavement, scarps, talus, slides, volcanic material, glacial debris, sand dunes, strip mines, gravel pits, and other accumulations of earthen material. Generally, vegetation accounts for less than $15 \%$ of total cover.

Unconsolidated material such as silt, sand, or gravel, which is subject to inundation and redistribution due to the action of water. Characterized by substrates lacking vegetation except for pioneering plants that become established during brief periods when growing conditions are favorable. Erosion and deposition by waves and currents produce a number of landforms representing this class.

\section{Forest}

- Areas dominated by trees generally $>5 \mathrm{~m}$ tall and $>20 \%$ of total vegetation cover. More than $75 \%$ of the tree species shed foliage simultaneously in response to seasonal change.

- Areas dominated by trees generally $>5 \mathrm{~m}$ tall, and $>20 \%$ of total vegetation cover. More than $75 \%$ of the tree species maintain their leaves all year. Canopy is never without green foliage.

- Areas dominated by trees generally $>5 \mathrm{~m}$ tall, and $>20 \%$ of total vegetation cover. Neither deciduous nor evergreen species are $>75 \%$ of total tree cover. 
Shrubland - Areas dominated by shrubs; $<5 \mathrm{~m}$ tall with shrub canopy typically $>20 \%$ of total vegetation. This class includes true shrubs, young trees in early successional stages, or trees stunted from environmental conditions.

Grassland - Areas dominated by grammanoid or herbaceous vegetation, generally $>80 \%$ of total vegetation. These areas are not subject to intensive management such as tilling, but can be used for grazing.

Pasture/Hay - Areas of grasses, legumes, or grass-legume mixtures planted for livestock grazing or the production of seed or hay crops, typically on a perennial cycle. Pasture/hay vegetation accounts for $>20 \%$ of total vegetation.

Cultivated Crops-Areas used for the production of annual crops, such as corn, soybeans, vegetables, tobacco, and cotton, and also perennial woody crops such as orchards and vineyards. Crop vegetation accounts for $>20 \%$ of total vegetation. This class also includes all land being actively tilled.

Emergent Wetlands - Areas where perennial herbaceous vegetation accounts for $>80 \%$ of vegetative cover and the soil or substrate is periodically saturated with or covered with water.

Land Use Metrics Definitions (McGargial et al. 2002)

Percentage of the Landscape (\%)-The proportional abundance of each land use type in the landscape, expressed as a percentage.

Interspersion and Juxtaposition (IJI) is a metric that is roughly 0 when a particular land use type is adjacent to only one other land use type. Juxtaposition is equal to roughly 100 when a particular land use type is equally adjacent to all other land use types.

Largest Patch Index (LPI) equals the area of the largest patch of a particular land use divided by the total landscape area, multiplied by 100 . This metric is highly correlated with percentage of a particular land cover in the landscape.

Edge Density (ED) is equal to the sum of all the edge lengths of a particular land use divided by the total landscape area, multiplied by 10,000 (to convert to hectares). 


\section{Appendix 2. Focal Species Susceptible Behaviors and Habitat Preferences that were Used to Determine the Season-specific Models for each Species during Different Portions of their Annual Cycle}

\begin{tabular}{|c|c|c|c|c|}
\hline Species & Season & Susceptible Behaviors & Habitat & Timeframe \\
\hline \multirow[t]{3}{*}{$\begin{array}{l}\text { Horned Lark } \\
\text { (Beason 1995) }\end{array}$} & Breeding & $\begin{array}{l}\text { Males often engage in territorial } \\
\text { aerial fights }\end{array}$ & $\begin{array}{l}\text { Habitat is similar throughout seasons with a } \\
\text { preference for open barren country and } \\
\text { areas with short vegetation; avoids forest } \\
\text { area (may have strong negative relationship). }\end{array}$ & May-August \\
\hline & Winter & Feeding in large flocks & Similar to breeding habitat & November-February \\
\hline & Migration & Diurnal migrant & Similar to breeding habitat & $\begin{array}{l}\text { Spring: } \\
\text { March-April } \\
\text { Fall: } \\
\text { September-October }\end{array}$ \\
\hline \multirow[t]{3}{*}{$\begin{array}{l}\text { Red-eyed Vireo } \\
\text { (Cimprich et al. } \\
\text { 2000) }\end{array}$} & Breeding & None & $\begin{array}{l}\text { Primarily occurs in forested habitats - } \\
\text { deciduous and mixed deciduous-coniferous } \\
\text { forest; prefers interior versus edge }\end{array}$ & June-August \\
\hline & Winter & Not applicable & Not applicable & Not applicable \\
\hline & Migration & $\begin{array}{l}\text { Long distance migrant; migrates at } \\
\text { night. }\end{array}$ & $\begin{array}{l}\text { Occupies a greater variety of forest than } \\
\text { during breeding season (shrubland, forest } \\
\text { edges, and city parks) }\end{array}$ & $\begin{array}{l}\text { Spring: } \\
\text { April-May } \\
\text { Fall: } \\
\text { September-October }\end{array}$ \\
\hline \multirow[t]{2}{*}{$\begin{array}{l}\text { Mallard (Drilling } \\
\text { et al. 2002) }\end{array}$} & Breeding & $\begin{array}{l}\text { Territorial males initiate aerial } \\
\text { pursuits flying at intruding pairs } \\
\text { and pursuing them by twisting and } \\
\text { turning in flight; flight among } \\
\text { wetlands and between nesting and } \\
\text { foraging areas; high flight speed } \\
\text { with lower maneuverability }\end{array}$ & $\begin{array}{l}\text { Breeds on wetlands with vegetation; nests in } \\
\text { in uplands with dense cover (grasslands, } \\
\text { shrublands, marshes, pastures, cropland. } \\
\text { Upland habitats are preferably next to water. }\end{array}$ & May-August \\
\hline & Winter & $\begin{array}{l}\text { Flight among feeding sites; high } \\
\text { flight speed with lower } \\
\text { maneuverability }\end{array}$ & $\begin{array}{l}\text { Open water near croplands where it feeds in } \\
\text { corn and potato fields }\end{array}$ & December-January \\
\hline
\end{tabular}




\begin{tabular}{|c|c|c|c|c|}
\hline Species & Season & Susceptible Behaviors & Habitat & Timeframe \\
\hline & Migration & $\begin{array}{l}\text { Short to medium distance migrant; } \\
\text { diurnal and nocturnal migrant; } \\
\text { typically use same } 80-250-\mathrm{km} \\
\text { wide corridor for spring and fall } \\
\text { migration (described in Bellrose } \\
\text { 1980). Mallards prefer to migrate } \\
\text { with tailwinds, low humidity, } \\
\text { warmth, and falling pressure in } \\
\text { spring; cold temperature and rising } \\
\text { pressure in autumn. Frequently } \\
\text { violates these weather preferences } \\
\text { and migrates during fair weather. } \\
\text { Prolonged autumn migration; high } \\
\text { flight speed with lower } \\
\text { maneuverability }\end{array}$ & $\begin{array}{l}\text { Shallow wetlands and marshes, small ponds, } \\
\text { and flooded agricultural fields }\end{array}$ & $\begin{array}{l} \\
\text { Spring: } \\
\text { February-April } \\
\text { Fall: } \\
\text { September-November }\end{array}$ \\
\hline \multirow[t]{3}{*}{$\begin{array}{l}\text { American Avocet } \\
\text { (Robinson et al. } \\
\text { 1997) }\end{array}$} & Breeding & None & Potholes, wetlands, mudflats, & June-July \\
\hline & Winter & Not Applicable & Not Applicable & November-March \\
\hline & Migration & $\begin{array}{l}\text { Medium distance migrant from } \\
\text { south Canada to Mexico. Stops for } \\
\text { prolonged periods at stopover } \\
\text { habitat. No data on specific routes } \\
\text { traveled. }\end{array}$ & Ponds, impoundments, rice fields & $\begin{array}{l}\text { Spring: } \\
\text { April-May; } \\
\text { Fall: } \\
\text { August-October }\end{array}$ \\
\hline $\begin{array}{l}\text { Golden Eagle } \\
\text { (Kochert et al. } \\
\text { 2002) }\end{array}$ & Breeding & $\begin{array}{l}\text { Soaring behavior; territorial } \\
\text { defense includes steep dives at } \\
\text { intruders; and courtship behavior } \\
\text { which may include mutual soaring, } \\
\text { cliff racing; may be more exposed } \\
\text { to turbines during days of higher } \\
\text { visibility because they are more } \\
\text { apt to be flying. }\end{array}$ & $\begin{array}{l}\text { Grasslands, brushlands, open forest, riparian } \\
\text { habitats, avoids heavily forested areas }\end{array}$ & June-August \\
\hline
\end{tabular}




\begin{tabular}{|c|c|c|c|c|}
\hline Species & Season & Susceptible Behaviors & Habitat & Timeframe \\
\hline & Winter & $\begin{array}{l}\text { Soaring behavior; may be more } \\
\text { exposed to turbines during days of } \\
\text { higher visibility because they are } \\
\text { more apt to be flying. }\end{array}$ & $\begin{array}{l}\text { Open habitats with native vegetation; avoids } \\
\text { urban, agricultural and forest areas. Also } \\
\text { forages in shrubland but avoids grassland } \\
\text { and agriculture. Will also frequent areas with } \\
\text { waterfowl concentrations }\end{array}$ & December-January \\
\hline & Migration & $\begin{array}{l}\text { Short to medium distance migrant; } \\
\text { migrates diurnally and does not } \\
\text { migrate in flocks; migration routes } \\
\text { poorly known but most seem to fly } \\
\text { along rocky mountain range, and } \\
\text { some migrate east of Rocky } \\
\text { Mountains. Commonly uses } \\
\text { orographic lift along ridges but also } \\
\text { migrates over flat featureless } \\
\text { terrain. Passage rates peak } 1 \text { day } \\
\text { after cold front; may be more } \\
\text { exposed to turbines during days of } \\
\text { higher visibility because they are } \\
\text { more apt to be flying. }\end{array}$ & 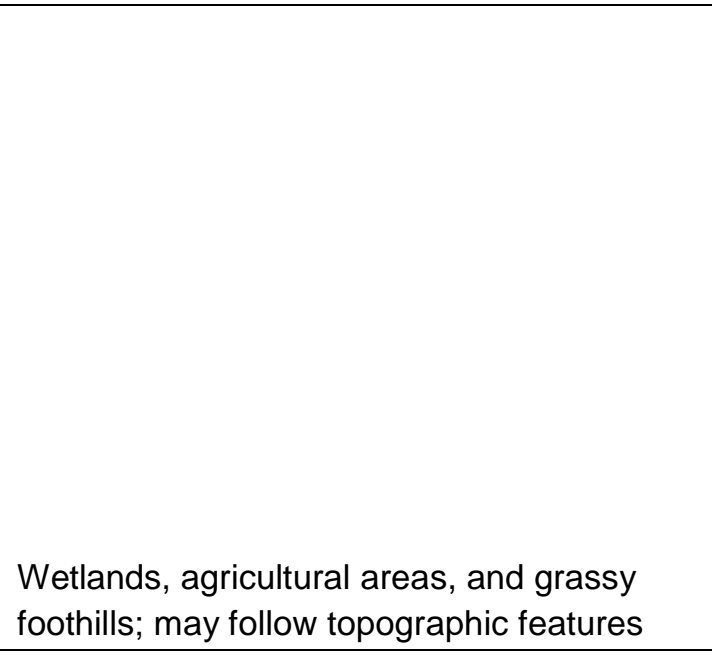 & $\begin{array}{l} \\
\text { Spring: } \\
\text { February-May } \\
\text { Fall: } \\
\text { September-November }\end{array}$ \\
\hline \multirow[t]{2}{*}{$\begin{array}{l}\text { Whooping Crane } \\
\text { (Lewis 1995, Tom } \\
\text { Stehn, USFWS } \\
\text { personal comm.) }\end{array}$} & Breeding & Not applicable & Not applicable & Not applicable \\
\hline & Winter & Not applicable & Not applicable & Not applicable \\
\hline
\end{tabular}




\begin{tabular}{|c|c|c|c|c|}
\hline Species & Season & Susceptible Behaviors & Habitat & Timeframe \\
\hline & Migration & $\begin{array}{l}\text { Diurnal migrant; makes regular } \\
\text { stops to feed and rest. Travels } \\
\text { singly, in pairs, or small family } \\
\text { groups. Migrate through fairly } \\
\text { defined corridor in the central US. } \\
\text { Cruising altitude is } 1000-6000 ; \\
\text { lower flight maneuverability. May } \\
\text { be more exposed to turbines } \\
\text { during days of higher visibility } \\
\text { because they are more apt to be } \\
\text { flying. During low visibility, they } \\
\text { may not be migrating. }\end{array}$ & $\begin{array}{l}\text { Birds roost in shallow lakes, ponds, or, } \\
\text { riverine areas; topography does not influence } \\
\text { flight although they do like thermal updrafts. } \\
\text { Feed in croplands, palustrine wetlands }\end{array}$ & $\begin{array}{l}\text { Spring: } \\
\text { April-May; } \\
\text { Fall: } \\
\text { September-November }\end{array}$ \\
\hline \multirow[t]{4}{*}{$\begin{array}{l}\text { Eastern Red Bat } \\
\text { (Kunz and Fenton } \\
\text { 2003; Mormann } \\
\text { and Robbins } \\
\text { 2007; Arroyo- } \\
\text { Cabrales et al. } \\
\text { 2008b) }\end{array}$} & Summer & $\begin{array}{l}\text { Aerial foraging: lower wind speeds } \\
\text { and minimal rain could increase } \\
\text { exposure due to increased bat } \\
\text { activity }\end{array}$ & $\begin{array}{l}\text { Forages at forest edges, in clearings around } \\
\text { streetlights, and along lake and stream } \\
\text { margins; feeds along the canopy edge at or } \\
\text { above the treetop level; roosts in deciduous } \\
\text { and evergreen tree foliage, often along the } \\
\text { forest edge }\end{array}$ & June-July \\
\hline & Winter & $\begin{array}{l}\text { Minimal exposure expected due to } \\
\text { reduced winter activity }\end{array}$ & Similar to breeding habitat & November-March \\
\hline & $\begin{array}{l}\text { Spring } \\
\text { Migration }\end{array}$ & $\begin{array}{l}\text { Aerial foraging; migration; lower } \\
\text { wind speeds and minimal rain } \\
\text { could increase exposure due to } \\
\text { increased bat activity }\end{array}$ & Similar to breeding habitat & April-May \\
\hline & $\begin{array}{l}\text { Fall } \\
\text { Migration }\end{array}$ & $\begin{array}{l}\text { Aerial foraging, migration, } \\
\text { reproductive behavior, pre- } \\
\text { hibernation behavior; lower wind } \\
\text { speeds and minimal rain could } \\
\text { increase exposure due to } \\
\text { increased bat activity }\end{array}$ & Similar to breeding habitat & August-October \\
\hline
\end{tabular}




\begin{tabular}{|c|c|c|c|c|}
\hline Species & Season & Susceptible Behaviors & Habitat & Timeframe \\
\hline \multirow[t]{4}{*}{$\begin{array}{l}\text { Hoary bat } \\
\text { (Barclay } 1984 ; \\
\text { Kunz and Fenton } \\
\text { 2003; Gonzalez } \\
\text { et al. 2008) }\end{array}$} & Summer & $\begin{array}{l}\text { Aerial foraging; lower wind speeds } \\
\text { and minimal rain could increase } \\
\text { exposure due to increased bat } \\
\text { activity }\end{array}$ & $\begin{array}{l}\text { Feeds over clearings-often along lake and } \\
\text { stream edges; prefers to roost in deciduous } \\
\text { and coniferous woodlands; found in the } \\
\text { foliage along forest edge; roosts } 3 \text { to } 5 \mathrm{~m} \\
\text { above ground }\end{array}$ & June-July \\
\hline & Winter & $\begin{array}{l}\text { Minimal exposure expected due to } \\
\text { reduced winter activity }\end{array}$ & Similar to breeding habitat & November-March \\
\hline & $\begin{array}{l}\text { Spring } \\
\text { Migration }\end{array}$ & $\begin{array}{l}\text { Aerial foraging; migration; lower } \\
\text { wind speeds and minimal rain } \\
\text { could increase exposure due to } \\
\text { increased bat activity }\end{array}$ & Similar to breeding habitat & April-May \\
\hline & $\begin{array}{l}\text { Fall } \\
\text { Migration }\end{array}$ & $\begin{array}{l}\text { Aerial foraging; migration; } \\
\text { reproductive behavior; pre- } \\
\text { hibernation behavior; lower wind } \\
\text { speeds and minimal rain could } \\
\text { increase exposure due to } \\
\text { increased bat activity }\end{array}$ & Similar to breeding habitat & August-October \\
\hline \multirow[t]{4}{*}{$\begin{array}{l}\text { Silver-haired bat } \\
\text { (Betts 1998; Kunz } \\
\text { and Fenton 2003; } \\
\text { Arroyo-Cabrales } \\
\text { et al. 2008a) }\end{array}$} & Summer & $\begin{array}{l}\text { Aerial foraging; lower wind speeds } \\
\text { and minimal rain could increase } \\
\text { exposure due to increased bat } \\
\text { activity }\end{array}$ & $\begin{array}{l}\text { Primarily forested areas; flies along forest } \\
\text { edges, small clearings, small roadways, and } \\
\text { flowing water bodies; roosts in tree cavities, } \\
\text { small hollows, under loose bark; typically in } \\
\text { wooded areas close to water. }\end{array}$ & June-July \\
\hline & Winter & $\begin{array}{l}\text { Minimal exposure expected due to } \\
\text { reduced winter activity }\end{array}$ & Similar to breeding habitat & November-March \\
\hline & $\begin{array}{l}\text { Spring } \\
\text { Migration }\end{array}$ & $\begin{array}{l}\text { Aerial foraging; migration; lower } \\
\text { wind speeds and minimal rain } \\
\text { could increase exposure due to } \\
\text { increased bat activity }\end{array}$ & Similar to breeding habitat & April-May \\
\hline & $\begin{array}{l}\text { Fall } \\
\text { Migration }\end{array}$ & $\begin{array}{l}\text { Aerial foraging; migration; } \\
\text { reproductive behavior; } \\
\text { prehibernation behavior; lower } \\
\text { wind speeds and minimal rain } \\
\text { could increase exposure due to } \\
\text { increased bat activity }\end{array}$ & Similar to breeding habitat & August-October \\
\hline
\end{tabular}




\section{Appendix 3. A Priori Habitat Models, Relevant Exposure Factors, and Final Seasonal Models for each Focal Species in the Study}

\begin{tabular}{|c|c|c|c|c|}
\hline Species & Season & A Priori Habitat Models ${ }^{a}$ & Exposure Factors & $\begin{array}{l}\text { Final Seasonal } \\
\text { Model }\end{array}$ \\
\hline \multirow[t]{2}{*}{$\begin{array}{l}\text { Horned } \\
\text { Lark }\end{array}$} & Breeding & 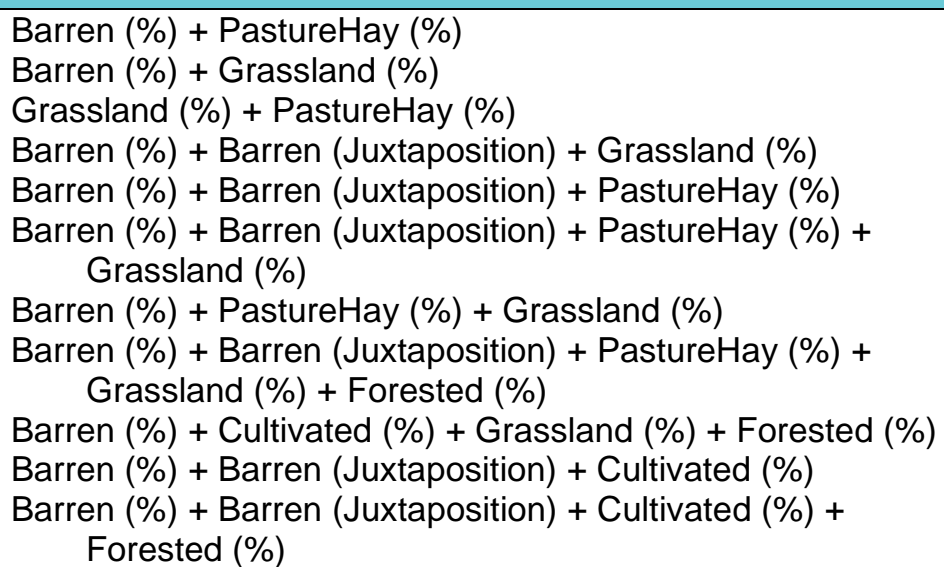 & $\begin{array}{l}\text { Avg \# of daylight hours of } \\
<0.5 \text { mi visibility } \\
\text { (May-August) } \\
\text { Susceptible Behavior } \\
\text { (male-male fights) }\end{array}$ & $\begin{array}{l}\text { Predicted Abundance }+ \\
\text { Exposure = Predicted } \\
\text { Relative Breeding } \\
\text { Collision Mortality }\end{array}$ \\
\hline & Winter & 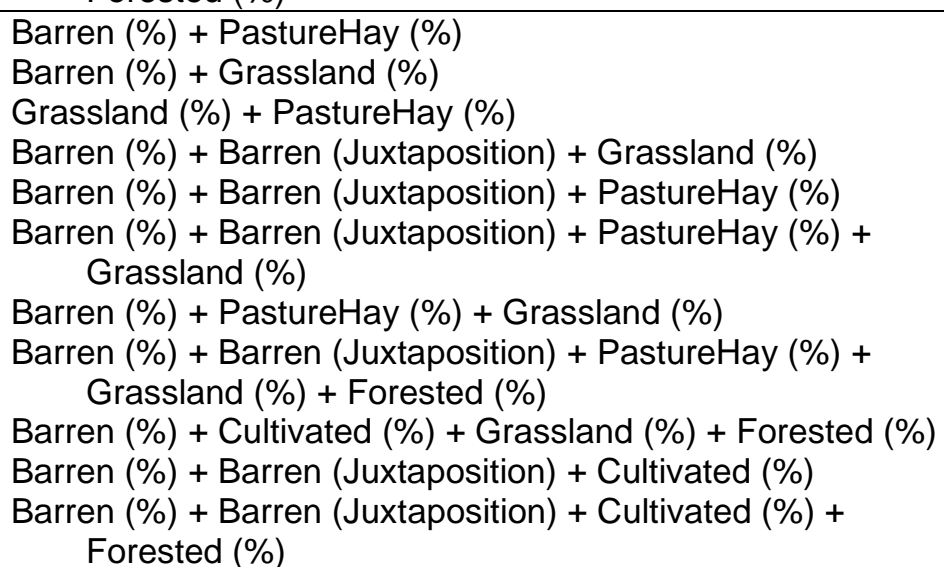 & $\begin{array}{l}\text { Avg \# of daylight hours of } \\
<0.5 \text { mi visibility } \\
\text { (November- } \\
\text { February) }\end{array}$ & $\begin{array}{l}\text { Predicted Abundance }+ \\
\text { Exposure }=\text { Predicted } \\
\text { Relative Winter } \\
\text { Collision Mortality }\end{array}$ \\
\hline
\end{tabular}




\begin{tabular}{|c|c|c|c|c|}
\hline & Migration & 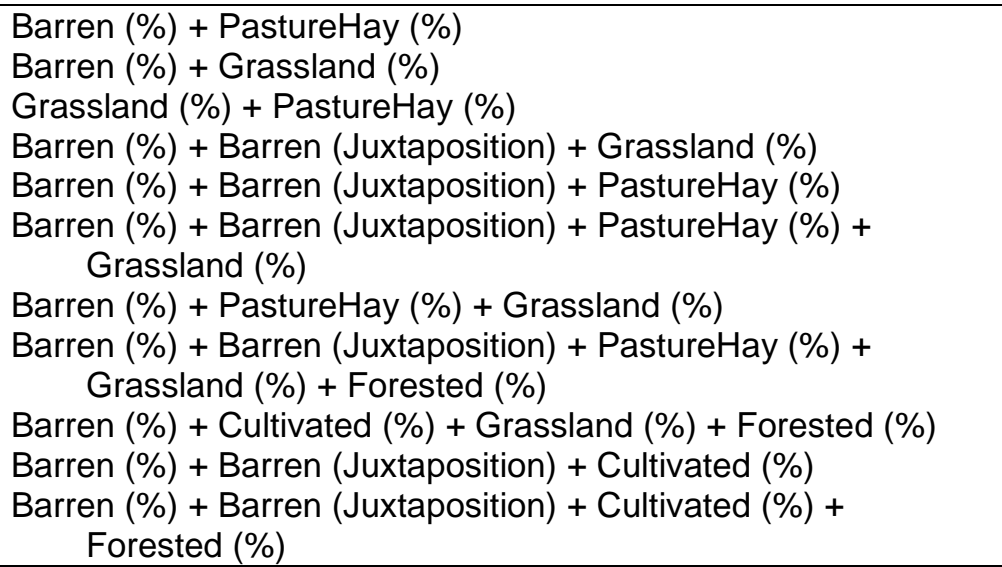 & $\begin{array}{l}\text { Avg \# of daylight hours of } \\
\text { < } 0.5 \text { mi visibility } \\
\text { (March-April, } \\
\text { September-October) } \\
\text { Susceptible Behavior } \\
\text { (Diurnal Migration) }\end{array}$ & $\begin{array}{l}\text { Predicted Abundance + } \\
\text { Exposure = Predicted } \\
\text { Relative Migration } \\
\text { Collision Mortality }\end{array}$ \\
\hline \multirow[t]{3}{*}{$\begin{array}{l}\text { Red-eyed } \\
\text { Vireo }\end{array}$} & Breeding & $\begin{array}{l}\text { Forest }(\%)+\text { Grassland }(\%)+\text { PastureHay }(\%)+\text { Developed }(\%) \\
\text { Forest }(\%)+\text { Shrubland }(\%)+\text { Developed }(\%) \\
\text { Forest (Largest Patch Index) + Shrubland }(\%)+\text { Developed }(\%) \\
\text { Forest (Largest Patch Index) + Developed }(\%) \\
\text { Forest }(\%)+\text { Developed } \\
\text { Forest }(\%) \\
\text { Forest (Edge Density) } \\
\text { Forest (Largest Patch Index) }\end{array}$ & $\begin{array}{l}\text { Minimal possible } \\
\text { exposure during } \\
\text { breeding; spends } \\
\text { little time outside } \\
\text { forest canopy and } \\
\text { associated habitats }\end{array}$ & Predicted Abundance \\
\hline & Winter & Not applicable & Not applicable & Not applicable \\
\hline & Migration & $\begin{array}{l}\text { Forest }(\%)+\text { Grassland }(\%)+\text { PastureHay }(\%)+\text { Developed }(\%) \\
\text { Forest }(\%)+\text { Shrubland }(\%)+\text { Developed }(\%) \\
\text { Forest (Largest Patch Index) + Shrubland }(\%)+\text { Developed (\%) } \\
\text { Forest (Edge Density) + Shrubland (\%) + Developed (\%) } \\
\text { Forest }(\%)+\text { Shrubland }(\%) \\
\text { Forest }(\%) \\
\text { Forest (Edge Density) } \\
\text { Forest (Largest Patch Index) }\end{array}$ & $\begin{array}{c}\text { Avg \# of daytime hours of } \\
<0.5 \text { mi visibility } \\
\text { (April-May, } \\
\text { September-October) } \\
\text { 2X Susceptible Behavior } \\
\text { (Nocturnal Migration) }\end{array}$ & $\begin{array}{l}\text { Predicted Abundance + } \\
\text { Exposure = Predicted } \\
\text { Relative Migration } \\
\text { Collision Mortality }\end{array}$ \\
\hline
\end{tabular}




\begin{tabular}{|c|c|c|c|c|}
\hline \multirow[t]{3}{*}{ Mallard } & Breeding & $\begin{array}{l}\text { Open Water (\%) + Cultivated Crops (\%) + Grassland (\%) + } \\
\text { Emergent Wetlands (\%) } \\
\text { Open Water (\%) + Cultivated Crops (\%) + Shrubland (\%) + } \\
\text { PastureHay (\%) + Emergent Wetlands (\%) } \\
\text { Open Water (\%) + Emergent Wetlands (\%) + Grassland (\%) } \\
\text { Open Water }(\%)+\text { Emergent Wetlands (\%) + HayPasture (\%) } \\
\text { Open Water (\%) + Emergent Wetlands (\%) } \\
\text { Open Water (Juxtaposition) + Cultivated Crops (\%) + Emergent } \\
\text { Wetlands (\%) } \\
\text { Open Water (Juxtaposition) + Cultivated Crops (\%) + } \\
\text { PastureHay (\%) + Emergent Wetlands (\%) } \\
\text { Open Water (Juxtaposition) + Cultivated Crops (Juxtaposition) } \\
\text { + PastureHay (\%) + (Juxtaposition) + Emergent Wetlands } \\
\text { (Juxtaposition) } \\
\text { Open Water (Juxtaposition) + Cultivated Crops (Juxtaposition) } \\
\text { + PastureHay (\%) + (Juxtaposition) + Emergent Wetlands } \\
\text { (Juxtaposition) + Grassland (Juxtaposition) }\end{array}$ & $\begin{array}{l}\text { Avg \# of daytime hours of } \\
<0.5 \text { mi visibility } \\
\text { (May - August) } \\
\text { Susceptible Behavior } \\
\text { (male-male } \\
\text { interactions + flights } \\
\text { between feeding and } \\
\text { nesting areas + low } \\
\text { flight } \\
\text { maneuverability) }\end{array}$ & $\begin{array}{l}\text { Predicted Abundance + } \\
\text { Exposure = Predicted } \\
\text { Relative Breeding } \\
\text { Collision Mortality }\end{array}$ \\
\hline & Winter & $\begin{array}{l}\text { Open Water }(\%)+\text { Cultivated Crops (\%) } \\
\text { Open Water }(\%)+\text { Cultivated Crops (\%) + Emergent Wetlands } \\
\quad(\%) \\
\text { Open Water (Juxtaposition) + Cultivated Crops (Juxtaposition) } \\
\text { Open Water (Juxtaposition) } \\
\text { Cultivated Crops (Juxtaposition) } \\
\text { Emergent Wetlands (\%) } \\
\text { Open Water (\%) } \\
\text { Cultivated Crops (\%) }\end{array}$ & $\begin{array}{l}\text { Avg \# of daytime hours of } \\
<0.5 \text { mi visibility } \\
\text { (December- } \\
\text { January) } \\
\text { Susceptible Behavior } \\
\text { (flights among } \\
\text { feeding areas + low } \\
\text { flight } \\
\text { maneuverability) }\end{array}$ & $\begin{array}{l}\text { Predicted Abundance + } \\
\text { Exposure = Predicted } \\
\text { Relative Winter } \\
\text { Collision Mortality }\end{array}$ \\
\hline & Migration & $\begin{array}{l}\text { Open Water (\%) + Cultivated Crops (\%) + Emergent Wetlands } \\
(\%) \\
\text { Open Water (\%) + Cultivated Crops (\%) } \\
\text { Open Water (\%) + Emergent Wetlands (\%) } \\
\text { Open Water (\%) + Emergent Wetlands (\%) + HayPasture (\%) } \\
\text { Open Water (Juxtaposition) + Cultivated Crops (\%) + Emergent } \\
\text { Wetlands (\%) } \\
\text { Open Water (Juxtaposition) + Cultivated Crops (Juxtaposition) } \\
\text { Open Water (Juxtaposition) + Cultivated Crops (Juxtaposition) } \\
\quad+\text { Emergent Wetlands (Juxtaposition) }\end{array}$ & $\begin{array}{l}\text { Avg \# of daylight hours of } \\
<0.5 \text { mi visibility } \\
\text { (February-April, } \\
\text { September- } \\
\text { November) } \\
\text { Susceptible Behavior } \\
\text { (Diurnal and } \\
\text { Nocturnal Migration } \\
\text { + low flight } \\
\text { maneuverability) }\end{array}$ & $\begin{array}{l}\text { Predicted Abundance + } \\
\text { Exposure = Predicted } \\
\text { Relative Migration } \\
\text { Collision Mortality }\end{array}$ \\
\hline
\end{tabular}




\begin{tabular}{|c|c|c|c|c|}
\hline \multirow[t]{3}{*}{$\begin{array}{l}\text { American } \\
\text { Avocet }\end{array}$} & Breeding & $\begin{array}{l}\text { Open Water (\%) + Emergent Wetland (\%) } \\
\text { Open Water (\%) } \\
\text { Emergent Wetland (\%) } \\
\text { Grassland (\%) } \\
\text { Open Water (Largest Patch Index) + Emergent Wetland } \\
\quad \text { (Largest Patch Index) } \\
\text { Open Water (Juxtaposition) + Emergent Wetland } \\
\quad \text { (Juxtaposition) } \\
\text { Open Water (Juxtaposition) + Emergent Wetland (\%) + } \\
\quad \text { Grassland (\%) } \\
\text { Open Water (\%) + Emergent Wetland (\%) + Grassland (\%) }\end{array}$ & None & $\begin{array}{l}\text { Predicted Breeding } \\
\text { Abundance }\end{array}$ \\
\hline & Winter & Not applicable & Not applicable & Not applicable \\
\hline & Migration & $\begin{array}{l}\text { Open Water (\%) + Emergent Wetland (\%) } \\
\text { Open Water (\%) } \\
\text { Emergent Wetland (\%) } \\
\text { Grassland }(\%) \\
\text { Open Water (Largest Patch Index) + Emergent Wetland } \\
\quad \text { (Largest Patch Index) } \\
\text { Open Water (Juxtaposition) + Emergent Wetland } \\
\quad \text { (Juxtaposition) } \\
\text { Open Water (Juxtaposition) + Emergent Wetland (\%) + } \\
\text { Cultivated Crops (\%) } \\
\text { Open Water (\%) + Emergent Wetland (\%) + Cultivated Crops } \\
(\%)\end{array}$ & $\begin{array}{l}\text { Avg \# of daylight hours of } \\
<0.5 \text { mi visibility } \\
\text { (April-May, August- } \\
\text { October) } \\
\text { Susceptible Behavior } \\
\text { (Migration) }\end{array}$ & $\begin{array}{l}\text { Predicted Abundance + } \\
\text { Exposure = Predicted } \\
\text { Relative Migration } \\
\text { Collision Mortality }\end{array}$ \\
\hline $\begin{array}{l}\text { Golden } \\
\text { Eagle }\end{array}$ & Breeding & $\begin{array}{l}\text { Grasslands (\%) + Shrubland (\%) + Open Water (Juxtaposition) } \\
\text { Grasslands (\%) } \\
\text { Shrubland (\%) } \\
\text { PastureHay (\%) } \\
\text { Grasslands (\%) + Shrubland (\%) } \\
\text { Grassland (Juxtapositon) + Shrubland (Juxtaposition) + Open } \\
\quad \text { Water (Juxtaposition) } \\
\text { Grasslands (Largest Patch Index) + Shrubland (Largest Patch } \\
\quad \text { Index) } \\
\text { Grasslands (\%) + Shrubland (\%) + Forest (\%) } \\
\text { Grasslands (\%) + Shrubland (\%) + PastureHay (\%) + Forest } \\
\quad(\%) \\
\text { Shrubland (\%) + PastureHay (\%) + Forest (\%) }\end{array}$ & $\begin{array}{l}\text { Avg \# of daytime hours of } \\
>1 \text { mi visibility } \\
\text { (June-August) } \\
\text { Susceptible Behavior } \\
\text { (territorial defense, } \\
\text { courtship behavior, } \\
\text { soaring) } \\
\text { Slope }\end{array}$ & $\begin{array}{l}\text { Predicted Abundance + } \\
\text { Exposure = Predicted } \\
\text { Relative Breeding } \\
\text { Collision Mortality }\end{array}$ \\
\hline
\end{tabular}




\begin{tabular}{|c|c|c|c|c|}
\hline & Winter & $\begin{array}{l}\text { Forest (\%) + Shrubland (\%) + Open Water (Juxtaposition) } \\
\text { Forest }(\%) \\
\text { Forest (Juxtaposition) } \\
\text { Shrubland (\%) } \\
\text { Open Water (\%) } \\
\text { Grasslands (\%) + Shrubland (\%) } \\
\text { Grassland (Juxtapositon) + Shrubland (Juxtaposition) + Open } \\
\quad \text { Water (Juxtaposition) } \\
\text { Grasslands (Largest Patch Index) + Shrubland (Largest Patch } \\
\quad \text { Index) } \\
\text { Grasslands (\%) + Shrubland (Juxtaposition) + Forest } \\
\quad \text { (Juxtaposition) } \\
\text { Grasslands }(\%)+\text { Shrubland }(\%)+\text { Forest }(\%) \\
\text { Shrubland (\%) + PastureHay (\%) + Forest (\%) }\end{array}$ & $\begin{array}{l}\text { Avg \# of daytime hours of } \\
>1 \text { mi visibility } \\
\text { (December- } \\
\text { January) } \\
\text { Susceptible Behavior } \\
\text { (territorial defense, } \\
\text { courtship behavior, } \\
\text { soaring) } \\
\text { Slope }\end{array}$ & $\begin{array}{l}\text { Predicted Abundance }+ \\
\text { Exposure = Predicted } \\
\text { Relative Winter } \\
\text { Collision Mortality }\end{array}$ \\
\hline & Migration & $\begin{array}{l}\text { Grasslands (\%) + Shrubland (\%) + Open Water (Juxtaposition) } \\
\quad \text { +Cultivated Crops (\%) } \\
\text { Grasslands (\%) } \\
\text { Shrubland (\%) } \\
\text { PastureHay (\%) } \\
\text { Cultivated Crops (\%) } \\
\text { Grasslands (\%) + Shrubland (\%) + Cultivated Crops (\%) } \\
\text { Grasslands (Largest Patch Index) + Shrubland (Largest Patch } \\
\text { Index) + Cultivated Crops ( Largest Patch Index ) } \\
\text { Grasslands (\%) + Shrubland (\%) + Cultivated Crops (\%) } \\
\text { Grasslands }(\%)+\text { Shrubland (\%) + PastureHay (\%) + } \\
\text { Cultivated Crops (\%) }\end{array}$ & $\begin{array}{l}\text { Avg \# of daytime hours of } \\
>1 \text { mi visibility } \\
\text { (February - May and } \\
\text { September - } \\
\text { November) } \\
\text { Susceptible Behavior } \\
\text { (diurnal migration) } \\
\text { Slope }\end{array}$ & $\begin{array}{l}\text { Predicted Abundance + } \\
\text { Exposure = Predicted } \\
\text { Relative Migratory } \\
\text { Collision Mortality }\end{array}$ \\
\hline \multirow[t]{2}{*}{$\begin{array}{l}\text { Whooping } \\
\text { Crane }\end{array}$} & Breeding & Not applicable & Not applicable & Not applicable \\
\hline & Winter & Not applicable & Not applicable & Not applicable \\
\hline
\end{tabular}




\begin{tabular}{|c|c|c|c|c|}
\hline & Migration & $\begin{array}{l}\text { Open Water (\%) + Emergent Wetland (\%) + Cultivated Crops } \\
(\%) \\
\text { Open Water (Juxtaposition) + Emergent Wetland } \\
\text { (Juxtaposition) + Cultivated Crops (Juxtaposition) } \\
\text { Emergent Wetland (Juxtaposition) + Cultivated Crops } \\
\text { (Juxtaposition) } \\
\text { Open Water (Edge Density) + Emergent Wetland (Edge } \\
\text { Density) + Cultivated Crops (\%) } \\
\text { Open Water (Edge Density) + Emergent Wetland } \\
\text { (Juxtaposition) + Cultivated Crops (Juxtaposition) } \\
\text { Open Water (Edge Density) + Emergent Wetland } \\
\text { (Juxtaposition) + Cultivated Crops (\%) }\end{array}$ & $\begin{array}{l}\text { Avg \# of daytime hours of } \\
1>\text { mi visibility (April } \\
\text { - May and } \\
\text { September - } \\
\text { November) } \\
\text { Susceptible Behavior } \\
\text { (diurnal migration } \\
\text { and a low flight } \\
\text { maneuverability) }\end{array}$ & $\begin{array}{l}\text { Predicted Abundance + } \\
\text { Exposure = Predicted } \\
\text { Relative Migratory } \\
\text { Collision Mortality }\end{array}$ \\
\hline \multirow[t]{2}{*}{$\begin{array}{l}\text { Eastern } \\
\text { Red Bat } \\
(2 \mathrm{~km} \\
\text { Scale })\end{array}$} & Summer & $\begin{array}{l}\text { Forest }(\%)+\text { Forest (Edge Density) + Forest Stand Age + } \\
\text { Distance to Nearest Water Body + Riparian Flyway (linear } \\
\text { corridor) }\end{array}$ & $\begin{array}{c}\text { Avg number of night } \\
\text { hours (June-July) } \\
\text { with }<7 \mathrm{~m} / \mathrm{s} \text { wind } \\
\text { speed } \\
\text { Avg number of night } \\
\text { hours (June-July) } \\
\text { with no rain } \\
\text { Avg number of night } \\
\text { hours (June-July) } \\
\text { with }>50 \text { degree } \\
\text { temperatures } \\
\text { Susceptible Behavior } \\
\text { (aerial foraging) }\end{array}$ & $\begin{array}{l}\text { Habitat Suitability + } \\
\text { Exposure = Predicted } \\
\text { Relative Summer } \\
\text { Collision Mortality }\end{array}$ \\
\hline & Winter & Not considered given minimal activity & $\begin{array}{c}\text { Not considered given } \\
\text { minimal activity }\end{array}$ & $\begin{array}{l}\text { Not considered given } \\
\text { minimal activity }\end{array}$ \\
\hline
\end{tabular}




\begin{tabular}{|c|c|c|c|}
\hline $\begin{array}{l}\text { Spring } \\
\text { Migration }\end{array}$ & $\begin{array}{l}\text { Forest }(\%)+\text { Forest (Edge Density) + Forest Stand Age + } \\
\text { Distance to Nearest Water Body + Riparian Flyway (linear } \\
\text { corridor) }\end{array}$ & $\begin{array}{l}\text { Avg number of night } \\
\text { hours (April-May) } \\
\text { with }<7 \text { m/s wind } \\
\text { speed } \\
\text { Avg number of night } \\
\text { hours (April-May) } \\
\text { with no rain } \\
\text { Avg number of night } \\
\text { hours (April-May) } \\
\text { with }>50 \text { degree } \\
\text { temperatures } \\
\text { Susceptible Behaviors } \\
\text { (aerial foraging + } \\
\text { migration) }\end{array}$ & $\begin{array}{l}\text { Habitat Suitability + } \\
\text { Exposure= Predicted } \\
\text { Relative Spring } \\
\text { Migration Collision } \\
\text { Mortality }\end{array}$ \\
\hline $\begin{array}{l}\text { Fall } \\
\text { Migration }\end{array}$ & $\begin{array}{l}\text { Forest }(\%)+\text { Forest (Edge Density) + Forest Stand Age + } \\
\text { Distance to Nearest Water Body + Riparian Flyway (linear } \\
\text { corridor) }\end{array}$ & $\begin{array}{l}\text { Avg number of night } \\
\text { hours (August- } \\
\text { September) with }<7 \\
\text { m/s wind speed } \\
\text { Avg number of night } \\
\text { hours (August- } \\
\text { September) with no } \\
\text { rain } \\
\text { Avg number of night } \\
\text { hours (August- } \\
\text { September) with }> \\
50 \text { degree } \\
\text { temperatures } \\
\text { Susceptible Behaviors } \\
\text { (aerial foraging + } \\
\text { migration + } \\
\text { reproductive } \\
\text { behavior + pre- } \\
\text { hibernation } \\
\text { behavior) }\end{array}$ & $\begin{array}{l}\text { Habitat Suitability }+ \\
\text { Exposure = Predicted } \\
\text { Relative Fall Migration } \\
\text { Collision Mortality }\end{array}$ \\
\hline
\end{tabular}




\begin{tabular}{|c|c|c|c|c|}
\hline \multirow[t]{3}{*}{$\begin{array}{l}\text { Hoary bat } \\
(10 \mathrm{~km} \\
\text { Scale) }\end{array}$} & Summer & $\begin{array}{l}\text { Forest }(\%)+\text { Forest (Edge Density) + Open Water (Edge } \\
\text { Density) + Forest Stand Age + Distance to Nearest Water } \\
\text { Body + Riparian Flyway (linear corridor) }\end{array}$ & $\begin{array}{l}\text { Avg number of night } \\
\text { hours (June-July) } \\
\text { with }<10 \mathrm{~m} / \mathrm{s} \text { wind } \\
\text { speed } \\
\text { Avg number of night } \\
\text { hours (June-July) } \\
\text { with no rain } \\
\text { Avg number of night } \\
\text { hours (June-July) } \\
\text { with >50 degree } \\
\text { temperatures } \\
\text { Susceptible Behavior } \\
\text { (aerial foraging) }\end{array}$ & $\begin{array}{l}\text { Habitat Suitability }+ \\
\text { Exposure = Predicted } \\
\text { Relative Summer } \\
\text { Collision Mortality }\end{array}$ \\
\hline & Winter & Not considered given minimal activity & $\begin{array}{c}\text { Not considered given } \\
\text { minimal activity }\end{array}$ & $\begin{array}{l}\text { Not considered given } \\
\text { minimal activity }\end{array}$ \\
\hline & $\begin{array}{l}\text { Spring } \\
\text { Migration }\end{array}$ & $\begin{array}{l}\text { Forest }(\%)+\text { Forest (Edge Density) + Open Water (Edge } \\
\text { Density) + Forest Stand Age + Distance to Nearest Water } \\
\text { Body + Riparian Flyway (linear corridor) }\end{array}$ & $\begin{array}{l}\text { Avg number of night } \\
\text { hours (April-May) } \\
\text { with }<10 \mathrm{~m} / \mathrm{s} \text { wind } \\
\text { speed } \\
\text { Avg number of night } \\
\text { hours (April-May) } \\
\text { with no rain } \\
\text { Avg number of night } \\
\text { hours (April-May) } \\
\text { with }>50 \text { degree } \\
\text { temperatures } \\
\text { Susceptible Behaviors } \\
\text { (aerial foraging + } \\
\text { migration) }\end{array}$ & $\begin{array}{l}\text { Habitat Suitability + } \\
\text { Exposure = Predicted } \\
\text { Relative Spring } \\
\text { Migration Collision } \\
\text { Mortality }\end{array}$ \\
\hline
\end{tabular}




\begin{tabular}{|c|c|c|c|c|}
\hline & $\begin{array}{l}\text { Fall } \\
\text { Migration }\end{array}$ & $\begin{array}{l}\text { Forest }(\%)+\text { Forest (Edge Density) + Open Water (Edge } \\
\text { Density) + Forest Stand Age + Distance to Nearest Water } \\
\text { Body + Riparian Flyway (linear corridor) }\end{array}$ & $\begin{array}{l}\text { Avg number of night } \\
\text { hours (August- } \\
\text { September) with }<10 \\
\text { m/s wind speed } \\
\text { Avg number of night } \\
\text { hours (August- } \\
\text { September) with no } \\
\text { rain } \\
\text { Avg number of night } \\
\text { hours (August- } \\
\text { September) with }>50 \\
\text { degree temperatures } \\
\text { Susceptible Behaviors } \\
\text { (aerial foraging + } \\
\text { migration + } \\
\text { reproductive } \\
\text { behavior + pre- } \\
\text { hibernation } \\
\text { behavior) }\end{array}$ & $\begin{array}{l}\text { Habitat Suitability }+ \\
\text { Exposure = Predicted } \\
\text { Relative Fall Migration } \\
\text { Collision Mortality }\end{array}$ \\
\hline \multirow[t]{2}{*}{$\begin{array}{l}\text { Silver- } \\
\text { haired bat } \\
(2 \mathrm{~km} \\
\text { Scale })\end{array}$} & Summer & $\begin{array}{l}\text { Forest }(\%)+\text { Forest (Edge Density) + Open Water } \\
\text { (Juxtaposition) + Forest Stand Age + Distance to Nearest } \\
\text { Water Body + Riparian Flyway (linear corridor) }\end{array}$ & $\begin{array}{l}\text { Avg number of night } \\
\text { hours (June-July) } \\
\text { with }<7 \mathrm{~m} / \mathrm{s} \text { wind } \\
\text { speed } \\
\text { Avg number of night } \\
\text { hours (June-July) } \\
\text { with no rain } \\
\text { Avg number of night } \\
\text { hours (June--July) } \\
\text { with }>50 \text { degree } \\
\text { temperatures } \\
\text { Susceptible Behavior } \\
\text { (aerial foraging) }\end{array}$ & $\begin{array}{l}\text { Habitat Suitability + } \\
\text { Exposure = Predicted } \\
\text { Relative Summer } \\
\text { Collision Mortality }\end{array}$ \\
\hline & Winter & Not considered given minimal activity & $\begin{array}{c}\text { Not considered given } \\
\text { minimal activity }\end{array}$ & $\begin{array}{l}\text { Not considered given } \\
\text { minimal activity }\end{array}$ \\
\hline
\end{tabular}




\begin{tabular}{|c|c|c|c|}
\hline $\begin{array}{l}\text { Spring } \\
\text { Migration }\end{array}$ & $\begin{array}{l}\text { Forest }(\%)+\text { Forest (Edge Density) + Open Water } \\
\text { (Juxtaposition) + Forest Stand Age + Distance to Nearest } \\
\text { Water Body + Riparian Flyway (linear corridor) }\end{array}$ & $\begin{array}{l}\text { Avg number of night } \\
\text { hours (April-May) } \\
\text { with }<7 \mathrm{~m} / \mathrm{s} \text { wind } \\
\text { speed } \\
\text { Avg number of night } \\
\text { hours (April-May) } \\
\text { with no rain } \\
\text { Avg number of night } \\
\text { hours (April-May) } \\
\text { with }>50 \text { degree } \\
\text { temperatures } \\
\text { Susceptible Behaviors } \\
\text { (aerial foraging + } \\
\text { migration) } \\
\end{array}$ & $\begin{array}{l}\text { Habitat Suitability + } \\
\text { Exposure= Predicted } \\
\text { Relative Spring } \\
\text { Migration Collision } \\
\text { Mortality }\end{array}$ \\
\hline $\begin{array}{l}\text { Fall } \\
\text { Migration }\end{array}$ & $\begin{array}{l}\text { Forest }(\%)+\text { Forest (Edge Density) + Open Water } \\
\text { (Juxtaposition) + Forest Stand Age + Distance to Nearest } \\
\text { Water Body + Riparian Flyway (linear corridor) }\end{array}$ & $\begin{array}{l}\text { Avg number of night } \\
\text { hours (August- } \\
\text { September) with }<7 \\
\text { m/s wind speed } \\
\text { Avg number of night } \\
\text { hours (August- } \\
\text { September) with no } \\
\text { rain } \\
\text { Avg number of night } \\
\text { hours (August- } \\
\text { September) with }>50 \\
\text { degree temperatures } \\
\text { Susceptible Behaviors } \\
\text { (aerial foraging + } \\
\text { migration + } \\
\text { reproductive } \\
\text { behavior + pre- } \\
\text { hibernation } \\
\text { behavior) }\end{array}$ & $\begin{array}{l}\text { Habitat Suitability + } \\
\text { Exposure = Predicted } \\
\text { Relative Fall Migration } \\
\text { Collision Mortality }\end{array}$ \\
\hline
\end{tabular}

${ }^{\mathrm{a}}$ Variable descriptions can be found in Appendix 1. 
Appendix 4. Model Scale and Explanatory Variables from the Best Subset of Models for each Bird Species in the US Bird Conservation Regions 11, 17, 18, and 19. Only Models within the $95 \%$ Confidence Set of Best Models are Included (Burnham and Anderson 2002). The Null Model (a Model Without Any Environmental Covariates) Was Included to Serve as a Comparison to Models Containing Environmental Variables

\begin{tabular}{|c|c|c|c|c|c|c|}
\hline Species & Season & Model $^{\mathrm{a}}$ & $K^{b}$ & $A I C^{c}$ & $\Delta \mathrm{AlC}^{\mathrm{d}}$ & $w i^{e}$ \\
\hline \multirow[t]{7}{*}{$\begin{array}{l}\text { Horned } \\
\text { Lark }\end{array}$} & Breeding & $\begin{array}{l}\text { COARSE Barren_PLAND + } \\
\text { CultivatedCrops_PLAND + } \\
\text { Herbaceous_PLAND + Forest_PLAND }\end{array}$ & 12 & 12901.453 & 0.000 & 0.997 \\
\hline & & Null & 8 & 13097.149 & 195.696 & 0.000 \\
\hline & Winter & $\begin{array}{l}\text { COARSE Barren_PLAND + } \\
\text { CultivatedCrops_PLAND + } \\
\text { Herbaceous_PLAND + Forest_PLAND }\end{array}$ & 10 & 5575.271 & 0.000 & 0.808 \\
\hline & & $\begin{array}{l}\text { MEDIUM Barren_PLAND + } \\
\text { CultivatedCrops_PLAND + } \\
\text { Herbaceous_PLAND + Forest_PLAND }\end{array}$ & 10 & 5578.140 & 2.869 & 0.192 \\
\hline & & Null & 6 & 5641.393 & 66.122 & 0.000 \\
\hline & Migration & $\begin{array}{l}\text { Barren_PLAND + CultivatedCrops_PLAND + } \\
\text { Herbaceous_PLAND + Forest_PLAND }\end{array}$ & 9 & 530.345 & 0.000 & 0.597 \\
\hline & & $\begin{array}{l}\text { Barren_PLAND + Barren_IJI + } \\
\text { HayPasture_PLAND + Herbaceous_PLAND + } \\
\text { Forest_PLAND }\end{array}$ & 10 & 532.855 & 2.509 & 0.170 \\
\hline
\end{tabular}




\begin{tabular}{|c|c|c|c|c|c|c|}
\hline Species & Season & Model $^{\mathrm{a}}$ & $\mathrm{K}^{\mathrm{b}}$ & $A I C^{c}$ & $\Delta \mathrm{AIC}^{\mathrm{d}}$ & $w i^{e}$ \\
\hline & & $\begin{array}{l}\text { Barren_PLAND + Barren_IJI + } \\
\text { Herbaceous_PLAND }\end{array}$ & 8 & 532.992 & 2.647 & 0.159 \\
\hline & & $\begin{array}{l}\text { Barren_PLAND + Barren_IJI + } \\
\text { HayPasture_PLAND + Herbaceous_PLAND }\end{array}$ & 9 & 534.988 & 4.643 & 0.059 \\
\hline & & Null & 5 & 548.661 & 18.316 & 0.000 \\
\hline \multirow{7}{*}{$\begin{array}{l}\text { Red-eyed } \\
\text { Vireo }\end{array}$} & Breeding & COARSE Forest_ED & 9 & 1748.862 & 0.000 & 0.858 \\
\hline & & MEDIUM Forest_ED & 9 & 1752.462 & 3.600 & 0.142 \\
\hline & & Null & 8 & 1794.229 & 45.366 & 0.000 \\
\hline & Migratory & Null & 5 & 182.144 & 0.000 & 0.383 \\
\hline & & Forest_LPI & 6 & 184.090 & 1.946 & 0.145 \\
\hline & & Forest_PLAND & 6 & 184.107 & 1.964 & 0.143 \\
\hline & & Forest_ED & 6 & 184.111 & 1.967 & 0.143 \\
\hline
\end{tabular}




\begin{tabular}{|c|c|c|c|c|c|c|}
\hline Species & Season & Model $^{\mathrm{a}}$ & $\mathrm{K}^{\mathrm{b}}$ & $\mathrm{AlC}^{\mathrm{C}}$ & $\Delta \mathrm{AlC}^{\mathrm{d}}$ & $w i^{e}$ \\
\hline & & Forest_PLAND + Developed_PLAND & 7 & 185.429 & 3.286 & 0.074 \\
\hline & & $\begin{array}{l}\text { Forest_LPI + ShrubScrub_PLAND + } \\
\text { Developed_PLAND }\end{array}$ & 8 & 187.079 & 4.936 & 0.032 \\
\hline & & $\begin{array}{l}\text { Forest_ED + ShrubScrub_PLAND + } \\
\text { Developed_PLAND }\end{array}$ & 8 & 187.088 & 4.944 & 0.032 \\
\hline \multirow[t]{6}{*}{ Mallard } & Breeding & $\begin{array}{l}\text { MEDIUM OpenWater_PLAND + } \\
\text { CultivatedCrops_PLAND + ShrubScrub_PLAND } \\
\text { + HayPasture_PLAND + } \\
\text { EmergentWetlands_PLAND }\end{array}$ & 13 & 9932.313 & 0.000 & 0.994 \\
\hline & & Null & 8 & 10028.623 & 96.310 & 0.000 \\
\hline & Winter & $\begin{array}{l}\text { MEDIUM OpenWater_PLAND + } \\
\text { CultivatedCrops_PLAND }\end{array}$ & 8 & 7038.550 & 0.000 & 0.398 \\
\hline & & $\begin{array}{l}\text { MEDIUM OpenWater_PLAND + } \\
\text { CultivatedCrops_PLAND + } \\
\text { EmergentWetlands_PLAND }\end{array}$ & 9 & 7039.800 & 1.250 & 0.213 \\
\hline & & $\begin{array}{l}\text { COARSE OpenWater_PLAND + } \\
\text { CultivatedCrops_PLAND }\end{array}$ & 8 & 7040.335 & 1.785 & 0.163 \\
\hline & & $\begin{array}{l}\text { COARSE OpenWater_PLAND + } \\
\text { CultivatedCrops_PLAND + } \\
\text { EmergentWetlands_PLAND }\end{array}$ & 9 & 7041.132 & 2.582 & 0.109 \\
\hline
\end{tabular}




\begin{tabular}{|c|c|c|c|c|c|c|}
\hline \multirow[t]{6}{*}{ Species } & Season & Model $^{\mathrm{a}}$ & $\mathrm{K}^{\mathrm{b}}$ & $\mathrm{AlC}^{\mathrm{C}}$ & $\Delta \mathrm{AlC}^{\mathrm{d}}$ & $w i^{e}$ \\
\hline & & MEDIUM OpenWater_PLAND & 7 & 7041.959 & 3.409 & 0.072 \\
\hline & & Null & 6 & 7054.214 & 15.664 & 0.000 \\
\hline & Migratory & $\begin{array}{l}\text { OpenWater_IJI + CultivatedCrops_IJI + } \\
\text { Emergent_Wetlands_IJI }\end{array}$ & 8 & 1013.762 & 0.000 & 0.852 \\
\hline & & $\begin{array}{l}\text { OpenWater_IJI + CultivatedCrops_PLAND + } \\
\text { Emergent_Wetlands_PLAND }\end{array}$ & 8 & 1017.648 & 3.887 & 0.122 \\
\hline & & Null & 5 & 1041.199 & 27.438 & 0.000 \\
\hline \multirow[t]{5}{*}{$\begin{array}{l}\text { American } \\
\text { Avocet }\end{array}$} & Breeding & $\begin{array}{l}\text { MEDIUM OpenWater_PLAND + } \\
\text { EmergentWetlands_PLAND + } \\
\text { Herbaceous_PLAND }\end{array}$ & 11 & 2465.371 & 0.000 & 0.578 \\
\hline & & $\begin{array}{l}\text { MEDIUM OpenWater_PLAND + } \\
\text { EmergentWetlands_PLAND }\end{array}$ & 10 & 2466.451 & 1.080 & 0.337 \\
\hline & & $\begin{array}{l}\text { FINE OpenWater_PLAND + } \\
\text { EmergentWetlands_PLAND }\end{array}$ & 10 & 2470.554 & 5.183 & 0.043 \\
\hline & & Null & 8 & 2500.524 & 35.153 & 0.000 \\
\hline & Migratory & $\begin{array}{l}\text { OpenWater_PLAND + EmergentWet_PLAND + } \\
\text { CultivatedCrops_PLAND }\end{array}$ & 8 & 461.355 & 0.000 & 0.330 \\
\hline
\end{tabular}




\begin{tabular}{|c|c|c|c|c|c|c|}
\hline Species & Season & Model $^{\mathrm{a}}$ & $\mathrm{K}^{\mathrm{b}}$ & $\mathrm{AlC}^{\mathrm{c}}$ & $\Delta \mathrm{AlC}^{\mathrm{d}}$ & $w i^{e}$ \\
\hline & & OpenWater_PLAND + EmergentWet_PLAND & 7 & 461.520 & 0.165 & 0.303 \\
\hline & & OpenWater_PLAND & 6 & 461.651 & 0.296 & 0.284 \\
\hline & & EmergentWet_PLAND & 6 & 466.396 & 5.041 & 0.026 \\
\hline & & OpenWater_LPI + EmergentWet_LPI & 7 & 467.436 & 6.081 & 0.016 \\
\hline & & Null & 5 & 467.594 & 6.239 & 0.015 \\
\hline \multirow[t]{5}{*}{$\begin{array}{l}\text { Golden } \\
\text { Eagle }\end{array}$} & Breeding & $\begin{array}{l}\text { MEDIUM Herbaceous_PLAND + } \\
\text { ShrubScrub_PLAND + Forest_PLAND }\end{array}$ & 11 & 995.538 & 0.000 & 0.221 \\
\hline & & $\begin{array}{l}\text { COARSE Herbaceous_PLAND + } \\
\text { ShrubScrub_PLAND + OpenWater_|J| }\end{array}$ & 11 & 995.579 & 0.041 & 0.217 \\
\hline & & $\begin{array}{l}\text { MEDIUM Herbaceous_PLAND + } \\
\text { ShrubScrub_PLAND + OpenWater_IJI }\end{array}$ & 11 & 996.099 & 0.561 & 0.167 \\
\hline & & $\begin{array}{l}\text { MEDIUM Herbaceous_PLAND + } \\
\text { ShrubScrub_PLAND + HayPasture_PLAND + } \\
\text { Forest_PLANND }\end{array}$ & 12 & 996.497 & 0.958 & 0.137 \\
\hline & & $\begin{array}{l}\text { MEDIUM Herbaceous_PLAND + } \\
\text { ShrubScrub_PLAND }\end{array}$ & 10 & 997.480 & 1.942 & 0.084 \\
\hline
\end{tabular}




\begin{tabular}{|c|c|c|c|c|c|c|}
\hline Species & Season & Model $^{\mathrm{a}}$ & $K^{b}$ & $\mathrm{AlC}^{\mathrm{C}}$ & $\Delta \mathrm{AlC}^{\mathrm{d}}$ & $w i^{e}$ \\
\hline & & \begin{tabular}{|l} 
FINE Herbaceous_PLAND + \\
ShrubScrub_PLAND + Forest_PLAND
\end{tabular} & 11 & 997.575 & 2.037 & 0.080 \\
\hline & & $\begin{array}{l}\text { FINE Herbaceous_PLAND + } \\
\text { ShrubScrub_PLAND + HayPasture_PLAND + } \\
\text { Forest_PLANND }\end{array}$ & 12 & 998.431 & 2.892 & 0.052 \\
\hline & & Null & 8 & 1023.788 & 28.250 & 0.000 \\
\hline & Winter & $\begin{array}{l}\text { COARSE Herbaceous_PLAND + } \\
\text { ShrubScrub_PLAND + Forest_PLAND }\end{array}$ & 9 & 1000.516 & 0.000 & 0.352 \\
\hline & & $\begin{array}{l}\text { MEDIUM Herbaceous_PLAND + } \\
\text { ShrubScrub_IJI + Forest_IJI }\end{array}$ & 9 & 1001.721 & 1.205 & 0.193 \\
\hline & & $\begin{array}{l}\text { MEDIUM Herbaceous_PLAND + } \\
\text { ShrubScrub_PLAND + Forest_PLAND }\end{array}$ & 9 & 1001.752 & 1.236 & 0.190 \\
\hline & & COARSE Herbaceous_LPI + ShrubScrub_LPI & 8 & 1003.230 & 2.714 & 0.091 \\
\hline & & $\begin{array}{l}\text { MEDIUM Herbaceous_PLAND + } \\
\text { ShrubScrub_PLAND }\end{array}$ & 8 & 1004.867 & 4.351 & 0.040 \\
\hline & & $\begin{array}{l}\text { COARSE Herbaceous_PLAND + } \\
\text { ShrubScrub_PLAND }\end{array}$ & 8 & 1005.218 & 4.702 & 0.034 \\
\hline & & $\begin{array}{l}\text { COARSE Forest_PLAND + } \\
\text { ShrubScrub_PLAND + OpenWater_IJI }\end{array}$ & 9 & 1005.316 & 4.800 & 0.032 \\
\hline
\end{tabular}




\begin{tabular}{|c|c|c|c|c|c|c|}
\hline Species & Season & Model $^{\mathrm{a}}$ & $\mathrm{K}^{\mathrm{b}}$ & $\mathrm{AlC}^{\mathrm{c}}$ & $\Delta \mathrm{AlC}^{\mathrm{d}}$ & $w i^{e}$ \\
\hline & & $\begin{array}{l}\text { COARSE Herbaceous_PLAND + } \\
\text { ShrubScrub_IJI + Forest_IJI }\end{array}$ & 9 & 1006.093 & 5.577 & 0.022 \\
\hline & & Null & 6 & 1014.325 & 13.809 & 0.000 \\
\hline & Migratory & Null & 5 & 203.243 & 0.000 & 0.289 \\
\hline & & CultivatedCrops_PLAND & 6 & 204.207 & 0.964 & 0.178 \\
\hline & & Herbaceous_PLAND & 6 & 204.724 & 1.481 & 0.138 \\
\hline & & ShrubScrub_PLAND & 6 & 204.927 & 1.684 & 0.124 \\
\hline & & HayPasture_PLAND & 6 & 204.947 & 1.704 & 0.123 \\
\hline & & $\begin{array}{l}\text { Herbaceous_PLAND + ShrubScrub_PLAND + } \\
\text { CultivatedCrops_PLAND }\end{array}$ & 8 & 206.549 & 3.306 & 0.055 \\
\hline & & $\begin{array}{l}\text { Herbaceous_LPI + ShrubScrub_LPI + } \\
\text { CultivatedCrops_LPI }\end{array}$ & 8 & 207.271 & 4.027 & 0.039 \\
\hline & & $\begin{array}{l}\text { Herbaceous_PLAND + ShrubScrub_PLAND + } \\
\text { HayPasture_PLAND + CultivatedCrops_PLAND }\end{array}$ & 9 & 207.762 & 4.519 & 0.030 \\
\hline
\end{tabular}




\begin{tabular}{|l|l|l|r|r|r|r|}
\hline \multicolumn{1}{|c|}{ Species } & \multicolumn{1}{|c|}{ Season } & \multicolumn{1}{c|}{ Model $^{\mathrm{a}}$} & \multicolumn{1}{c|}{$\mathrm{K}^{\mathrm{b}}$} & \multicolumn{1}{c|}{ AIC $^{\mathrm{c}}$} & \multicolumn{1}{c|}{$\Delta$ AIC $^{\mathrm{d}}$} & \multicolumn{1}{c|}{ Wi $^{\mathbf{e}}$} \\
\hline $\begin{array}{l}\text { Whooping } \\
\text { Crane }\end{array}$ & Migratory & $\begin{array}{l}\text { OpenWater_ED + EmergentWet_IJI + } \\
\text { Cultivated_rops_IJI }\end{array}$ & 7 & 1756.050 & 0.000 \\
\hline & Null & 4 & 1837.165 & 81.116 & 0.000 \\
\hline
\end{tabular}

${ }^{a}$ Descriptions of model parameters can be found in Appendix 1. Scales are identified in the following way: for breeding models, fine represents the 1,000-ha scale, medium represents the 10,000-ha scale, and coarse represents the 100,000-ha scale; for winter models medium represents the 50,000-ha scale, and coarse represents the 100,000-ha scale; migratory models were only performed at the 100,000-ha scale

${ }^{\mathrm{b}}$ The effective number of parameters is in each model.

c Akaike's Information Criterion.

d $\triangle \mathrm{AIC}$ is the AIC difference between the best model and the model for which the $\triangle \mathrm{AIC}$ is given.

${ }^{\mathrm{e}}$ Model weights provide a measure of support for the model relative to the others in the table and are calculated with the following equation where $\Delta_{i}$ and $\Delta_{r}$ are the $\Delta$ DIC values for each model (Burnham and Anderson 2002).

$$
w_{i}=\frac{\exp \left(-\frac{1}{2} \Delta_{i}\right)}{\sum_{r=1}^{R} \exp \left(-\frac{1}{2} \Delta_{r}\right)}
$$


Appendix 5. Model-averaged standardized Parameter Values and Associated Confidence Intervals of Explanatory Variables in the Best Subset of Models for Explaining Bird Abundance in US Bird Conservation Regions 11, 17,18 , and 19

\begin{tabular}{|c|c|c|c|c|c|}
\hline Species & Season & Variable $^{a}$ & $\begin{array}{l}\text { Mean Beta } \\
\text { Parameter }\end{array}$ & 95\% LCL & 95\% UCL \\
\hline \multirow[t]{27}{*}{ Horned Lark } & Breeding & Intercept & 2.003 & 1.766 & 2.240 \\
\hline & & Latitude & 0.218 & 0.036 & 0.399 \\
\hline & & Longitude & -1.126 & -1.354 & -0.898 \\
\hline & & Barren \% Coarse & -0.020 & -0.229 & 0.189 \\
\hline & & Cultivated \% Coarse & 1.269 & 0.955 & 1.583 \\
\hline & & Herbaceous \% Coarse & 0.713 & 0.424 & 1.001 \\
\hline & & Forest \% Coarse & -1.805 & -2.378 & -1.232 \\
\hline & Winter & Intercept & 0.894 & 0.637 & 1.151 \\
\hline & & Latitude & -0.395 & -0.636 & -0.154 \\
\hline & & Longitude & -0.541 & -0.815 & -0.266 \\
\hline & & Barren \% Coarse & -0.047 & -0.226 & 0.133 \\
\hline & & Cultivated \% Coarse & 1.341 & 0.940 & 1.741 \\
\hline & & Herbaceous \% Coarse & 1.156 & 0.833 & 1.480 \\
\hline & & Forest \% Coarse & -0.125 & -0.381 & 0.131 \\
\hline & & Barren \% med & -0.051 & -0.232 & 0.130 \\
\hline & & Cultivated $\%$ med & 1.128 & 0.763 & 1.493 \\
\hline & & Herbaceous \% med & 1.050 & 0.749 & 1.351 \\
\hline & & Forest \% med & -0.223 & -0.471 & 0.026 \\
\hline & Migratory & Intercept & -2.309 & -2.997 & -1.621 \\
\hline & & Latitude & -0.478 & -1.042 & 0.085 \\
\hline & & Longitude & -1.312 & -2.032 & -0.592 \\
\hline & & Barren \% & -0.491 & -1.373 & 0.391 \\
\hline & & Barren IJI & 0.784 & 0.103 & 1.465 \\
\hline & & Cultivated \% & 1.037 & 0.128 & 1.946 \\
\hline & & Hay Pasture \% & -0.083 & -1.311 & 1.146 \\
\hline & & Herbaceous \% & 1.266 & 0.482 & 2.050 \\
\hline & & Forest \% & -0.533 & -1.585 & 0.519 \\
\hline $\begin{array}{l}\text { Red-eyed } \\
\text { Vireo }\end{array}$ & Breeding & Intercept & -4.363 & -4.857 & -3.869 \\
\hline
\end{tabular}


A Habitat-based Wind-Wildlife Collision Model with Application to the Upper Great Plains Region-Final Report

\begin{tabular}{|c|c|c|c|c|c|}
\hline Species & Season & Variable $^{a}$ & $\begin{array}{l}\text { Mean Beta } \\
\text { Parameter }\end{array}$ & 95\% LCL & 95\% UCL \\
\hline & & Latitude & 1.530 & 1.131 & 1.928 \\
\hline & & Longitude & 1.415 & 1.097 & 1.733 \\
\hline & & Forest ED Medium & 1.013 & 0.736 & 1.290 \\
\hline & & Forest ED Coarse & 1.052 & 0.768 & 1.336 \\
\hline & Migratory & Intercept & -3.754 & -4.434 & -3.074 \\
\hline & & Latitude & 0.391 & -0.257 & 1.040 \\
\hline & & Longitude & 0.520 & -0.099 & 1.138 \\
\hline & & Forest \% & 0.039 & -0.498 & 0.576 \\
\hline & & Developed \% & 0.138 & -0.274 & 0.551 \\
\hline & & ShrubScrub \% & -0.234 & -1.426 & 0.957 \\
\hline & & Forest LPI & 0.061 & -0.582 & 0.705 \\
\hline & & Forest ED & 0.045 & -0.552 & 0.642 \\
\hline Mallard & Breeding & Intercept & 0.242 & 0.034 & 0.450 \\
\hline & & Latitude & 0.776 & 0.590 & 0.962 \\
\hline & & Longitude & -0.402 & -0.599 & -0.205 \\
\hline & & OpenWater \% Medium & 0.295 & 0.152 & 0.439 \\
\hline & & Cultivated \% Medium & 0.567 & 0.375 & 0.760 \\
\hline & & ShrubScrub \% Medium & -0.313 & -0.541 & -0.086 \\
\hline & & HayPasture \% Medium & 0.265 & 0.114 & 0.416 \\
\hline & & $\begin{array}{l}\text { EmergentWetlands \% } \\
\text { Medium }\end{array}$ & 0.484 & 0.304 & 0.665 \\
\hline & Winter & Intercept & 1.476 & 1.113 & 1.840 \\
\hline & & Latitude & -0.962 & -1.389 & -0.535 \\
\hline & & Longitude & -0.753 & -1.257 & -0.248 \\
\hline & & OpenWater \% Medium & 0.920 & 0.494 & 1.346 \\
\hline & & Cultivated \% Medium & 0.559 & 0.095 & 1.022 \\
\hline & & Emergent \% Medium & -0.175 & -0.568 & 0.218 \\
\hline & & OpenWater \% Coarse & 0.959 & 0.485 & 1.433 \\
\hline & & Cultivated \% Coarse & 0.575 & 0.083 & 1.067 \\
\hline & & Emergent \% Coarse & -0.231 & -0.640 & 0.179 \\
\hline & Migratory & Intercept & -1.263 & -1.739 & -0.786 \\
\hline & & Latitude & -0.900 & -1.418 & -0.381 \\
\hline & & Longitude & -0.382 & -0.920 & 0.156 \\
\hline & & OpenWater IJI & 0.661 & 0.034 & 1.287 \\
\hline
\end{tabular}


A Habitat-based Wind-Wildlife Collision Model with Application to the Upper Great Plains Region-Final Report

\begin{tabular}{|c|c|c|c|c|c|}
\hline Species & Season & Variable $^{a}$ & $\begin{array}{l}\text { Mean Beta } \\
\text { Parameter }\end{array}$ & 95\% LCL & 95\% UCL \\
\hline & & Cultivated IJI & 0.311 & -0.197 & 0.819 \\
\hline & & Emergent IJI & 0.844 & 0.261 & 1.427 \\
\hline & & Cultivated \% & 0.567 & -0.015 & 1.150 \\
\hline & & Emergent \% & 0.573 & 0.080 & 1.066 \\
\hline \multirow[t]{16}{*}{$\begin{array}{l}\text { American } \\
\text { Avocet }\end{array}$} & Breeding & Intercept & -5.875 & -6.617 & -5.133 \\
\hline & & Latitude & -0.461 & -1.018 & 0.096 \\
\hline & & Longitude & -1.521 & -2.278 & -0.764 \\
\hline & & OpenWater \% Fine & 0.619 & 0.286 & 0.953 \\
\hline & & OpenWater \% Medium & 0.782 & 0.396 & 1.168 \\
\hline & & $\begin{array}{l}\text { EmergentWetlands \% } \\
\text { Fine }\end{array}$ & 0.864 & 0.399 & 1.328 \\
\hline & & $\begin{array}{l}\text { EmergentWetlands \% } \\
\text { Medium }\end{array}$ & 0.870 & 0.318 & 1.423 \\
\hline & & Herbaceous \% Medium & -0.412 & -0.986 & 0.161 \\
\hline & Migratory & Intercept & -5.269 & -6.472 & -4.065 \\
\hline & & Latitude & -0.598 & -1.852 & 0.657 \\
\hline & & Longitude & -0.951 & -2.409 & 0.507 \\
\hline & & OpenWater \% & 0.852 & 0.179 & 1.526 \\
\hline & & Emergent \% & 0.519 & -0.415 & 1.452 \\
\hline & & Cultivated \% & 0.555 & -0.693 & 1.802 \\
\hline & & Openwater LPI & 0.558 & -0.101 & 1.218 \\
\hline & & Emergent LPI & 0.217 & -0.214 & 0.647 \\
\hline \multirow[t]{11}{*}{$\begin{array}{l}\text { Golden } \\
\text { Eagle }\end{array}$} & Breeding & Intercept & -5.953 & -6.802 & -5.104 \\
\hline & & Latitude & 0.406 & -0.028 & 0.839 \\
\hline & & Longitude & -1.545 & -2.143 & -0.948 \\
\hline & & Herbaceous \% Med & 1.072 & 0.606 & 1.537 \\
\hline & & ShrubScrub \% Med & 0.717 & 0.322 & 1.112 \\
\hline & & Forest \% Med & -0.941 & -2.304 & 0.422 \\
\hline & & Herbaceous \% Coarse & 1.321 & 0.777 & 1.866 \\
\hline & & ShrubScrub \% Coarse & 0.937 & 0.475 & 1.399 \\
\hline & & OpenWater IJI Coarse & 0.509 & 0.107 & 0.912 \\
\hline & & OpenWater IJI Med & 0.304 & -0.033 & 0.641 \\
\hline & & HayPasture \% Med & 0.263 & -0.299 & 0.825 \\
\hline
\end{tabular}


A Habitat-based Wind-Wildlife Collision Model with Application to the Upper Great Plains Region-Final Report

\begin{tabular}{|c|c|c|c|c|c|}
\hline Species & Season & Variable $^{a}$ & $\begin{array}{l}\text { Mean Beta } \\
\text { Parameter }\end{array}$ & 95\% LCL & 95\% UCL \\
\hline & & Herbaceous \% Fine & 0.878 & 0.476 & 1.281 \\
\hline & & ShrubScrub \% Fine & 0.615 & 0.241 & 0.990 \\
\hline & & Forest \% Fine & -1.903 & -4.358 & 0.552 \\
\hline & & HayPasture \% Fine & 0.295 & -0.305 & 0.895 \\
\hline & Winter & Intercept & -1.276 & -1.410 & -1.142 \\
\hline & & Latitude & 0.035 & -0.168 & 0.238 \\
\hline & & Longitude & -0.746 & -0.959 & -0.533 \\
\hline & & Herbaceous \% Coarse & 0.253 & 0.098 & 0.408 \\
\hline & & ShrubScrub \% Coarse & -0.154 & -0.346 & 0.038 \\
\hline & & Forest \% Coarse & 0.144 & 0.034 & 0.253 \\
\hline & & Herbaceous $\%$ med & 0.291 & 0.129 & 0.453 \\
\hline & & ShrubScrub IJI med & 0.194 & 0.025 & 0.363 \\
\hline & & Forest IJI med & -0.049 & -0.197 & 0.100 \\
\hline & & ShrubScrub \% med & -0.087 & -0.270 & 0.096 \\
\hline & & Forest \% med & 0.126 & 0.019 & 0.234 \\
\hline & & $\begin{array}{l}\text { Herbaceous LPI } \\
\text { Coarse }\end{array}$ & 0.114 & -0.028 & 0.256 \\
\hline & & ShrubScrub LPI Coarse & -0.286 & -0.480 & -0.092 \\
\hline & & OpenWater IJI Coarse & -0.167 & -0.304 & -0.030 \\
\hline & & ShrubScrub IJI Coarse & 0.085 & -0.098 & 0.267 \\
\hline & & Forest IJI Coarse & -0.068 & -0.220 & 0.085 \\
\hline & Migratory & Intercept & -3.593 & -4.206 & -2.981 \\
\hline & & Latitude & 0.147 & -0.410 & 0.705 \\
\hline & & Longitude & -0.741 & -1.354 & -0.129 \\
\hline & & Cultivated Crops \% & -0.431 & -1.344 & 0.481 \\
\hline & & Herbaceous \% & -0.064 & -0.980 & 0.852 \\
\hline & & ShrubScrub \% & -0.325 & -1.215 & 0.566 \\
\hline & & Herbaceous LPI & -0.152 & -0.789 & 0.484 \\
\hline & & ShrubScrub LPI & -0.336 & -1.203 & 0.531 \\
\hline & & Cultivated Crops LPI & -0.370 & -1.184 & 0.445 \\
\hline \multirow[t]{3}{*}{$\begin{array}{l}\text { Whooping } \\
\text { Crane }\end{array}$} & Migratory & Intercept & 8.644 & 4.926 & 12.362 \\
\hline & & Latitude & 0.015 & -0.017 & 0.047 \\
\hline & & Longitude & 0.109 & 0.071 & 0.148 \\
\hline
\end{tabular}


A Habitat-based Wind-Wildlife Collision Model with Application to the Upper Great Plains Region-Final Report

\begin{tabular}{|c|c|c|c|c|c|}
\hline Species & Season & Variable $^{a}$ & $\begin{array}{l}\text { Mean Beta } \\
\text { Parameter }^{\text {b }}\end{array}$ & 95\% LCL & 95\% UCL \\
\hline & & OpenWater ED & 0.606 & 0.455 & 0.757 \\
\hline & & Emergent IJI & 0.011 & 0.004 & 0.018 \\
\hline & & Cultivated IJI & -0.278 & -0.428 & -0.128 \\
\hline
\end{tabular}

a Descriptions of model parameters can be found in Appendix 1. Scales are identified in the following way: for breeding models, fine represents the 1,000 ha scale, medium represents the 10,000 ha scale, and coarse represents the 100,000 ha scale; for winter models medium represents the 50,000 ha scale, and coarse represents the 100,000 ha scale; migratory models were only performed at the 100,000-ha scale

$\mathrm{b}$ Mean represents a model averaged value of the beta parameter based on the values of the beta parameters in each model and the corresponding weight (wi) of each model (Burnham and Anderson 2002). 